\title{
Enhanced Aqueous Solubility of the Solid Forms of a BCS Class-II Anti-Tuberculosis Drug, Prothionamide
}

S. Amrutha, Lopamudra Giri, Sunil SeethaLekshmi* and Sunil Varughese*

\section{Supporting Information}




\section{EXPERIMENTAL}

Preparation method: PRT form II was crystallized from acetonitrile by a slow evaporation method. Good quality crystals suitable for single-crystal XRD were obtained after three days. Samples of cocrystals obtained were prepared by solvent-drop grinding with ethanol and carried out slow evaporation from different solvents. PRT-OXA cocrystal was obtained from EtOH, that of PRT-FUM from MeOH, PRT-2,5-DHT from MeOH. PRT-SAL and PRT-26DHB cocrystals were obtained by seeding the saturated solution with the complex obtained by fast solvent removal. The former was obtained from EtOAc and the latter from 1:1 EtOH-DCM solution.

Fast removal of solvent using rotary evaporation was employed to screen for solid-forms of PRT. We used ethanol and ethyl acetate as representative solvent systems for protic and aprotic solvents. The resultant crystalline powder was analyzed using PXRD and melting point to confirm the formation of molecular complexes or eutectics. Eutectics were generated with PRT and coformers by neat grinding.

Single crystal X-ray Diffraction: The diffraction data of single crystals were collected on a Rigaku Saturn 724+ diffractometer using graphite monochromated Mo-Ka radiation. In these cases, data were processed with the Rigaku CrystalClear software. The structure solution was carried out by direct methods, and the refinements were performed by full-matrix least-squares on F2 using the SHELXTL suite of programs. All calculations of intermolecular interactions were done with the HBOND NORM option of PLATON. A misassigned or additional symmetry check by the PLATON program confirms that each of the dimorphs is unique, and more convincingly, the packing and the conformational preferences of the molecules in the two structures are different.

Differential Scanning Calorimetry (DSC): The crystallization and melting behavior of samples were analyzed using a differential scanning calorimeter (TA Q2000). About $3 \mathrm{mg}$ of each sample was accurately weighed in aluminum pans and subjected to the thermal scan from room temperature to $200^{\circ} \mathrm{C}$ at a rate of $5^{\circ} \mathrm{C} / \mathrm{min}$.

Thermogravimetric analysis: The stability and desolvation behavior of the samples were analysed using thermogravimetry (TA Q500). About $5 \mathrm{mg}$ of each sample was accurately weighed 
in ceramic pans and subjected to the thermal scan from room temperature to $500^{\circ} \mathrm{C}$ at a rate of $5^{\circ} \mathrm{C} / \mathrm{min}$ in an inert atmosphere.

Powder X-ray Diffraction (PXRD): PXRD patterns of both cocrystal and eutectics were recorded at room temperature $\left(25.0 \pm 2.0^{\circ} \mathrm{C}\right)$ on Philips X'pert Pro with $\mathrm{Cu} \mathrm{K \alpha}$ radiation $\left(1.54 \mathrm{~A}^{\circ}\right)$, at 30 $\mathrm{mA}, 45 \mathrm{kV}$. The analysis was performed in a continuous mode with a step size of $0.03^{\circ}$ and a step time of $10 \mathrm{~s}$ over an angular range of 5-35 $2 \theta$. Variable temperature PXRD patterns for the polymorphic form of PRT between room temperature and $150{ }^{\circ} \mathrm{C}$ for three heating cycles at different intervals were also recorded.

Microscopic Analysis. Optical and Hot-Stage Microscope (HSM). Phase transition studies were performed on a Leica DM $2500 \mathrm{P}$ optical transmission microscope. The apparatus was equipped with a wide zoom camera and Mettler Toledo hot-stage. The powdered samples were placed on a micro slide, inserted in the hot stage, and observed under the microscope. Images were recorded on heating and cooling in the same temperature regions where phase transitions were observed in DSC. The heating-cooling rate was $5^{\circ} \mathrm{c} / \mathrm{min}$.

Scanning electron microscopy: The electron microscopy image of the crystalline analytes were determined using a Carl Ziess EVO MA18. The crystalline sample was evenly distributed on a carbon strip and sputtered with gold before imaging.

Infrared (IR) Spectroscopy: FTIR spectra of solid phases were collected on a Bruker Alfa-E Unit. Twenty-five scans were collected for each sample at a resolution of $4 \mathrm{~cm}^{-1}$ over a wavenumber region of 4000 to $600 \mathrm{~cm}^{-1}$.

Phase Stability: Stability studies were performed in a desiccator maintained at a humidity rate of $75 \%$ using a saturated sodium chloride solution for three weeks. The samples were then analyzed using PXRD, DSC, TG and IR measurements.

Dissolution studies: Kinetic solubility of PRT, cocrystals and eutectics were determined using deionised water as the solvent. A Shimadzu UV-1800 spectrophotometer was used to measure the 
absorbance of the solution at $289 \mathrm{~nm}$, which is specific for PRT (corresponds to an electron transition from an occupied to a vacant $\pi^{*}$ of the $\mathrm{C}=\mathrm{N}$ in pyridine). The spectra were recorded at a range of 200 to $800 \mathrm{~nm}$ in a $1 \mathrm{~cm}$ quartz cuvette. Standard stock solution of PRT was prepared in the dissolution media. Molar absorptivity was calculated by plotting the calibration curve by appropriate dissolution of stock solution. Then the solubility values of PRT and the newly prepared molecular complexes and eutectic mixtures were determined. A pellet of weight $300 \mathrm{mg}$ was prepared for all the samples and were shaken for $24 \mathrm{hrs}$ in a shaker at 100RPM speed. $1 \mathrm{ml}$ of aliquot solution was withdrawn periodically and an equal amount of pure deionised water was added to it. The solution was suitably diluted and measured the absorbance value to determine the solubility. 


\section{CSD Search}

Table S1. The database analysis for the fragments and the corresponding hits are provided. The search was restricted to 'only organic.'

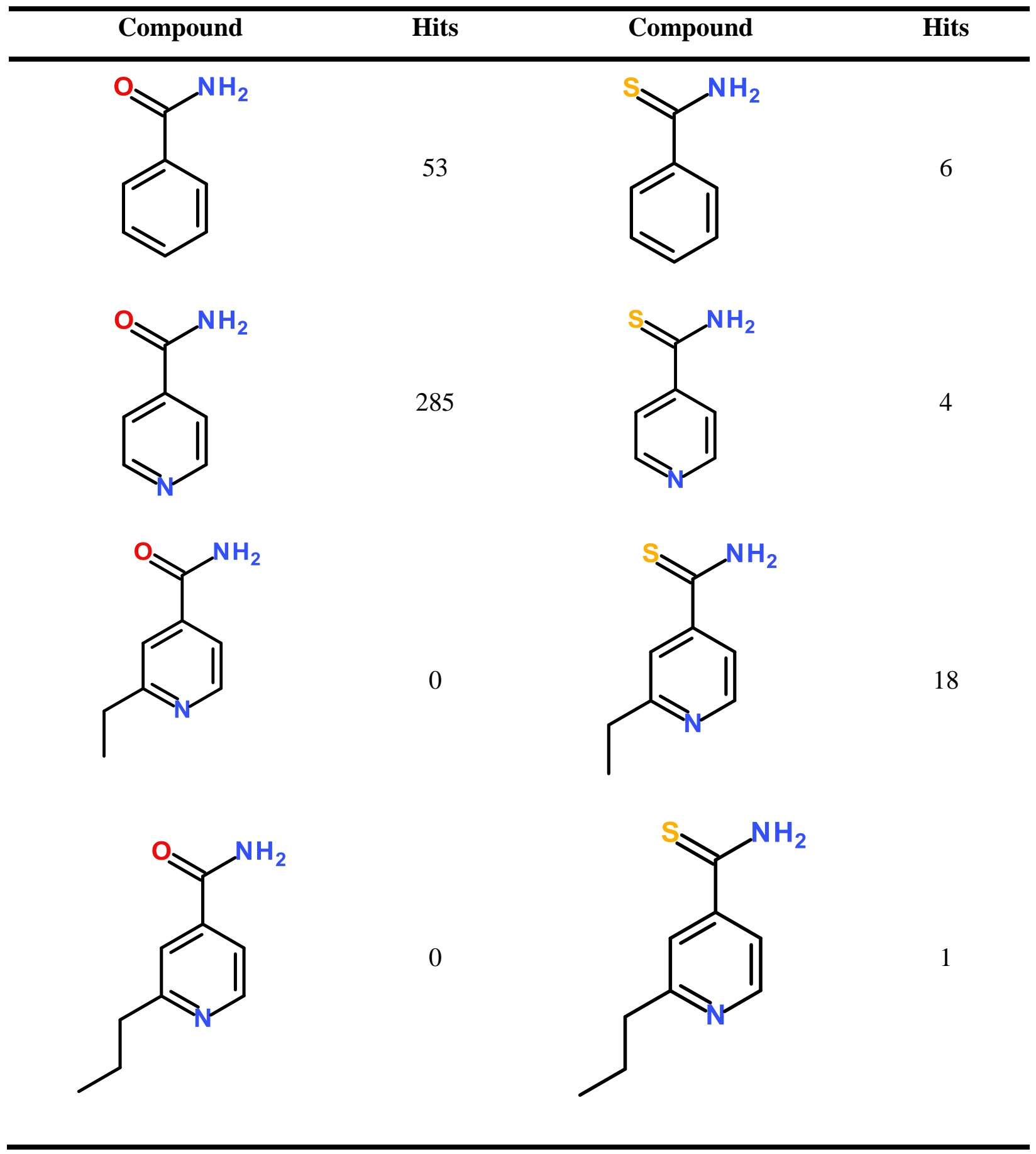


$\mathrm{HOOC}-\mathrm{COOH}$

Oxalic acid (OXA)

HOOC $\mathrm{COOH}$

Malonic acid (MAL)

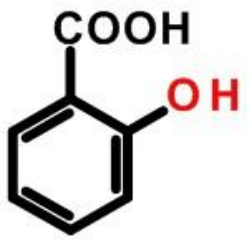

Salicylic acid (FUM)<smiles>O=C(O)CCC(=O)O</smiles>

Succinic acid (SUC)

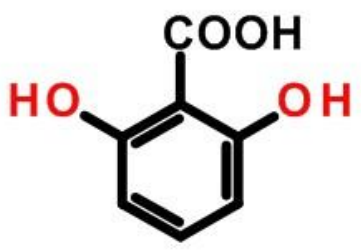

2,6-Dihydroxybenzoic acid

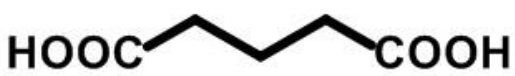

(26DHB)

Glutaric acid (GLT)<smiles>O=C(O)CCCCCC(=O)O</smiles>

Adipic acid (ADA)

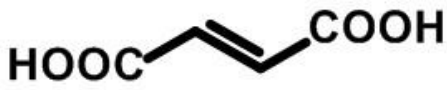

Dihyroxyterephthalic acid

(DHT)

Fumaric acid (FUM)

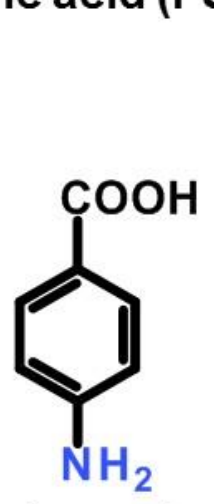<smiles>O=C(O)c1cc(O)c(C(=O)O)cc1O</smiles>

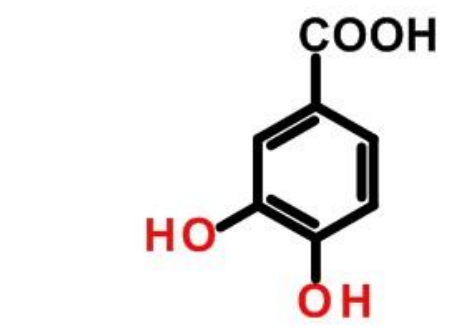

3,4-Dihydroxybenzoic acid (34DHB)

4-Aminobenzoic acid

(ABA)

Scheme S1. Molecular structures of the coformers employed in the study (contd...) 


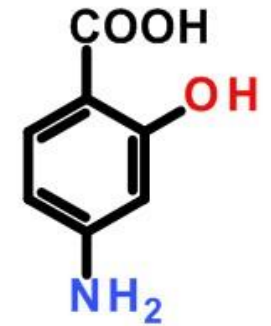

4-Aminosaslicylic acid (ASA)<smiles>O=C(O)C=Cc1ccc(O)c(O)c1</smiles>

Caffeic acid (CFA)<smiles>Oc1ccc(O)cc1</smiles>

Hydroquinone (HQN)

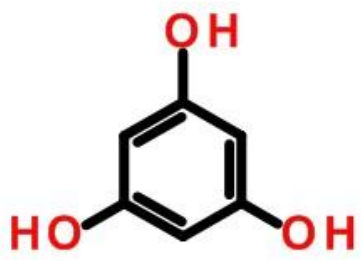

Phluroglucinol (PHL)<smiles>NC(N)=S</smiles>

Thiourea (THU)

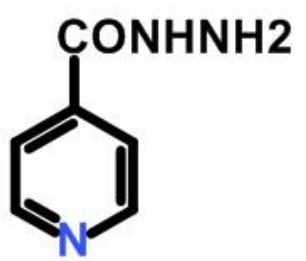

Isoniazid (INZ)

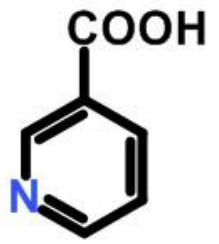

Nicotinic acid (NTA)

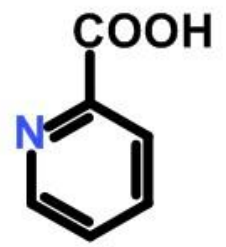

Picolinic acid (PCA)<smiles>NC(N)=O</smiles>

Urea (URE)<smiles>NC(=S)C(N)=S</smiles>

Dithioxamde (DTX)

Scheme S1. Molecular structures of the coformers employed in the study 
Table S2. Crystallographic information

\begin{tabular}{|c|c|c|c|c|c|c|c|}
\hline & PRT I & PRT II & PRT-OXA & PRT-FUM & PRT-SAL & PRT-26DHB & PRT-DHT \\
\hline Formula & $\mathrm{C}_{9} \mathrm{H}_{12} \mathrm{~N}_{2} \mathrm{~S}$ & $\mathrm{C}_{9} \mathrm{H}_{12} \mathrm{~N}_{2} \mathrm{~S}$ & $\begin{array}{c}\left(\mathrm{C}_{9} \mathrm{H}_{12} \mathrm{~N}_{2} \mathrm{~S}\right): \\
\left(\mathrm{C}_{2} \mathrm{H}_{2} \mathrm{O}_{4}\right)\end{array}$ & $\begin{array}{c}\left(\mathrm{C}_{9} \mathrm{H}_{12} \mathrm{~N}_{2} \mathrm{~S}\right): \\
\left(\mathrm{C}_{4} \mathrm{H}_{4} \mathrm{O}_{4}\right)\end{array}$ & $\begin{array}{c}\left(\mathrm{C}_{9} \mathrm{H}_{12} \mathrm{~N}_{2} \mathrm{~S}\right): \\
\left(\mathrm{C}_{7} \mathrm{H}_{6} \mathrm{O}_{3}\right)\end{array}$ & $\begin{array}{c}\left(\mathrm{C}_{9} \mathrm{H}_{12} \mathrm{~N}_{2} \mathrm{~S}\right): \\
\left(\mathrm{C}_{7} \mathrm{H}_{6} \mathrm{O}_{4}\right)\end{array}$ & $\begin{array}{c}\left(\mathrm{C}_{9} \mathrm{H}_{12} \mathrm{~N}_{2} \mathrm{~S}\right): \\
\left(\mathrm{C}_{8} \mathrm{H}_{6} \mathrm{O}_{6}\right)\end{array}$ \\
\hline CCDC Nos. & 1980291 & 1978489 & 1978492 & 1978487 & 1978491 & 1978488 & 1978490 \\
\hline Formula Wt. & 180.27 & 179.26 & 558.62 & 296.34 & 318.38 & 334.38 & 378.39 \\
\hline Crystal habit & Block & Block & Block & Block & Block & Block & Block \\
\hline Crystal color & Yellow & Yellow & Orange & Orange & Yellow & Yellow & Yellow \\
\hline Crystal system & Monoclinic & Monoclinic & Monoclinic & Triclinic & Monoclinic & Monoclinic & Monoclinic \\
\hline Space group & $P 2_{1} / c$ & $P 2{ }_{1} / c$ & $C 2 / c$ & $P_{\overline{1}}$ & $P 2{ }_{1} / c$ & $P 2_{1} / c$ & $P 2{ }_{1} / c$ \\
\hline$a(\AA)$ & $7.774(3)$ & $7.918(6)$ & $41.694(6)$ & $5.303(3)$ & $13.488(9)$ & $13.59(4)$ & $9.5705(6)$ \\
\hline$b(\AA)$ & $17.015(7)$ & $15.957(11)$ & $5.6080(8)$ & $10.145(5)$ & $7.802(2)$ & $7.90(2)$ & $19.1474(10)$ \\
\hline$c(\AA)$ & $7.463(3)$ & $7.417(5)$ & $24.676(4)$ & $14.083(9)$ & $15.729(8)$ & $16.19(5)$ & $10.4185(7)$ \\
\hline$\alpha\left(^{\circ}\right)$ & 90 & 90 & 90 & $107.96(2)$ & 90 & 90 & 90 \\
\hline$\beta\left(^{\circ}\right)$ & $103.640(7)$ & $96.689(9)$ & $100.519(9)$ & $95.12(4)$ & $93.30(2)$ & $95.503(9)$ & $114.324(2)$ \\
\hline$\gamma\left({ }^{\circ}\right)$ & 90 & 90 & 90 & $95.66(3)$ & 90 & 90 & 90 \\
\hline$V\left(\AA^{3}\right)$ & $959.4(7)$ & $930.7(11)$ & $5672.6(15)$ & $711.5(7)$ & $1652.5(15)$ & $1730(9)$ & 1739.71(19) \\
\hline$Z$ & 4 & 4 & 8 & 2 & 4 & 4 & 4 \\
\hline$D_{\text {calc }}\left(\mathrm{g} \mathrm{cm}^{-3}\right)$ & 1.248 & 1.279 & 1.308 & 1.383 & 1.280 & 1.284 & 1.445 \\
\hline$T(\mathrm{~K})$ & $123(2)$ & $248(2)$ & $248(2)$ & $123(2)$ & $273(2)$ & $173(2)$ & $301(2)$ \\
\hline$(\lambda) \mathrm{Mo} \mathrm{K}_{\alpha}$ & 0.71073 & 0.71073 & 0.71073 & 0.71073 & 0.71073 & 0.71073 & 0.71073 \\
\hline$\mu\left(\mathrm{mm}^{-1}\right)$ & 0.284 & 0.293 & 0.241 & 0.242 & 0.209 & 0.207 & 0.224 \\
\hline $2 \theta$ range $\left(^{\circ}\right)$ & 55.0 & 51 & 51.0 & 54.8 & 50.4 & 50.4 & 56.78 \\
\hline Total Reflns. & 8515 & 6948 & 49304 & 6420 & 12058 & 11592 & 36990 \\
\hline Unique Reflns. & 2185 & 1724 & 5251 & 3128 & 2979 & 3117 & 4257 \\
\hline Reflns. Used & 1485 & 1341 & 4639 & 2032 & 1427 & 1390 & 3697 \\
\hline No. Parameters & 109 & 109 & 408 & 197 & 203 & 224 & 264 \\
\hline GOF on $F^{2}$ & 0.812 & 1.099 & 1.071 & 0.922 & 0.806 & 0.978 & 1.051 \\
\hline Final $R_{1}, w R_{2}$ & $\begin{array}{l}0.0469 \\
0.1266\end{array}$ & $\begin{array}{c}0.0788 \\
0.2403\end{array}$ & $\begin{array}{c}0.0690 \\
0.1758\end{array}$ & $\begin{array}{l}0.0444, \\
0.0940\end{array}$ & $\begin{array}{l}0.0554, \\
0.1185\end{array}$ & $\begin{array}{l}0.0779, \\
0.1943\end{array}$ & $\begin{array}{l}0.0537 \\
0.1373\end{array}$ \\
\hline
\end{tabular}




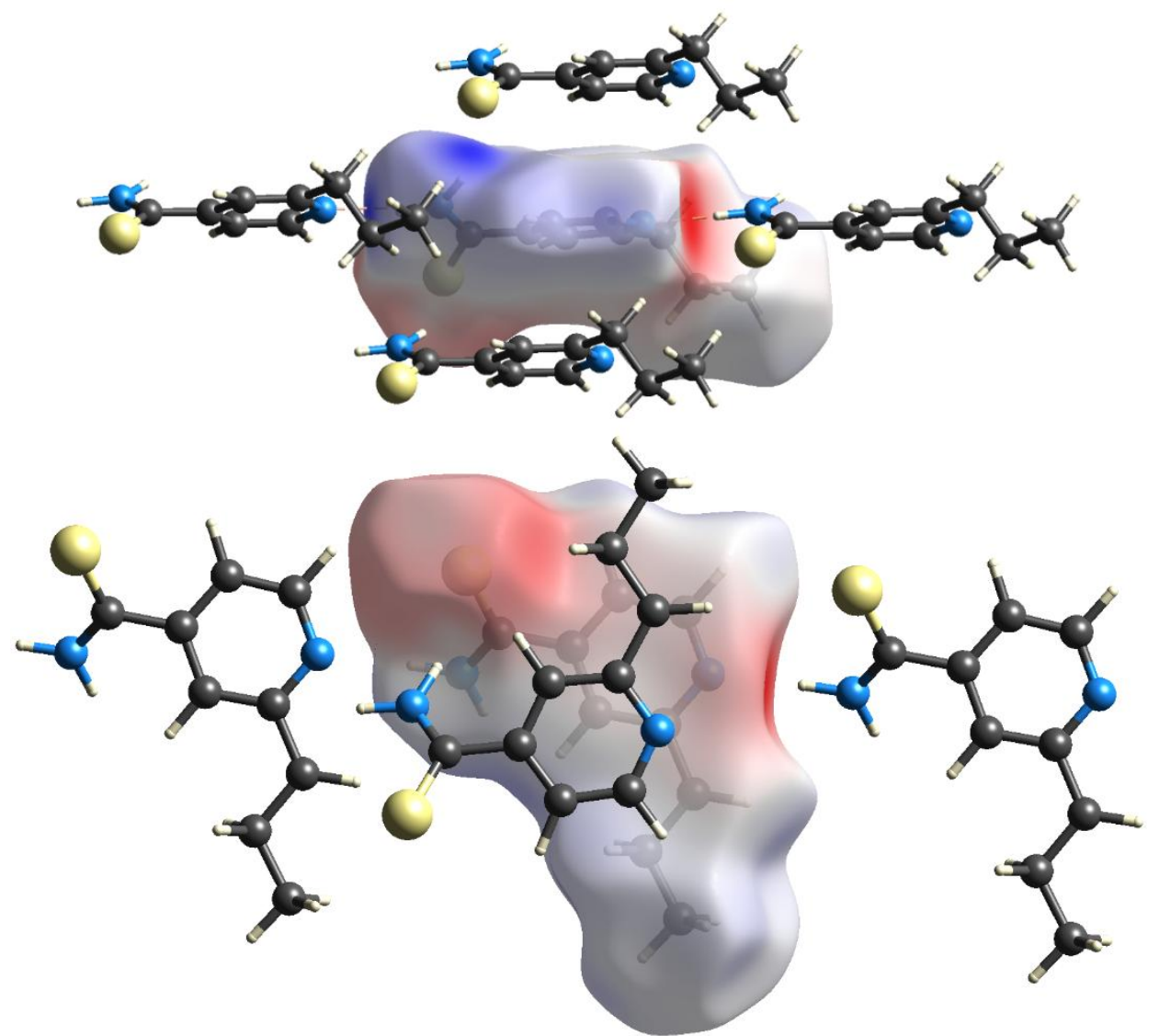

Figure S1. Hirshfeld surface of the dimorphs of PRT, with mapped electrostatic potential. 
(a)

(b)

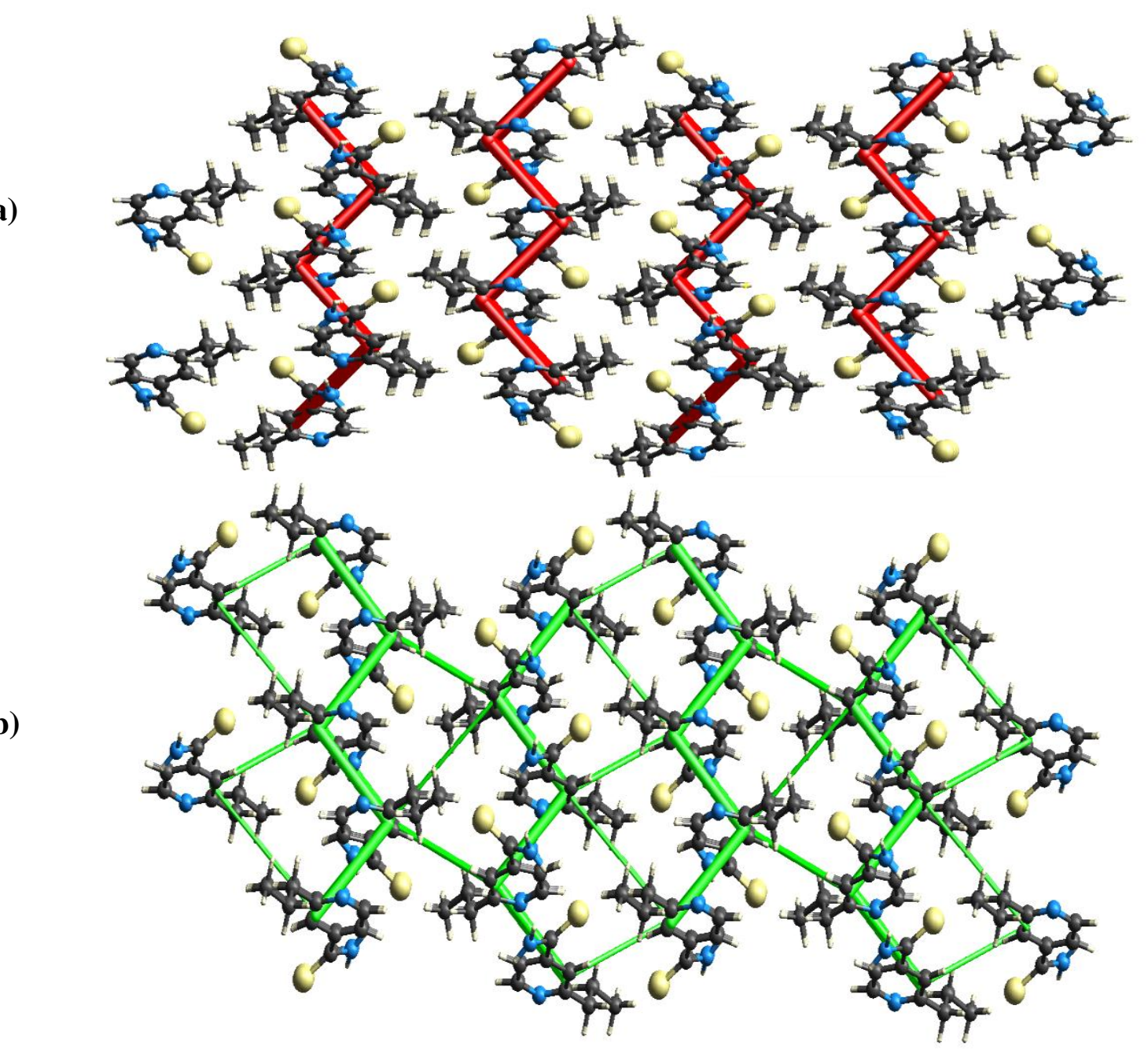

(c)

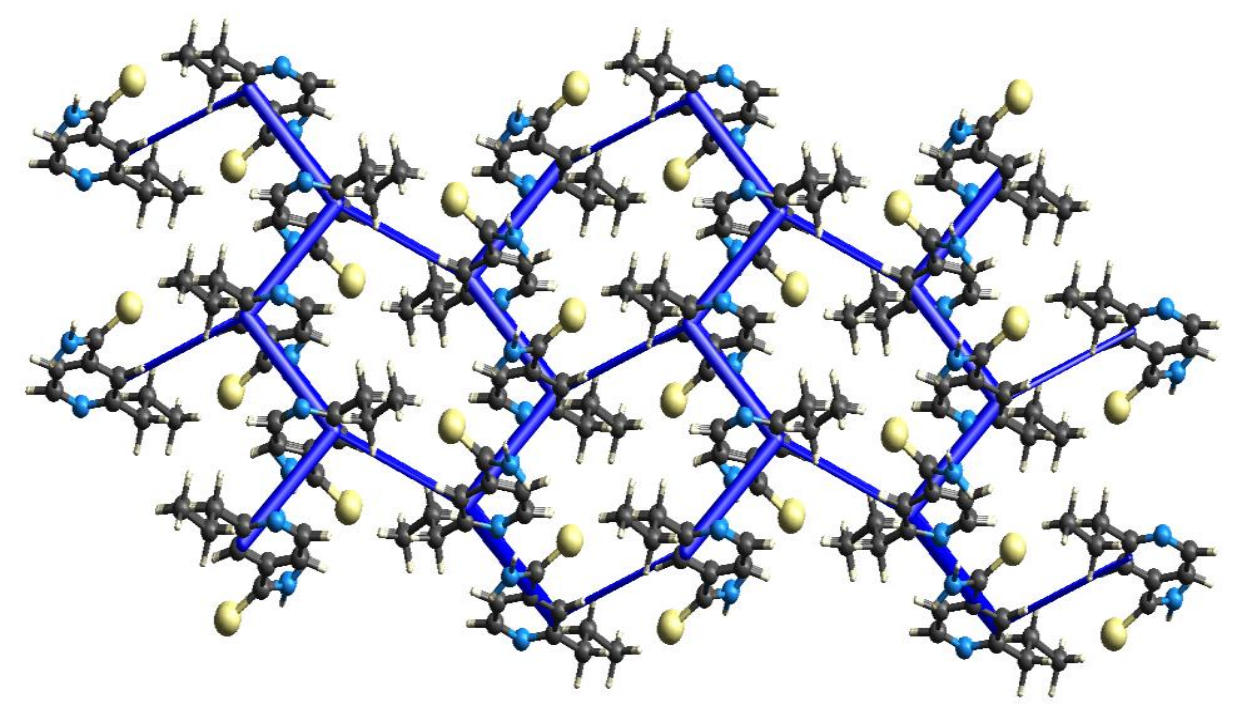

Figure S2. Energy frameworks for PRT-I (a) Coulombic; (b) Dispersive; (c) Total energy 
(a)

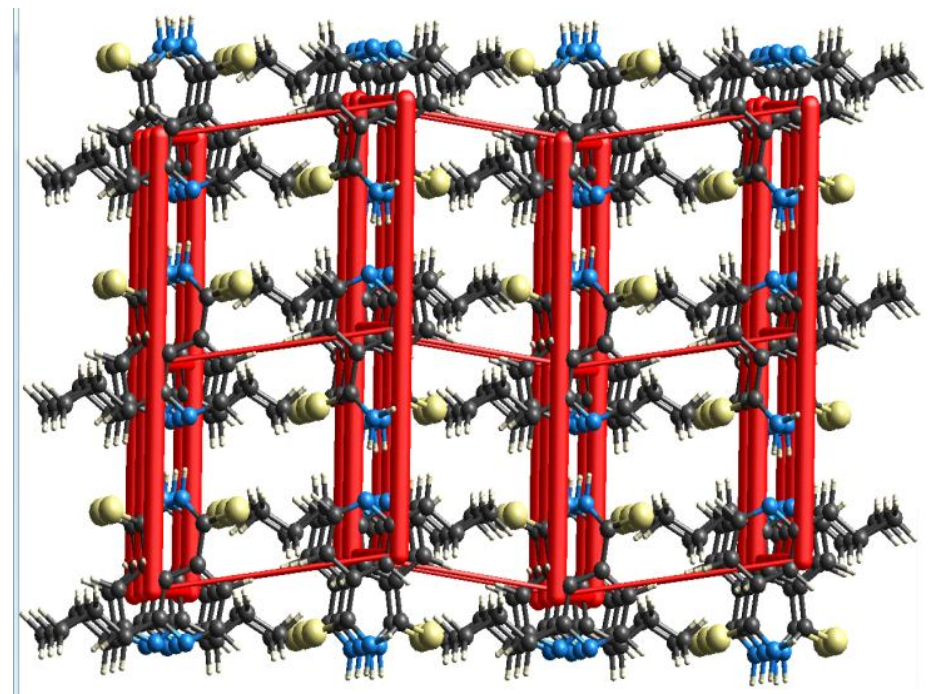

(b)

(c)

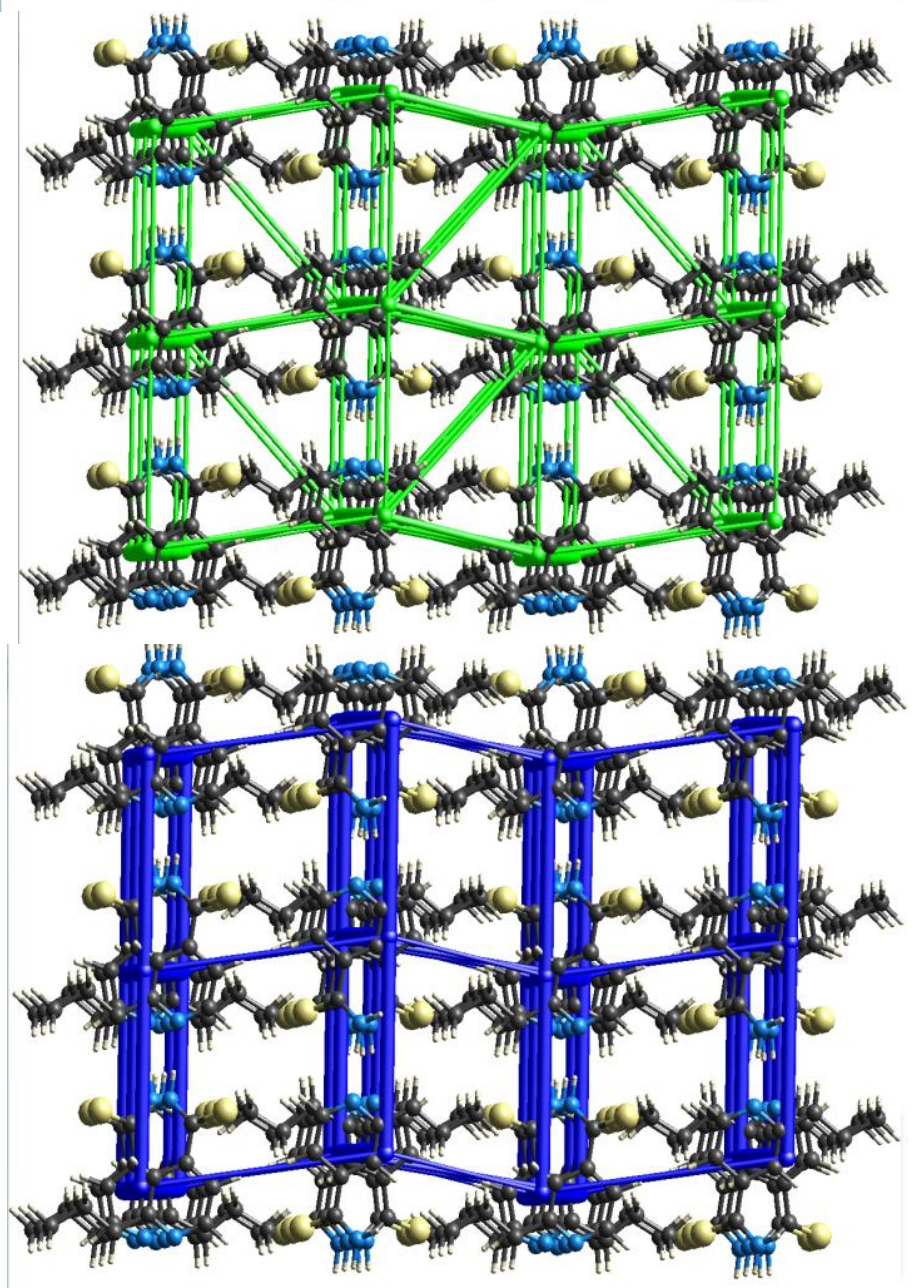

Figure S3. Energy frameworks for PRT-II (a) Coulombic; (b) Dispersive; (c) Total energy 


\section{PXRD and IR Results of Dimorphs}

(a)

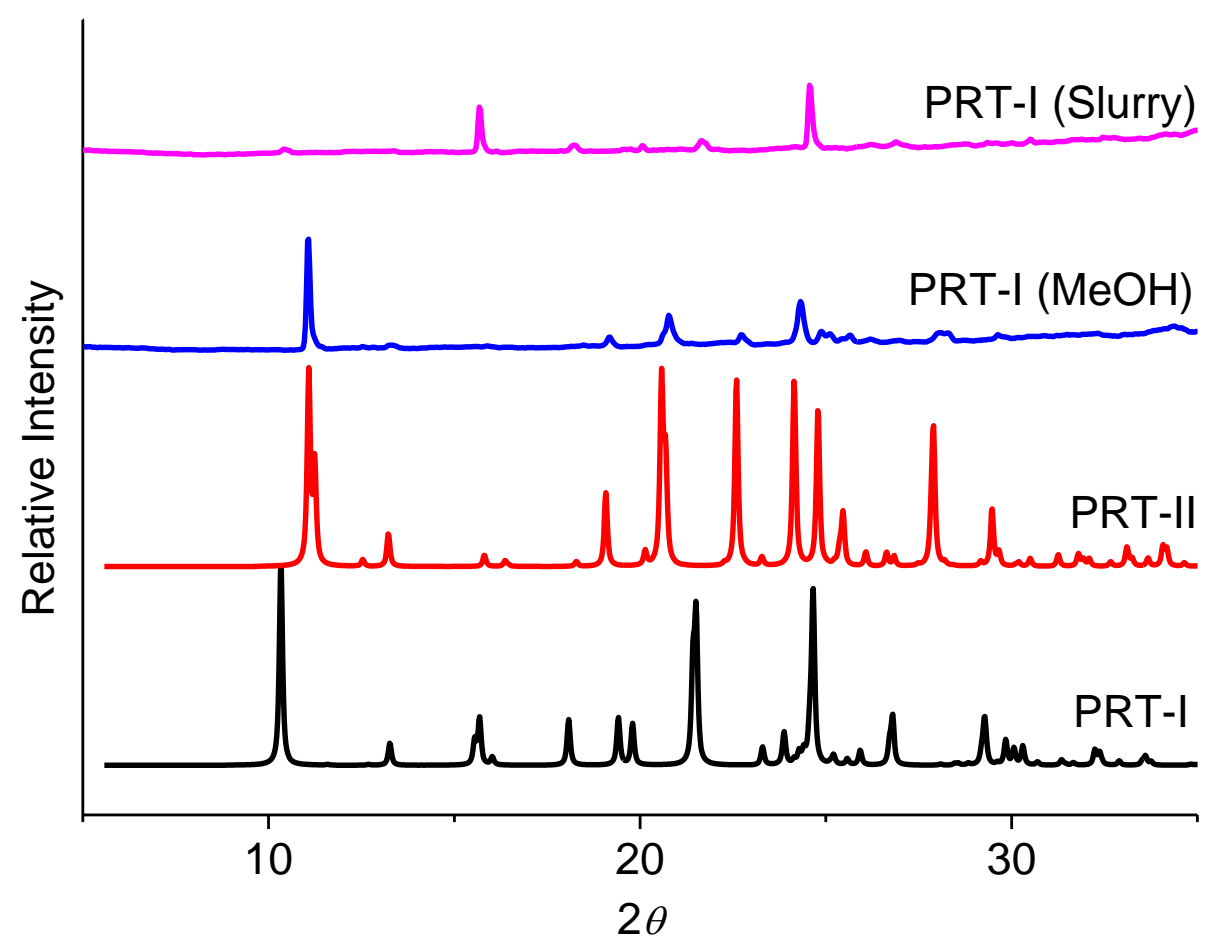

(b)

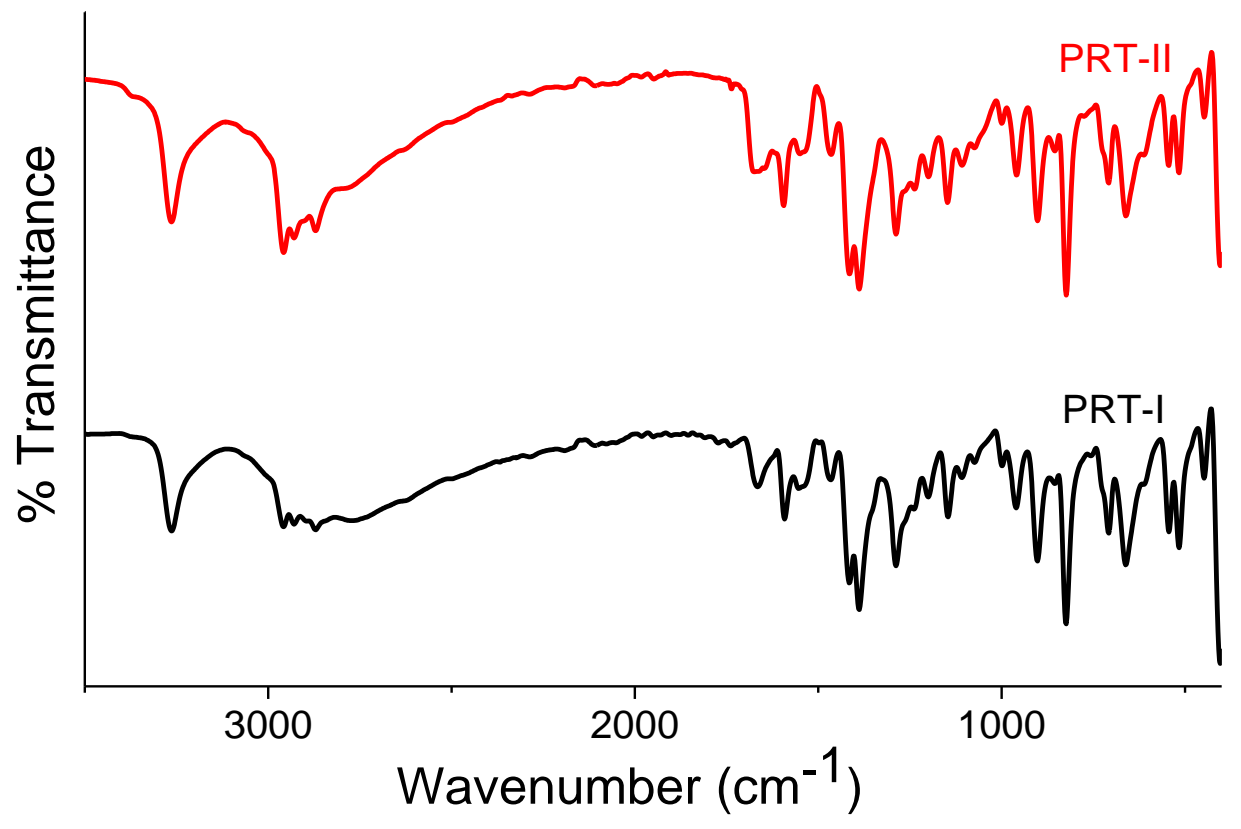

Figure S4. (a) PRT-I in the presence of MeOH recrystallizes to PRT II. The slurry experiment using PRT-I with seeds of PRT-II after 24 hours yielded a PXRD pattern corresponding to PRT I, indicating the systems to be monotropically related. (b) Because the dimorphs have similar interaction types, their IR spectral signatures remain comparable. 
PXRD Results for complexes

\section{PRT-OXA}

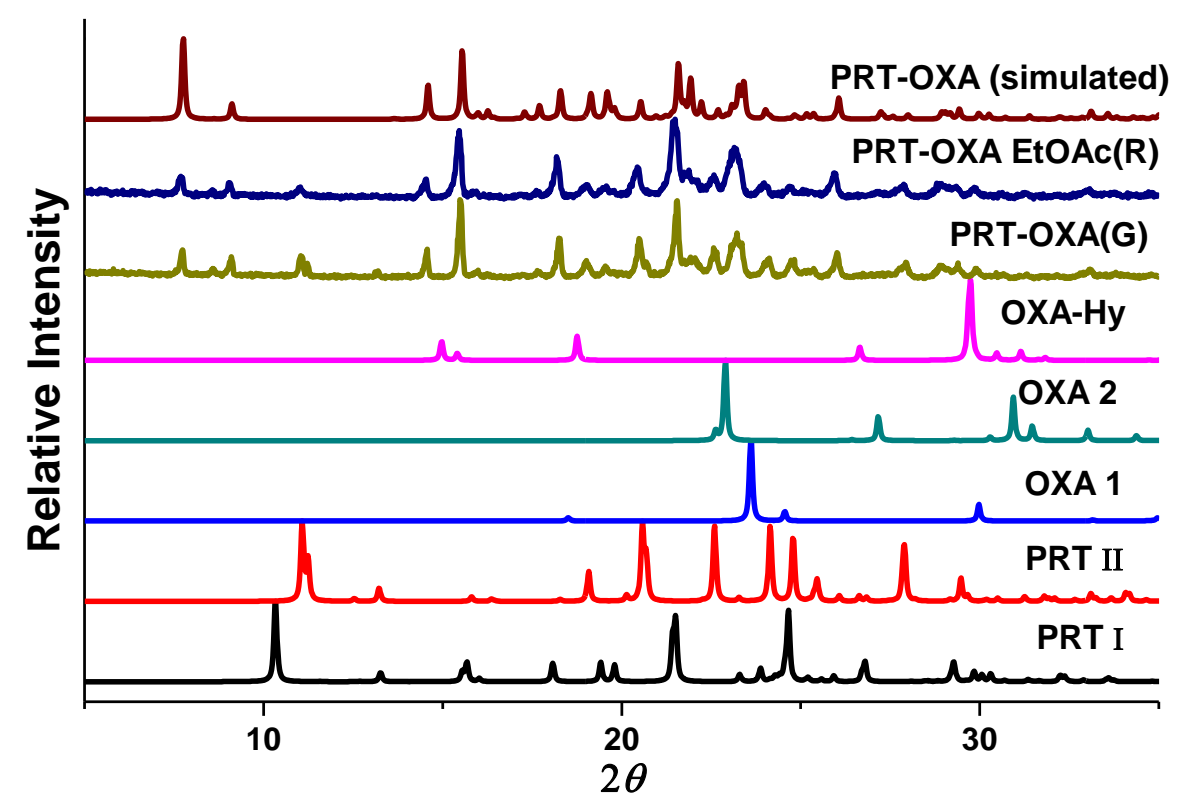

Figure S5. Prothionamide forms 1:1 cocrystal with oxalic acid

- PRT-FUM

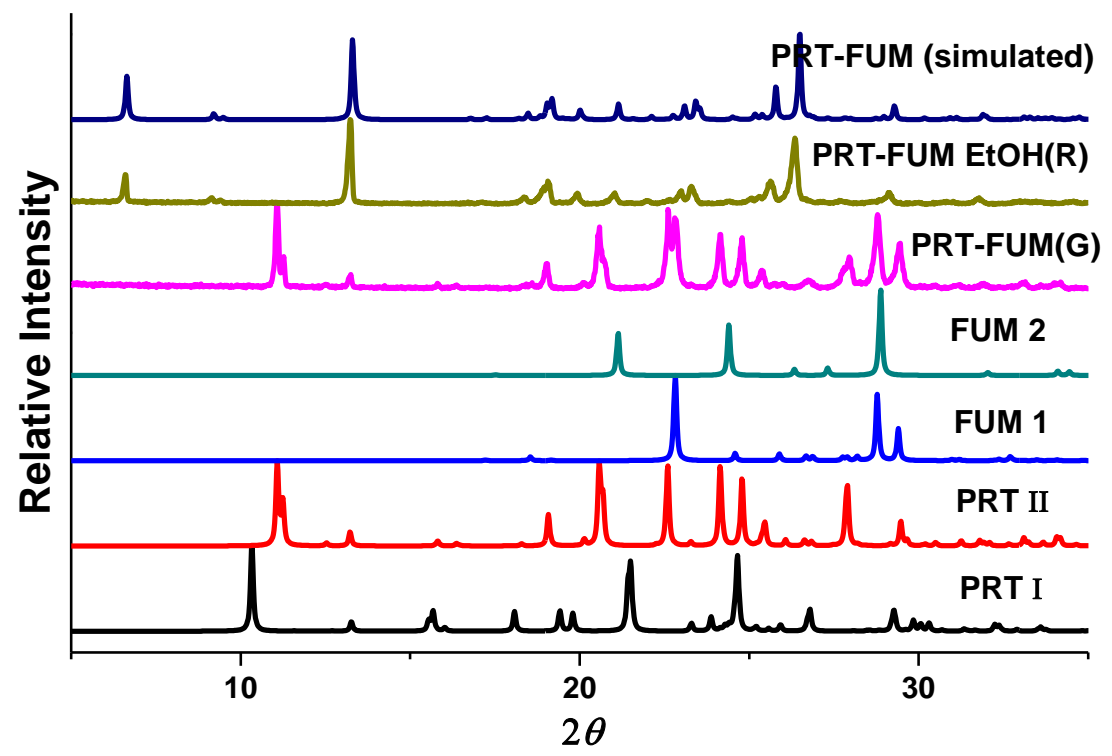

Figure S6. Prothionamide forms 1:1 cocrystal with fumaric acid. The neat ground sample is a physical mixture of prothionamide and fumaric acid. However, on slow evaporation and a fast evaporation method resulted in cocrystal. 
- PRT-SAL

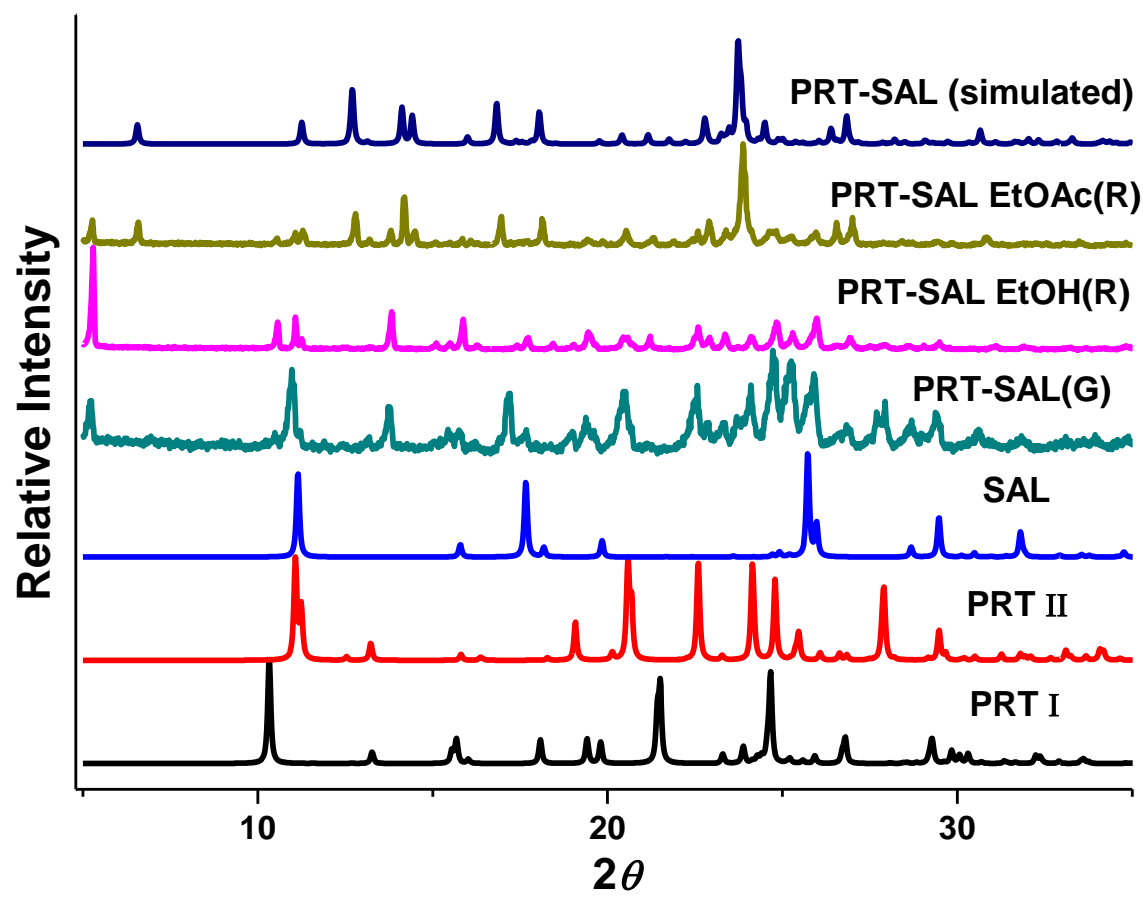

Figure S7. Prothionamide forms 1:1 complex with salicylic acid. Ground sample and rotary evaporated samples from ethanol form a crystalline phase different from that obtained by slow evaporation (simulated). Fast solvent removal from ethyl acetate, but, is a mixture of two crystalline forms of the complex.

\section{- PRT-DHT}

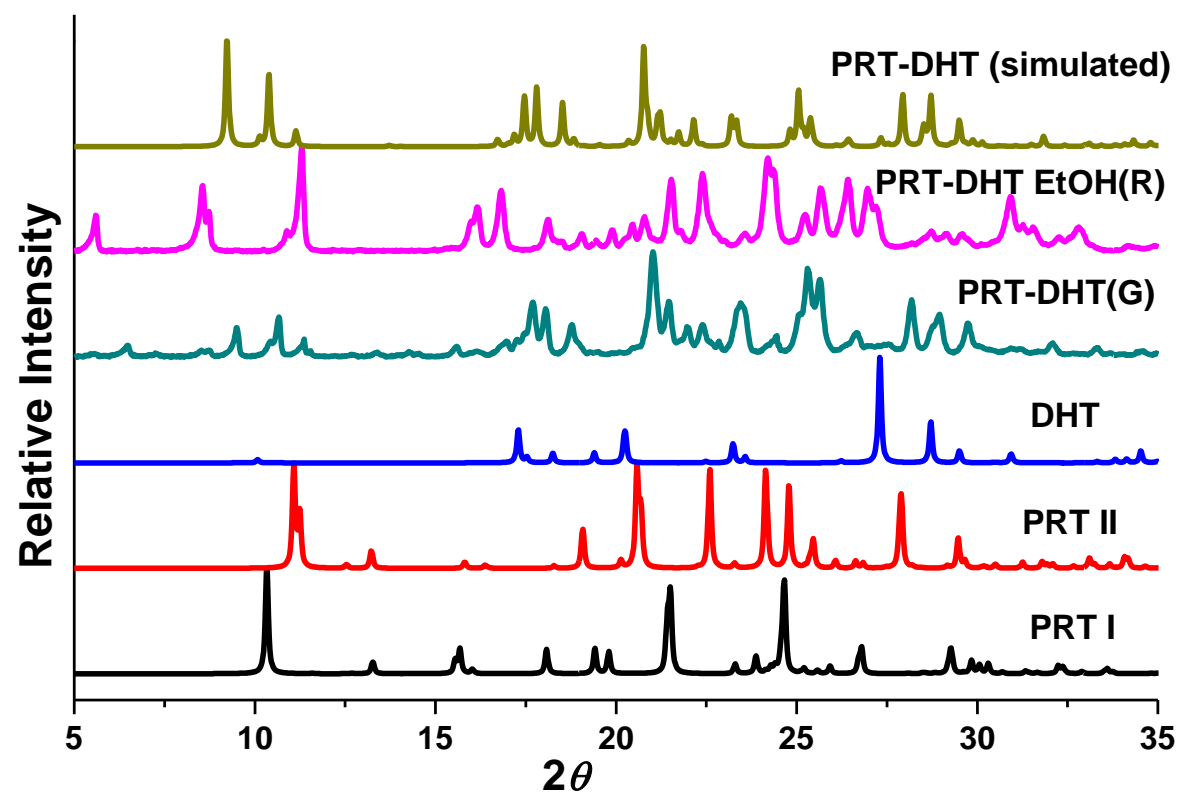

Figure S8. Prothionamide forms a 1:1 molecular complex with 2,5-dihydroxy terephthalic acid. The cocrystal obtained on slow evaporation from methanol is different from that obtained on neat grinding and on rota evaporation from ethanol. 
- PRT-GLT

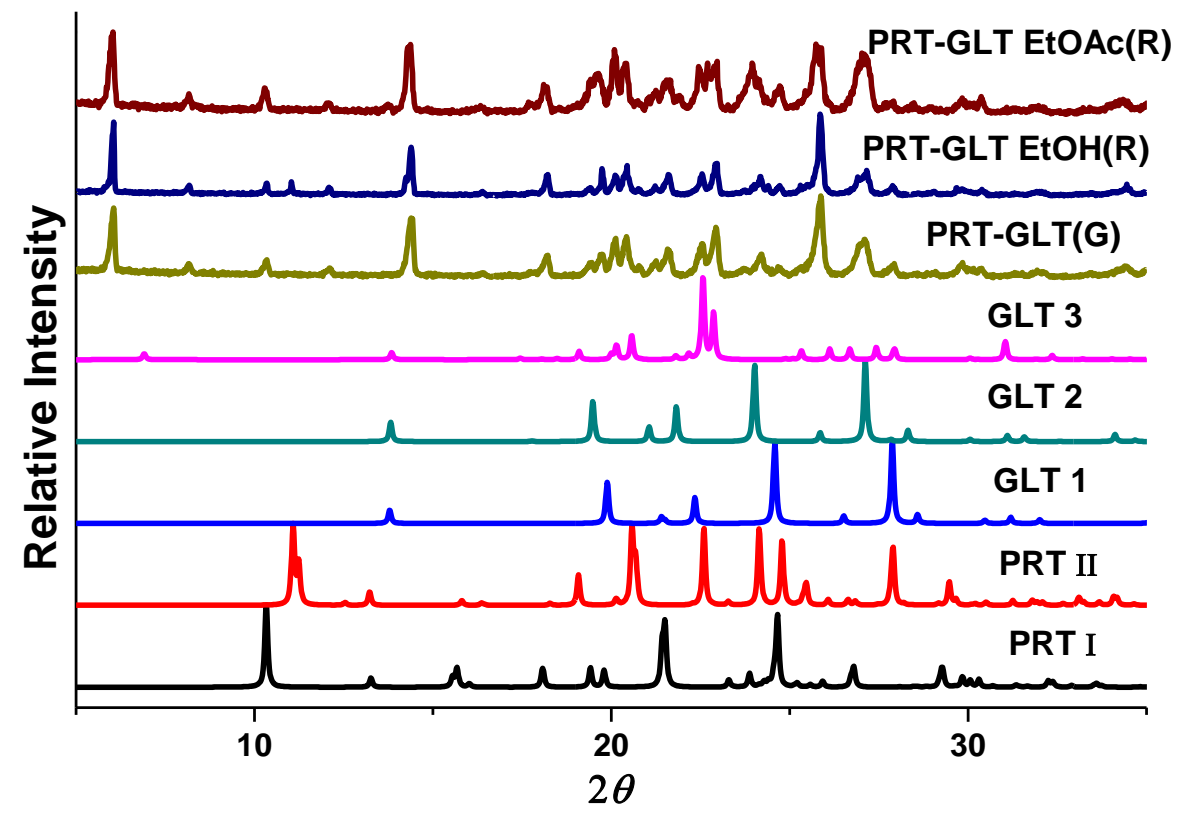

Figure S9. Prothionamide forms complex with glutaric acid.

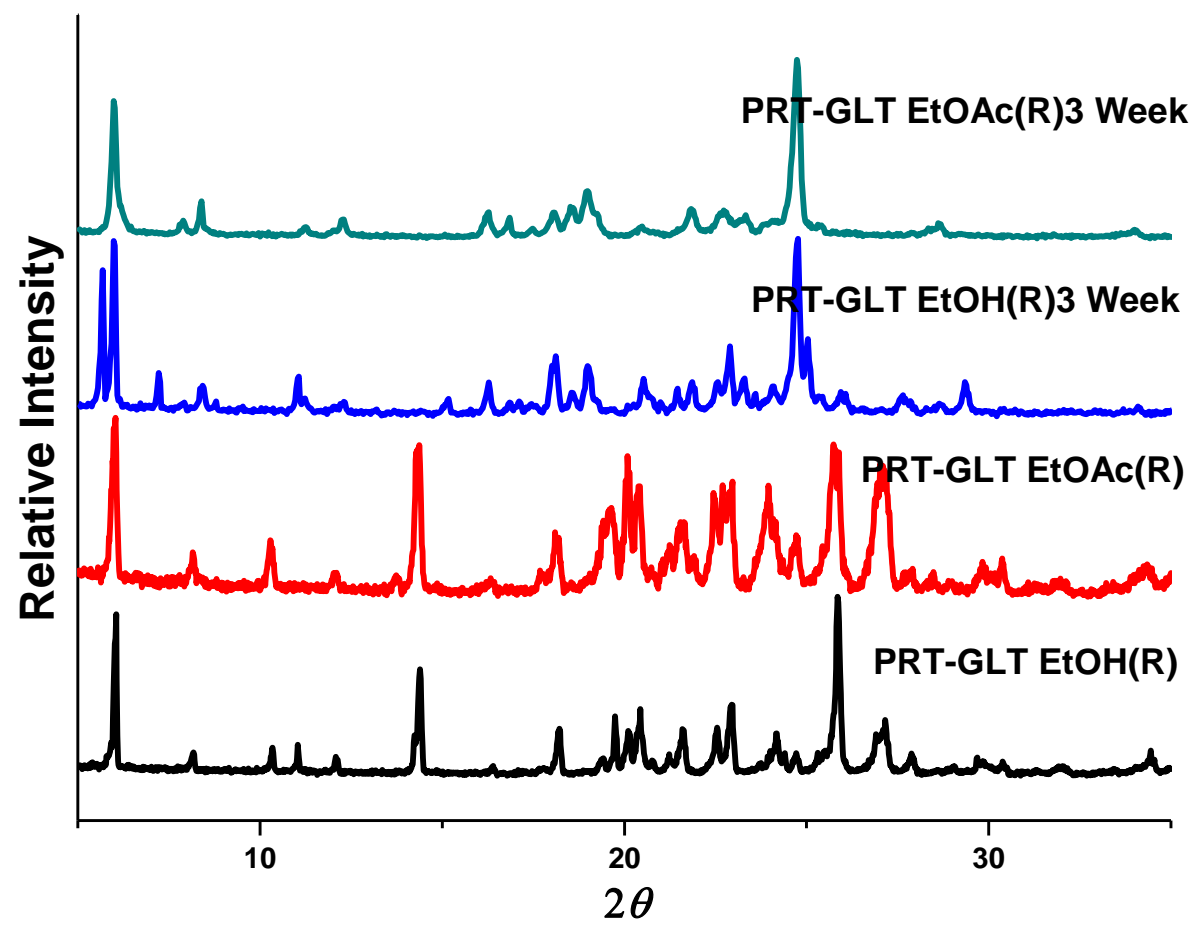

Figure S10. PXRD patterns after exposing PRT-GLT to the humidity of RH $75 \%$ for three weeks. The complexes transform into new crystalline forms, giving rise to two distinct PXRD patterns. 


\section{- PRT-26DHB}

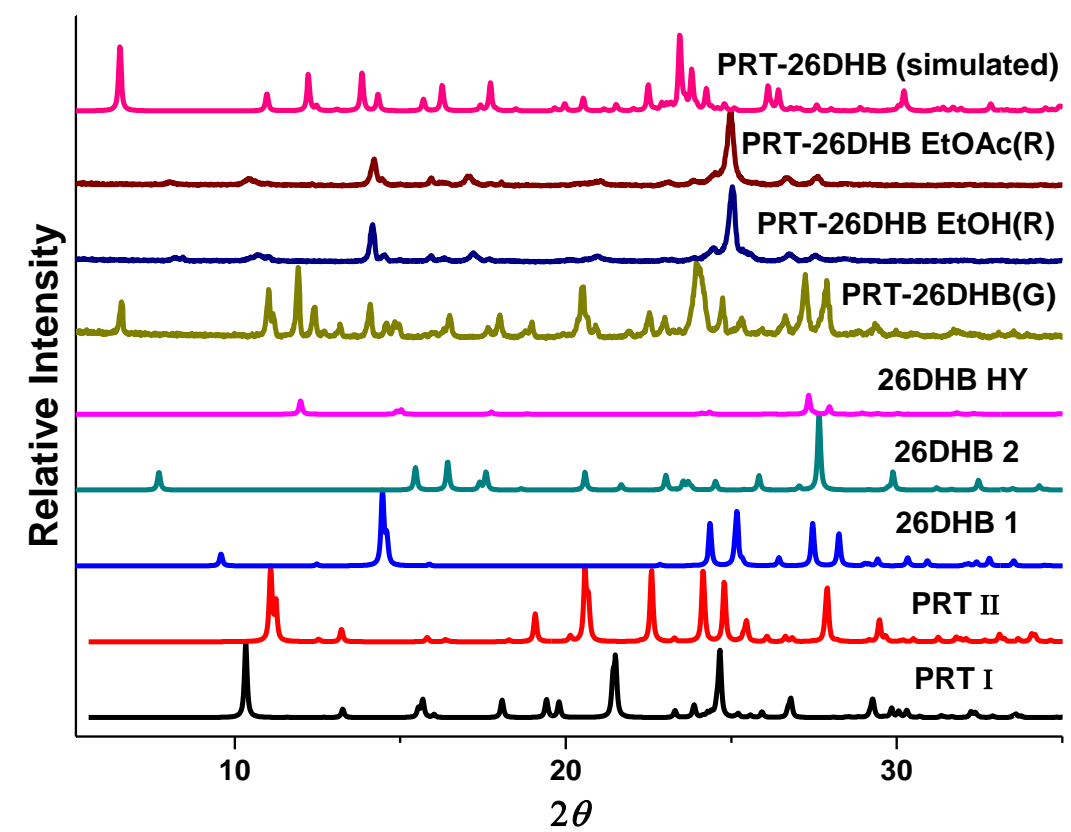

Figure S11. Prothionamide forms 1:1 complex with 26DHB. Ground sample and the crystal obtained by slow evaporation from ethanol-DCM 1:1 mixture are different from those obtained by fast solvent evaporation from ethanol or ethyl acetate.

\section{TG results for different cocrystal forms}

- PRT-SAL

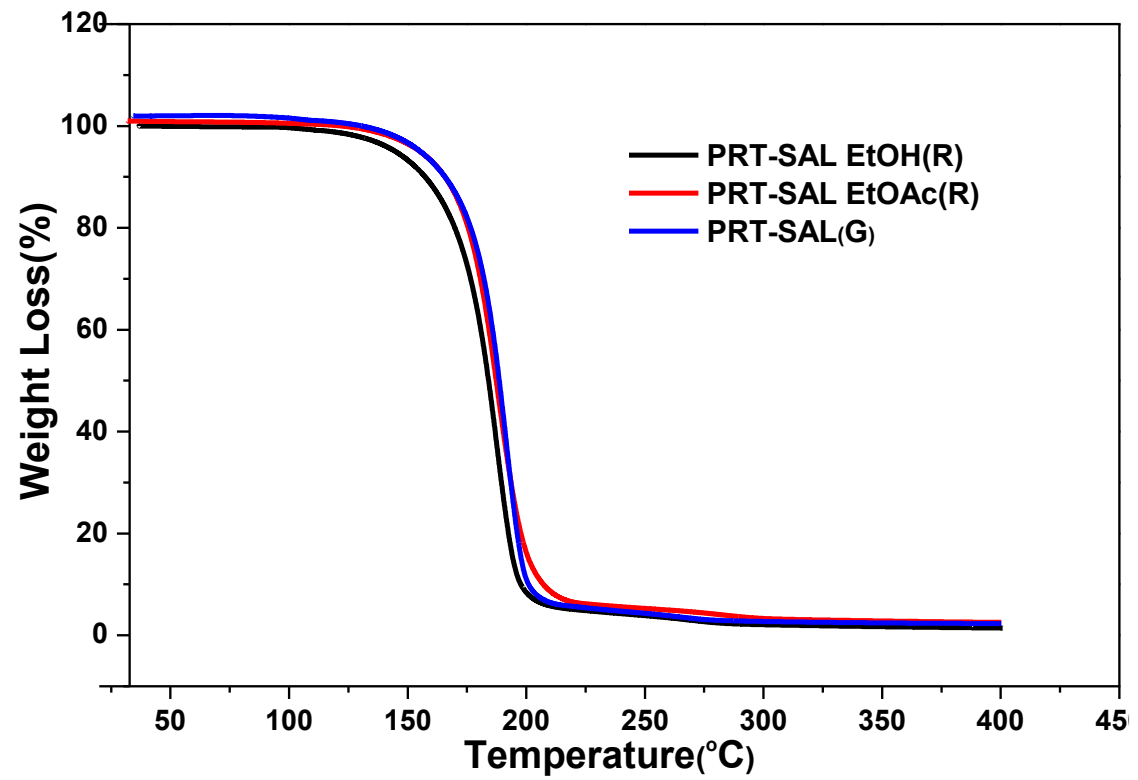

Figure S12. There is no difference in \%weight loss for the ground and rota evaporated samples confirming them to be distinct anhydrous forms of the PRT-SAL molecular complex. 
- PRT-DHT

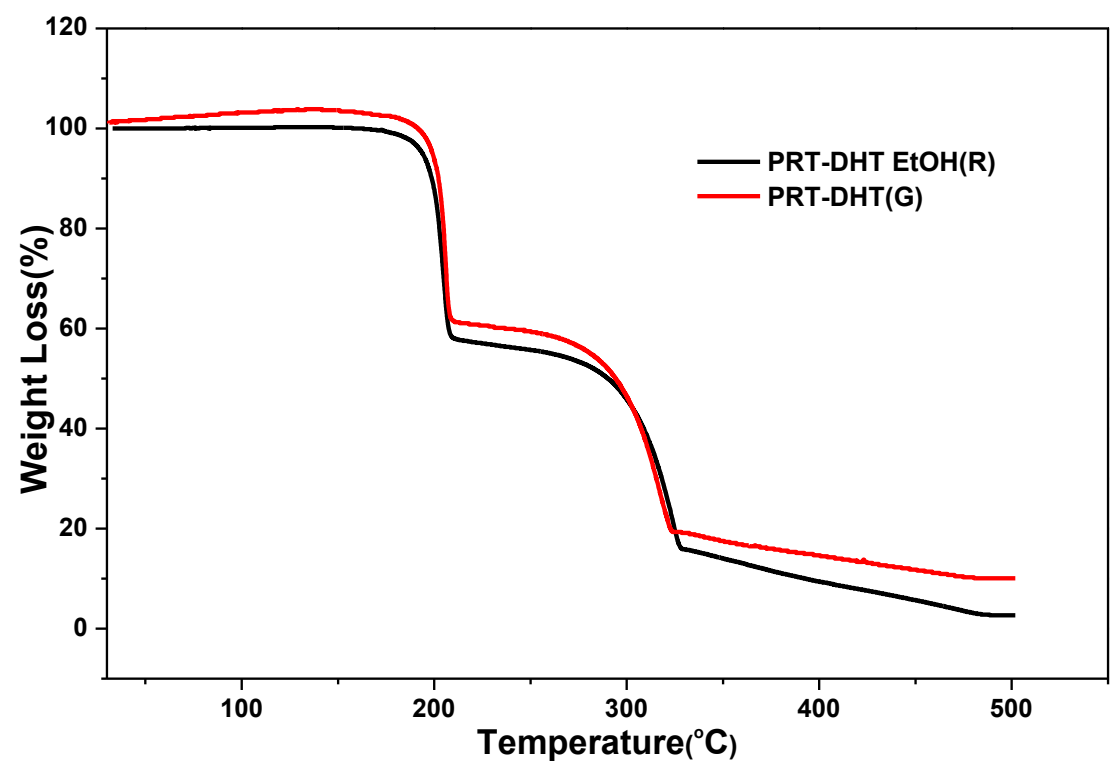

Figure S13. No observable difference is noted in \%weight loss for the ground and fast evaporated samples confirming them to be distinct anhydrous forms of the PRT-DHT molecular complex.

- PRT-GLT

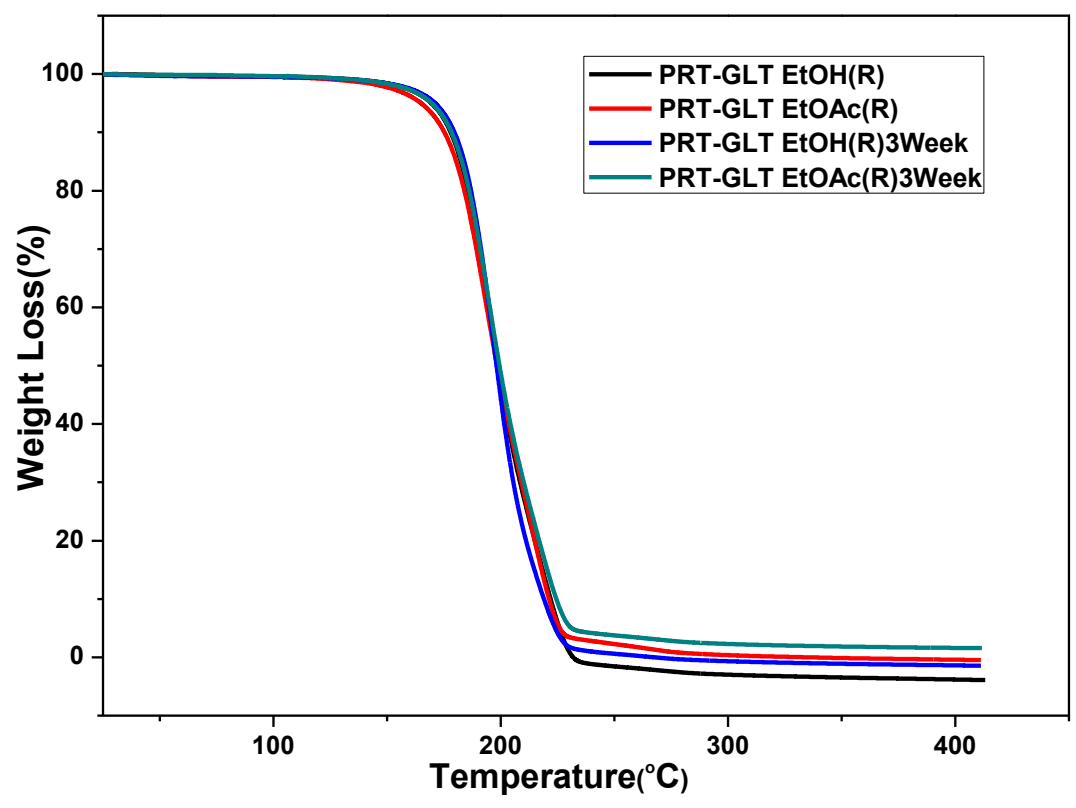

Figure S14. The ground and rota evaporated samples of the PRT-GLT molecular complex confirming have similar thermal profile. 


\section{IR results for complexes}

- PRT-OXA

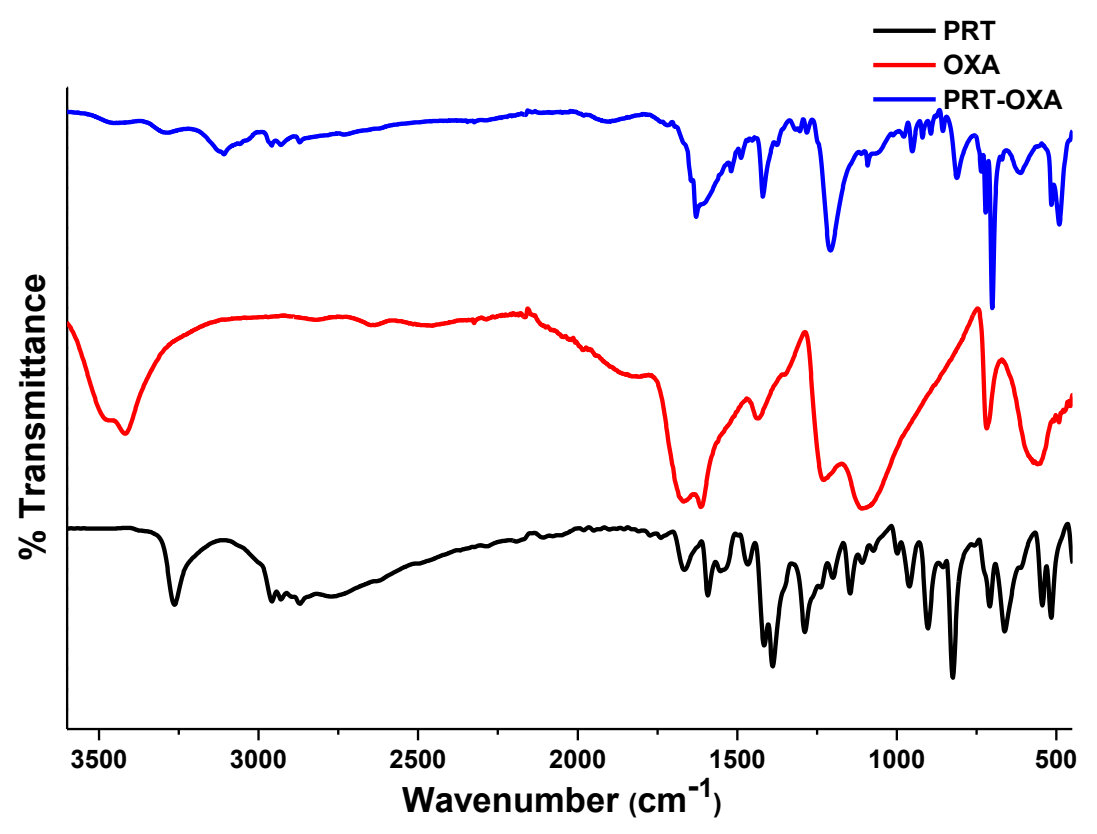

Figure S15. The 1:1 ground sample of PRT-OXA exhibits a significant shift in the stretching and bending frequencies in comparison to the parent compounds.

- PRT-FUM

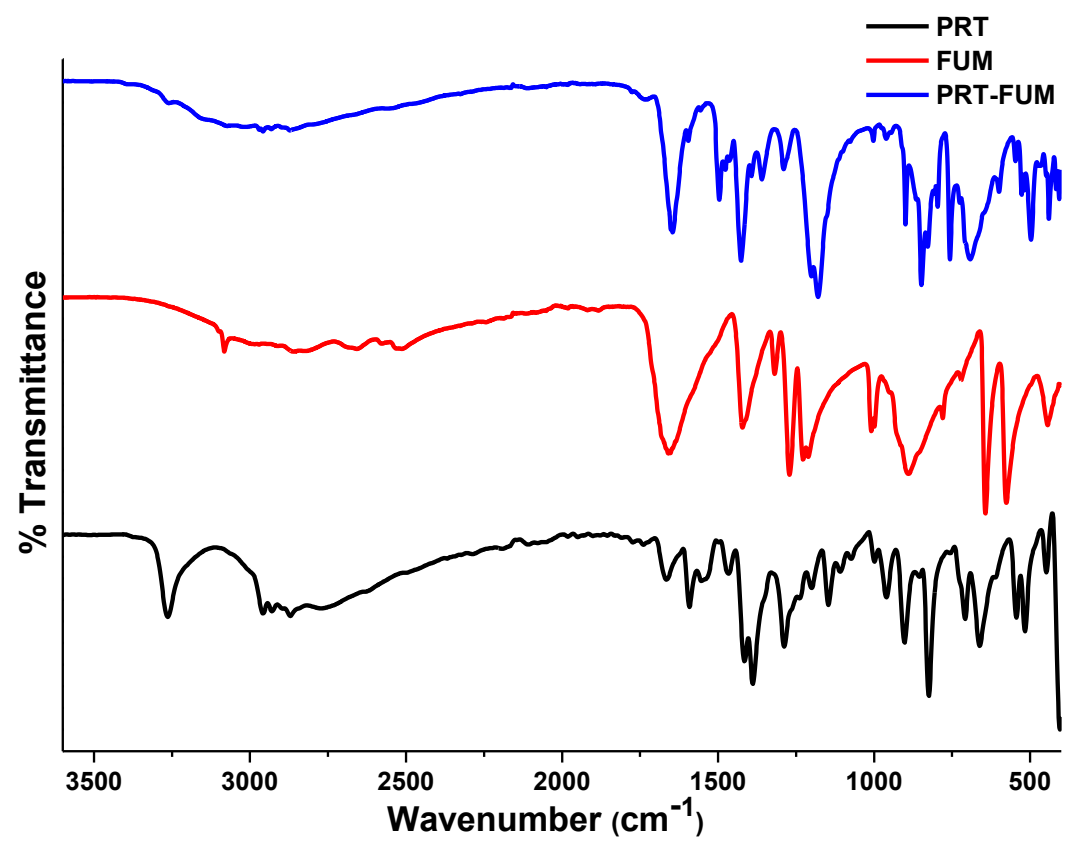

Figure S16. The IR spectra of the PRT-FUM and the parent compounds. 
- PRT-SAL

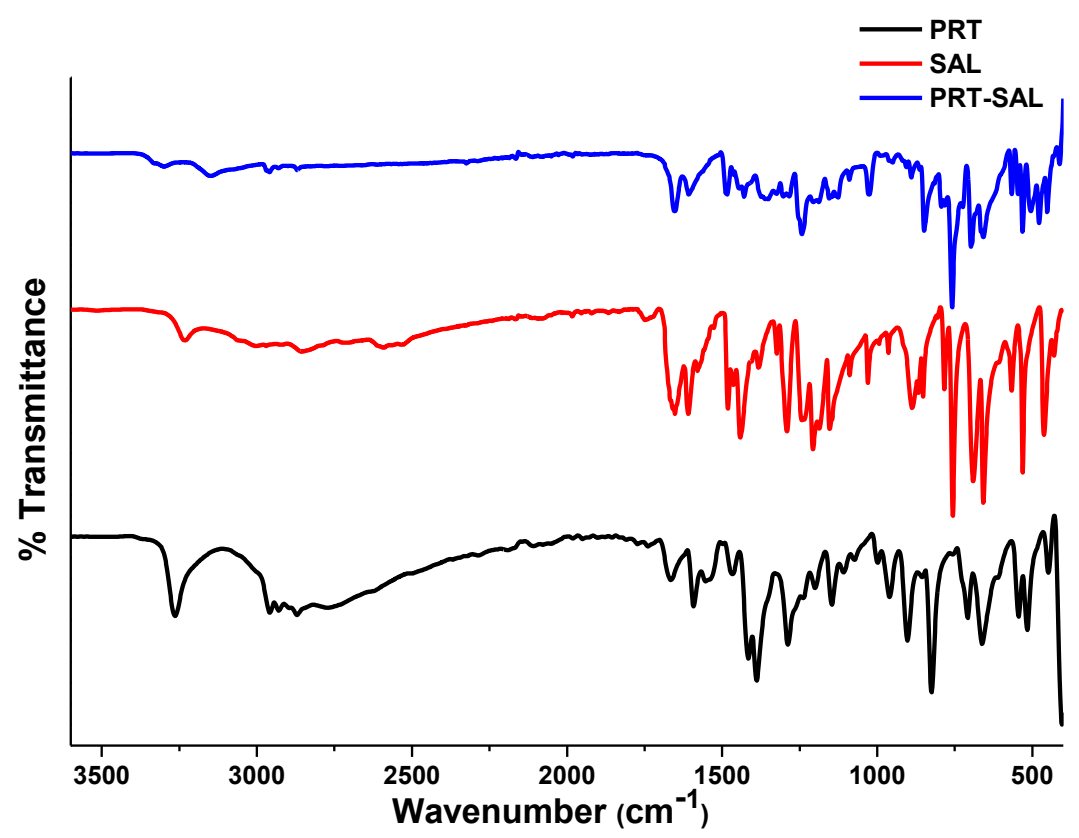

Figure S17. The IR spectra of the PRT-SAL and the parent compounds.

\section{- PRT-GLT}

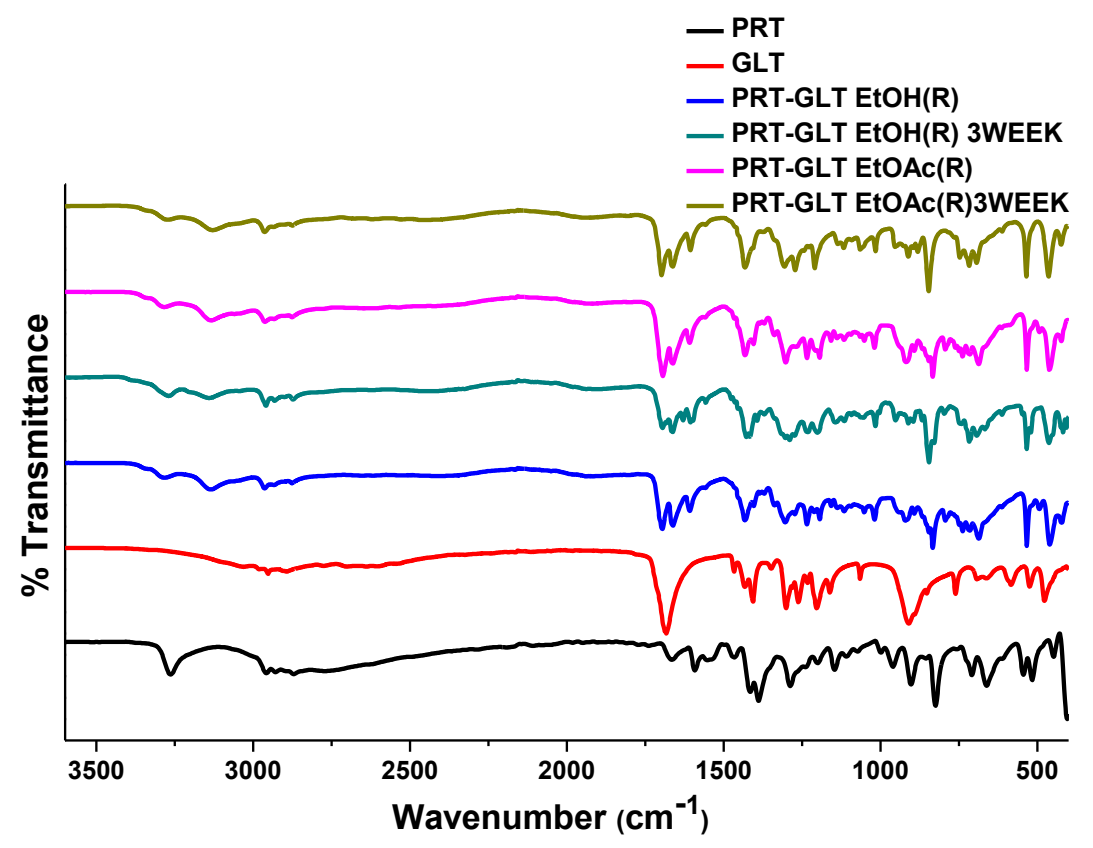

Figure S18. The IR spectra of the PRT-GLT and the parent compounds. 
- PRT-DHT

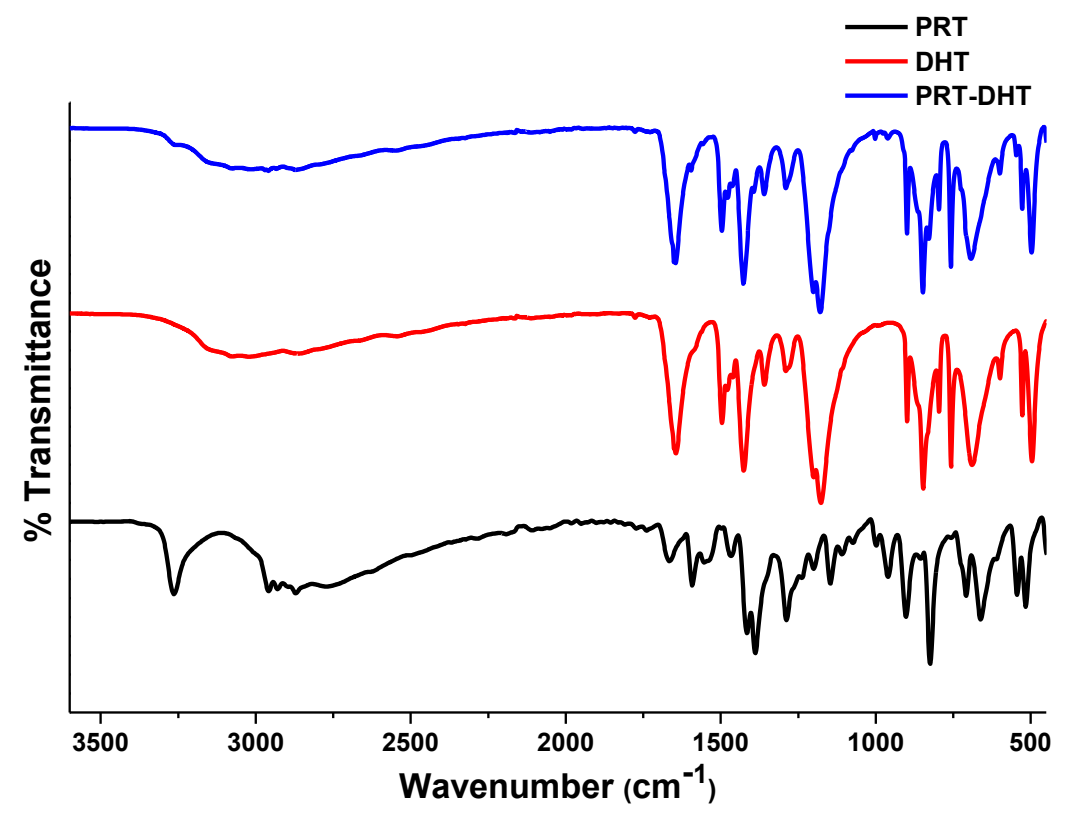

Figure S19. The IR spectra of the PRT-DHT and the parent compounds.

- PRT-26DHB

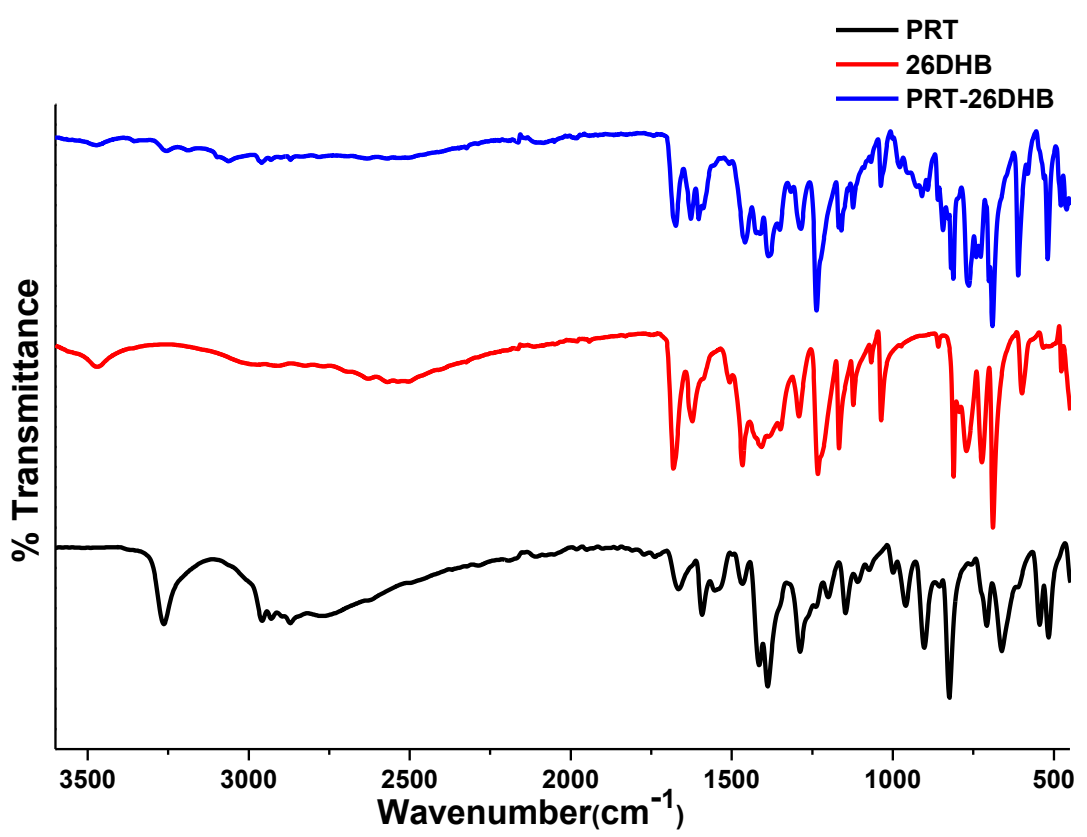

Figure S20. The IR spectra of the PRT-FUM and the parent compounds. 
Table S3. IR spectral information of the complexes

\begin{tabular}{|c|c|c|c|c|c|}
\hline $\begin{array}{c}\text { SI } \\
\text { NO }\end{array}$ & COMPOUNDS & $\mathbf{N}-\mathbf{H}_{\text {str }}$ & $\Delta \mathbf{N}-\mathbf{H}_{\text {str }}$ & $\mathbf{C}=\mathbf{S}_{\text {str }}$ & $\Delta \mathbf{C}=\mathbf{S}_{\text {str }}$ \\
\hline 1 & & & & & \\
\hline 2 & PRT-OXA & 3111 & 147 & 1091 & 53 \\
\hline 3 & PRT-FUM & 2962 & 296 & 1003 & 141 \\
\hline 4 & PRT-GLU & 3130 & 128 & 1015 & 129 \\
\hline 5 & PRT-SAL & 3150 & 108 & 1090 & 54 \\
\hline 6 & PRT-26DHB & 3064 & 194 & 1040 & 104 \\
\hline 7 & PRT-25DHB & & & & \\
\hline
\end{tabular}

\section{THERMAL ANALYSIS}

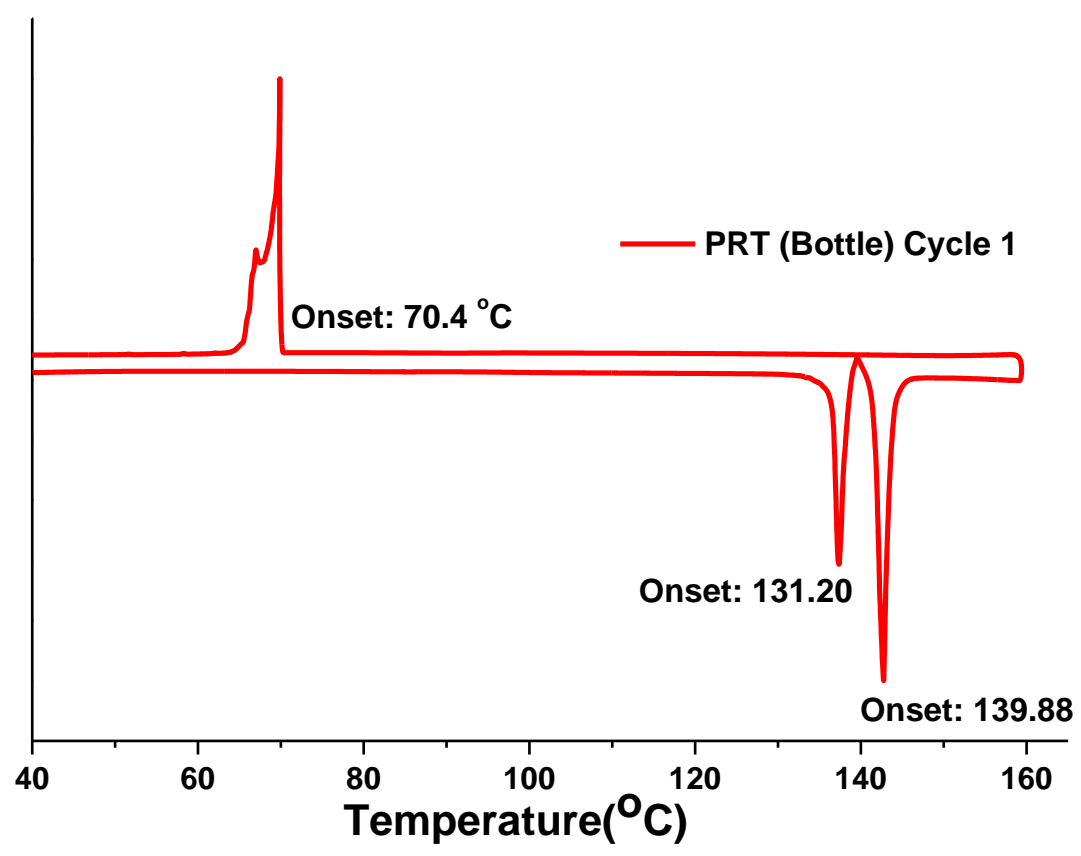

Figure S21. DSC thermogram of PRT (bottle sample). 


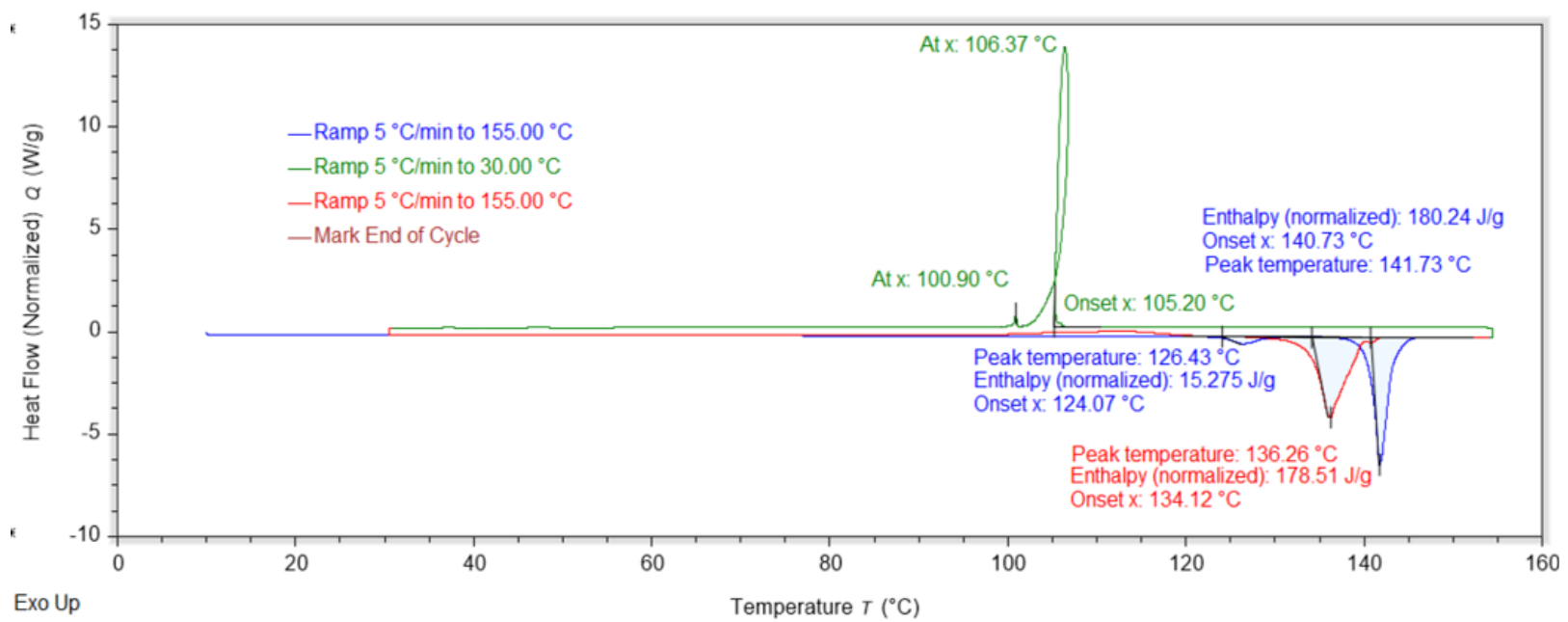

Cooling cycle:

Supercooling phenomenon observed along with small exotherm, possibly a residual crystallization peak

(Rate: $5{ }^{\circ} \mathrm{C} / \mathrm{min}$ )

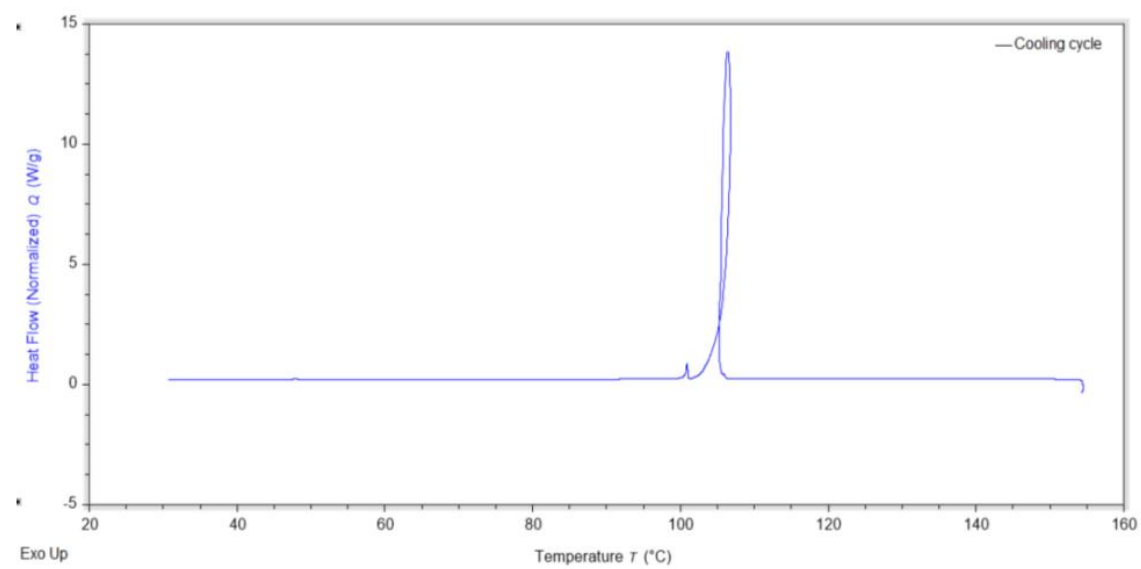

Second heating:

A possible phase transformation could be happening before the thermodynamic melting in the second heat cycle.

(Rate: $5{ }^{\circ} \mathrm{C} / \mathrm{min}$ )

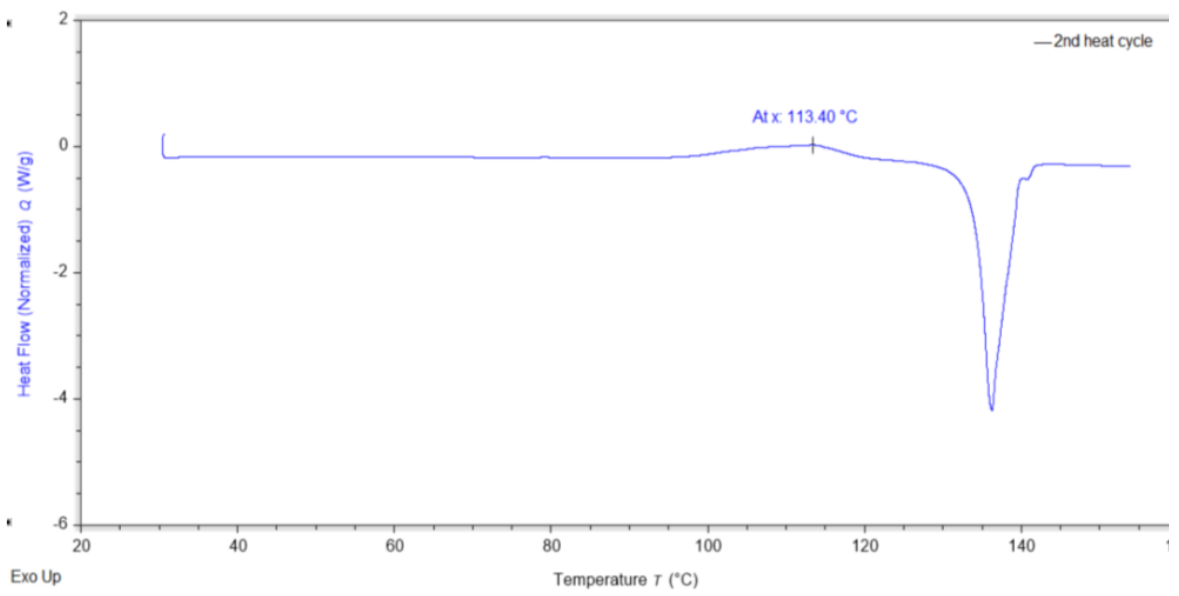




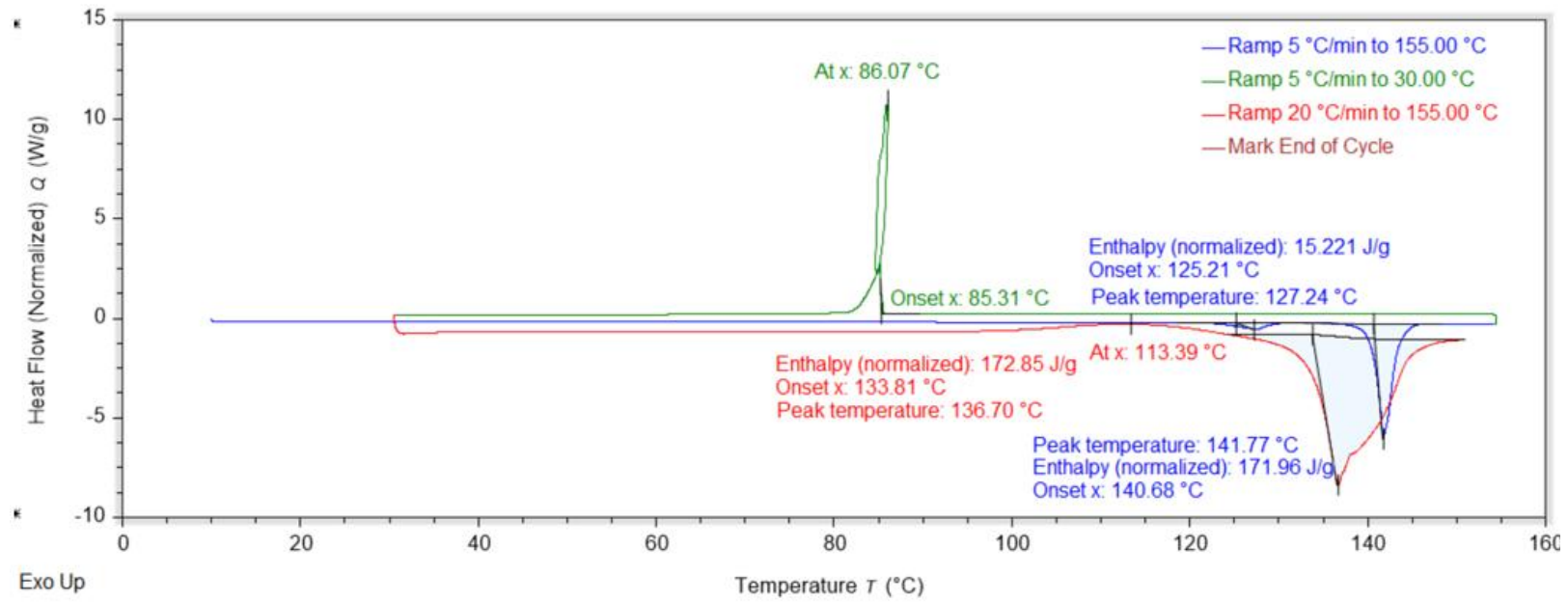

Cooling cycle:

Supercooling phenomenon observed along with small

exotherm, possibly a residual crystallization peak (Rate: $5^{\circ} \mathrm{C} / \mathrm{min}$ )

Second heating:

A possible phase transformation could be happening before the thermodynamic melting in the second heat cycle. (Rate: $20^{\circ} \mathrm{C} / \mathrm{min}$ )
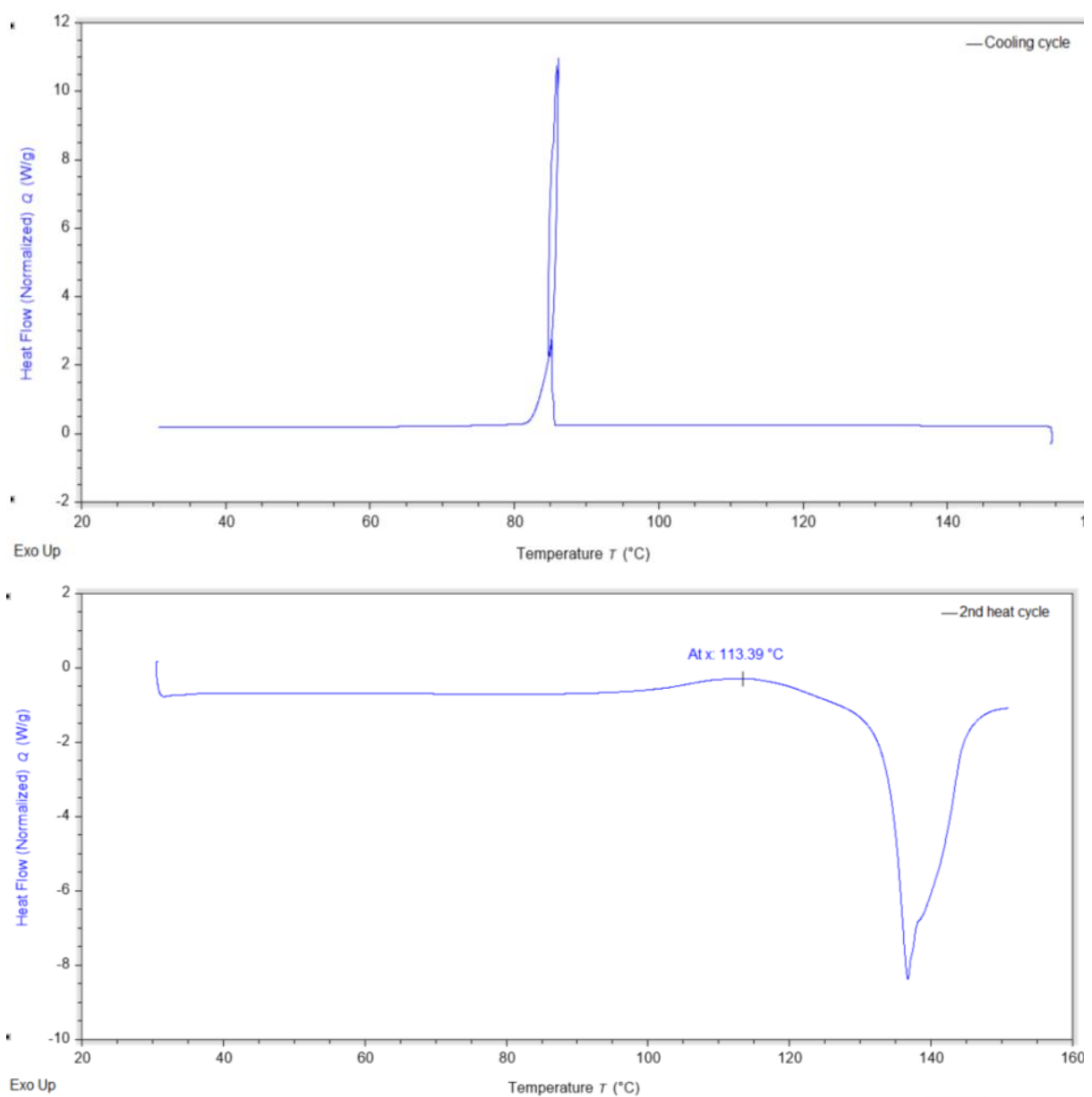

Figure S22. The DSC thermograms of PRT-II at different heating/cooling rates. Because the exothermic peak in the second heating is independent of the heating rate, this can be assigned to a thermodynamic event, probably a phase transformation. 
Table S4. Melting point results of cocrystals

\begin{tabular}{|c|c|c|c|c|}
\hline SL NO & DRUG/COFORMERS & TEMP $\left({ }^{\circ} \mathbf{C}\right)$ & COCRYSTALS & TEMP $\left({ }^{\circ} \mathbf{C}\right)$ \\
\hline 1 & PRT & $137.7,142.5$ & & \\
\hline 2 & OXA & 189 & PRT-OXA & 89.1 \\
\hline 3 & FUM & 287 & PRT-FUM & 135.1 \\
\hline 4 & GLT & 95 & PRT-GLT & 107.8 \\
\hline 5 & SAL & $>300$ & PRT-SAL & 108.8 \\
\hline 6 & DHT & 343 & PRT-26DHB & 148.5 \\
\hline 7 & 26DHB & & & \\
\hline
\end{tabular}

\section{EUTECTIC SYSTEMS}

PXRD results for eutectic systems

- PRT-NTA

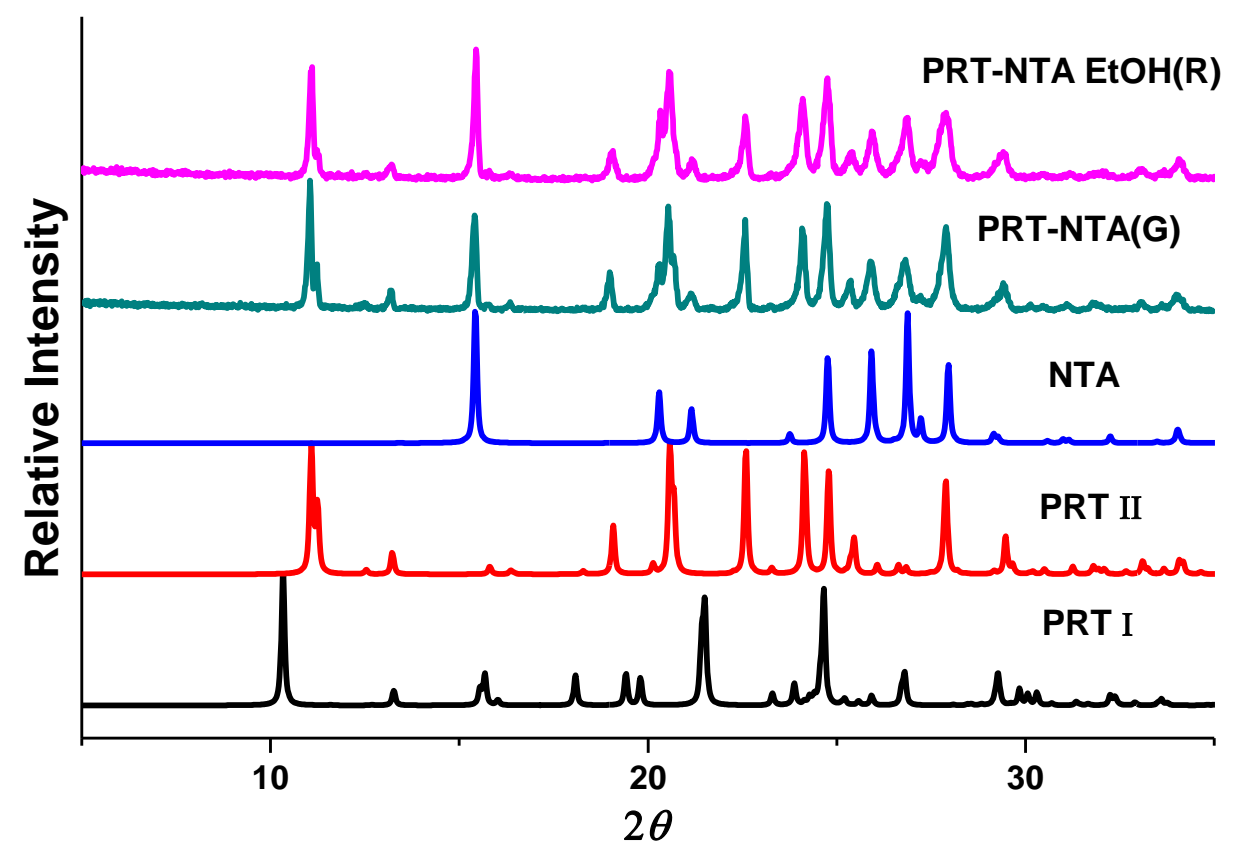

Figure S23. PXRD pattern of PRT-NTA eutectic along with PRT and NTA. 
- PRT-PCA

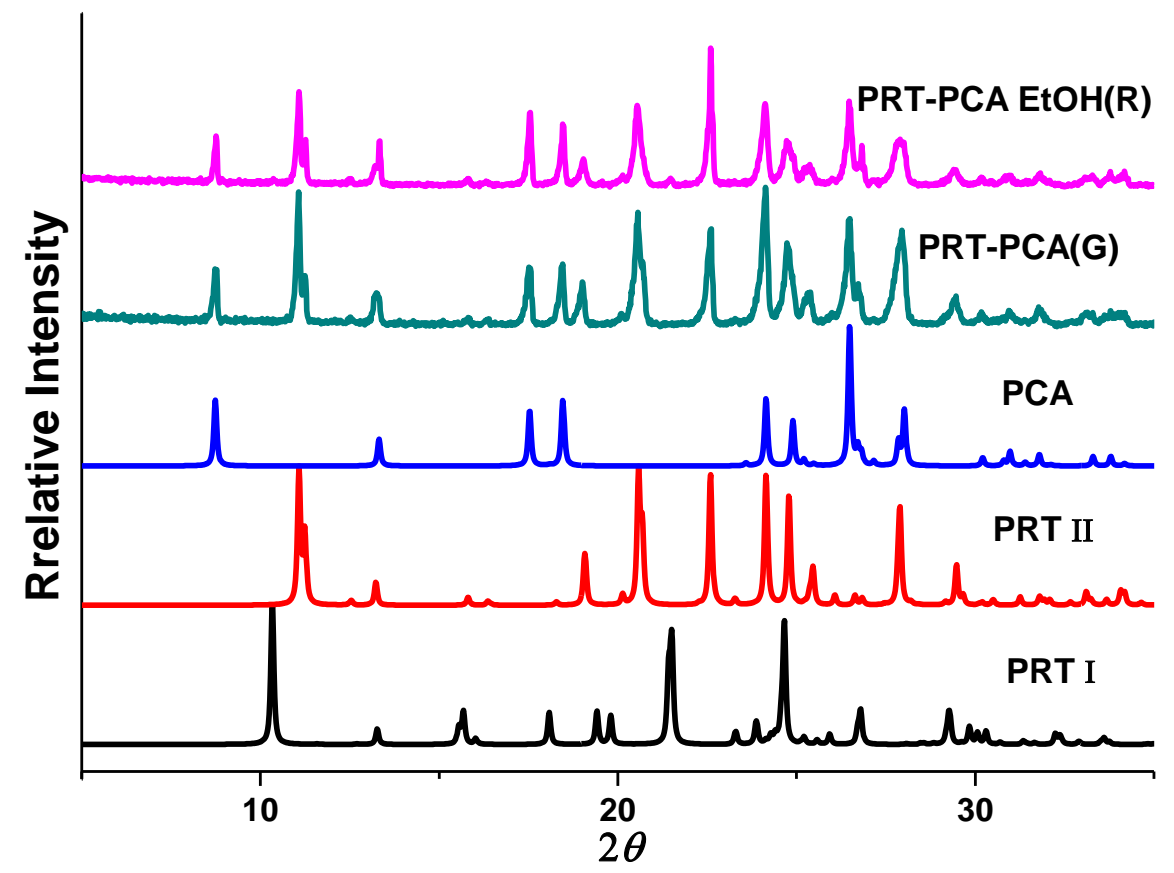

Figure S24. PXRD pattern of PRT-PCA eutectic along with PRT and PCA.

- PRT-CFA

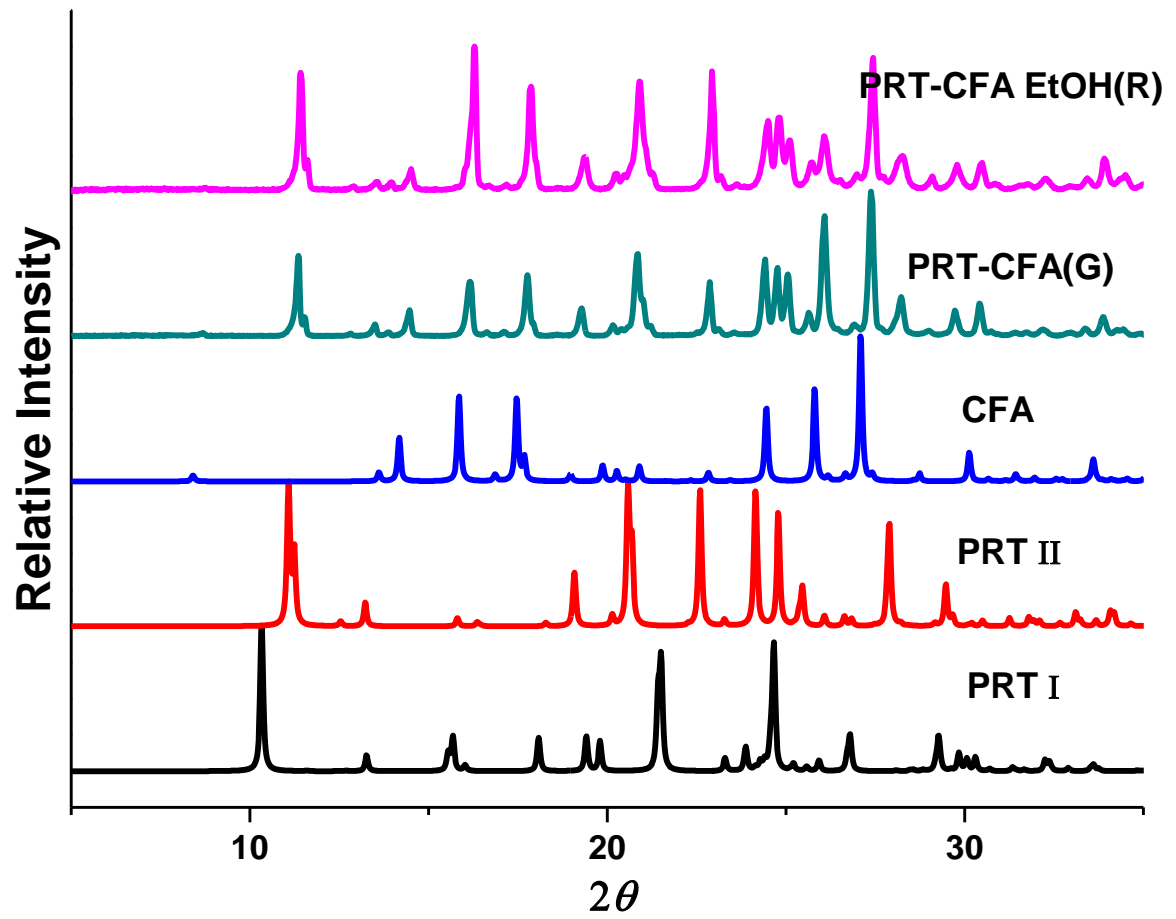

Figure S25. PXRD pattern of PRT-CFA eutectic along with PRT and CFA. 
- PRT-PHL

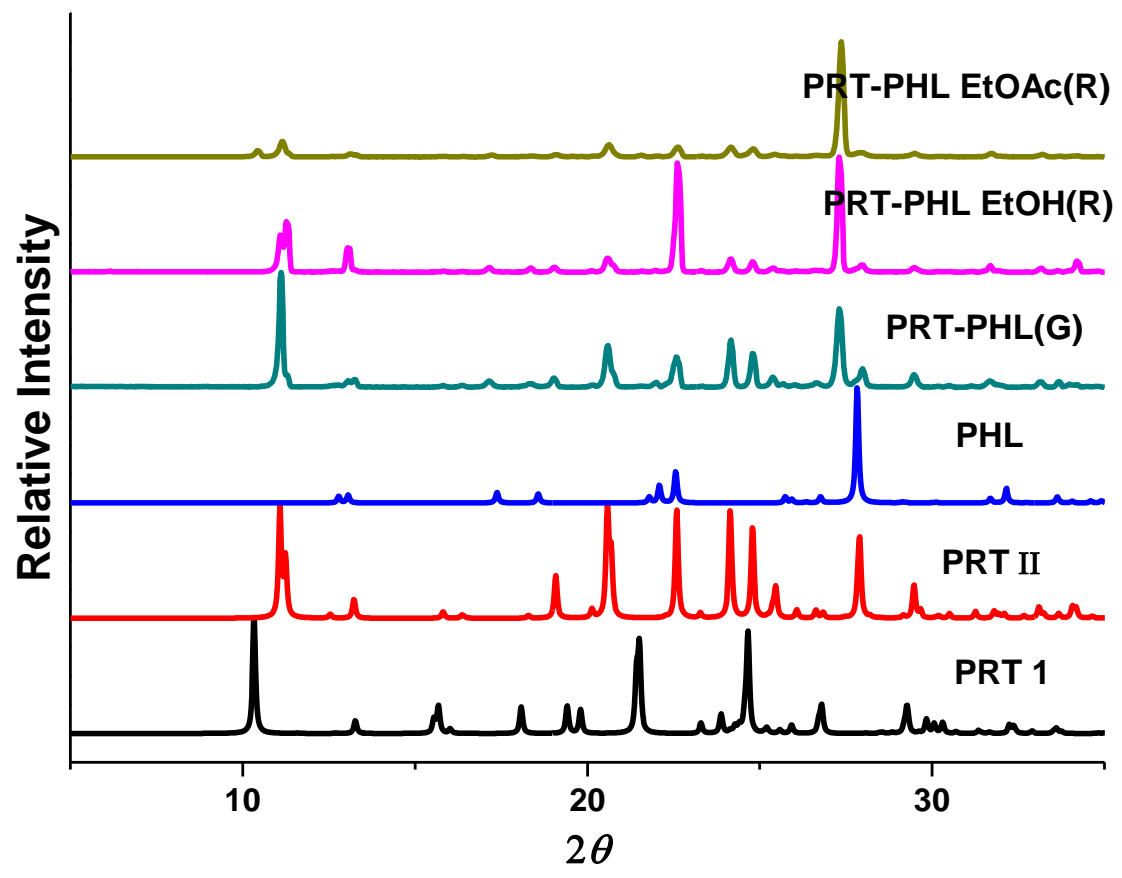

Figure S26. PXRD pattern of PRT-PHL eutectic along with PRT and PHL.

- PRT-HQN

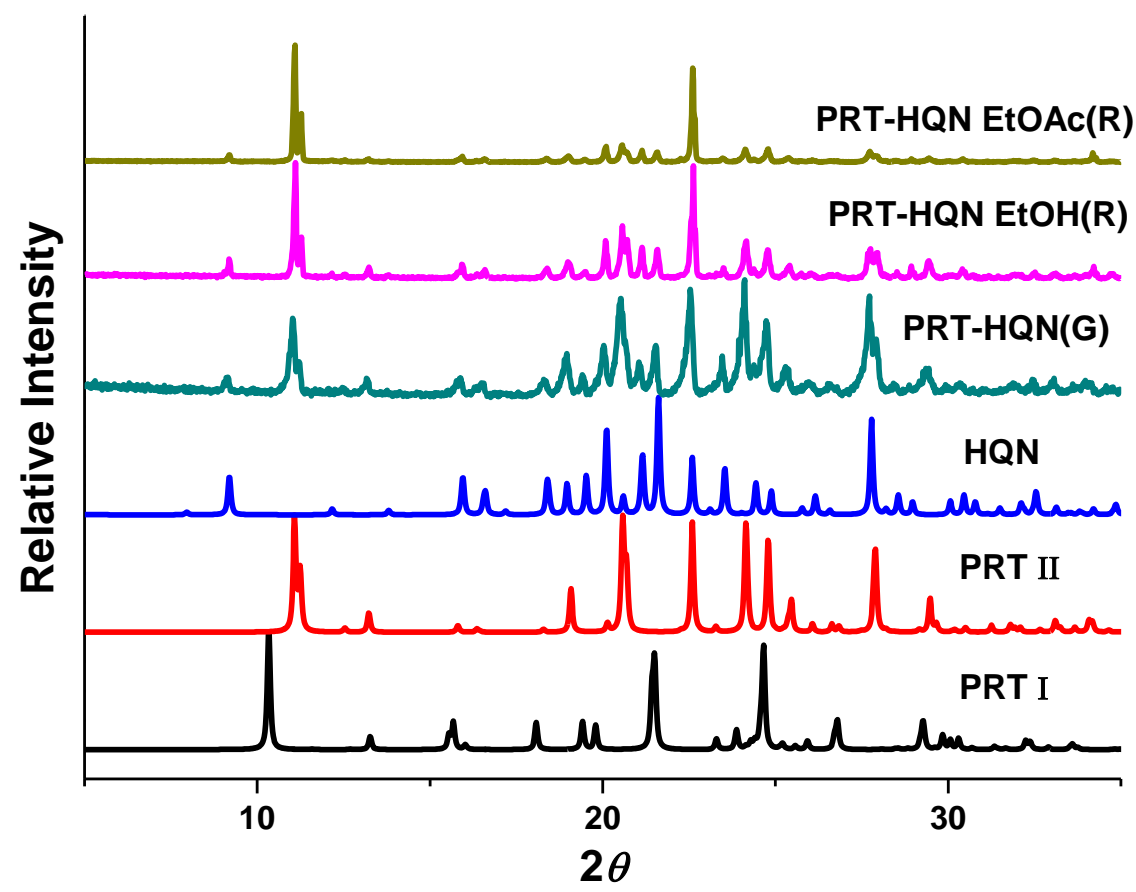

Figure S27. PXRD pattern of PRT-HQN eutectic along with PRT and HQN. 
- PRT-THU

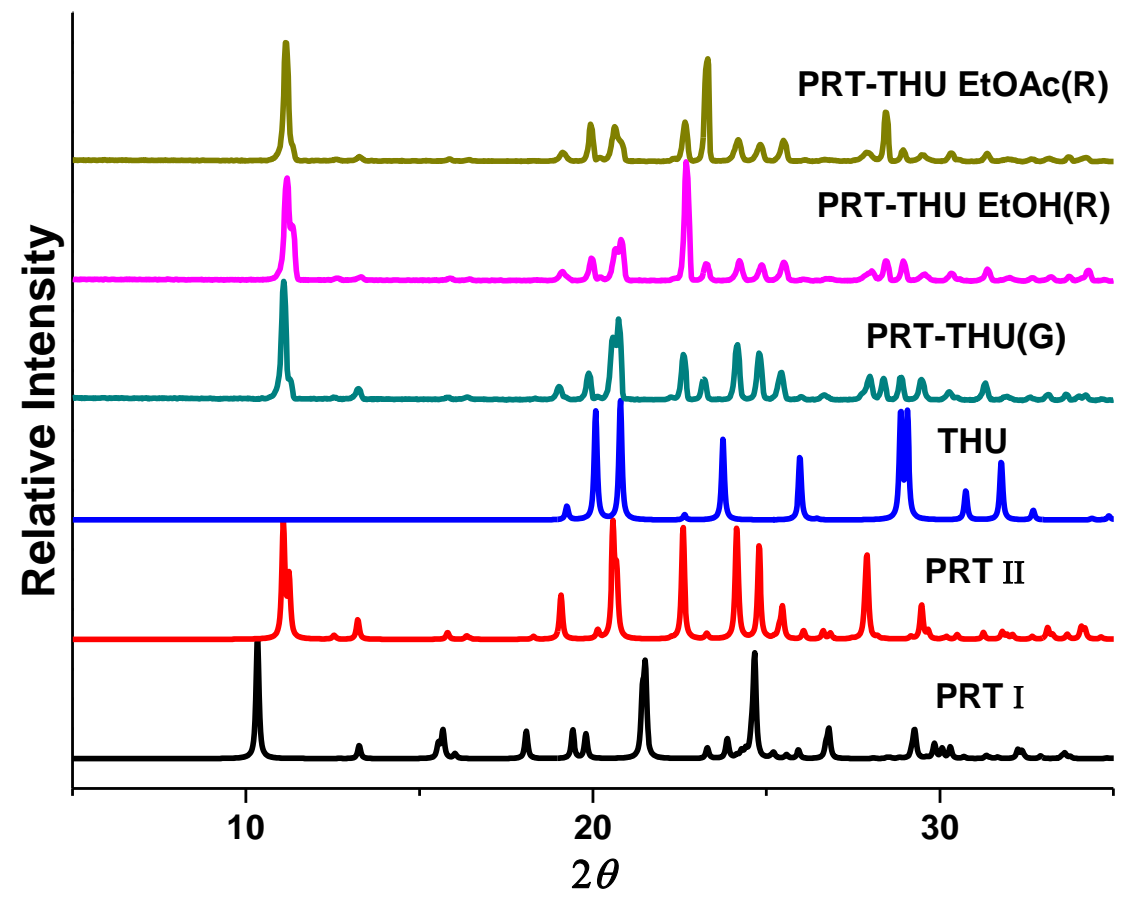

Figure S28. PXRD pattern of PRT-THU eutectic along with PRT and THU.

- PRT-ADA

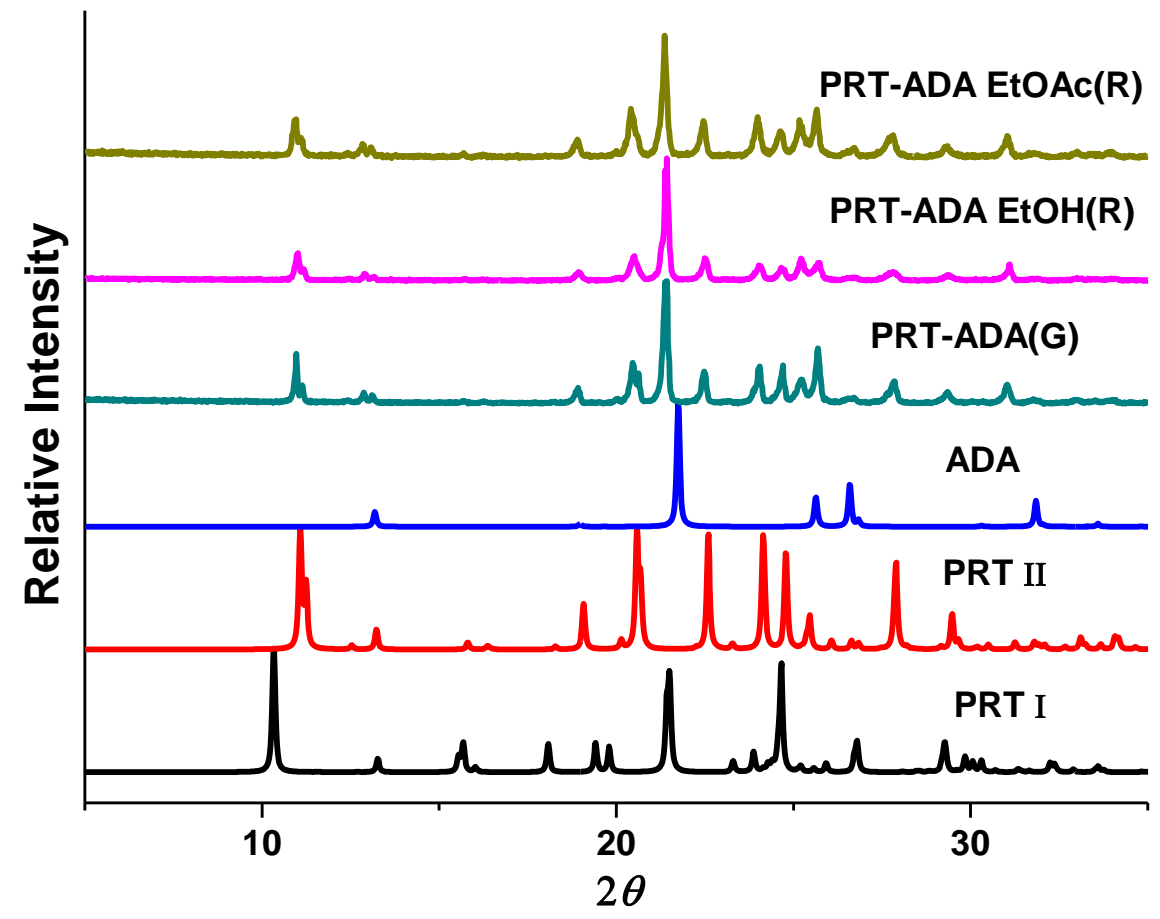

Figure S29. PXRD pattern of PRT-ADA eutectic along with PRT and ADA. 


\section{- PRT-SUC}

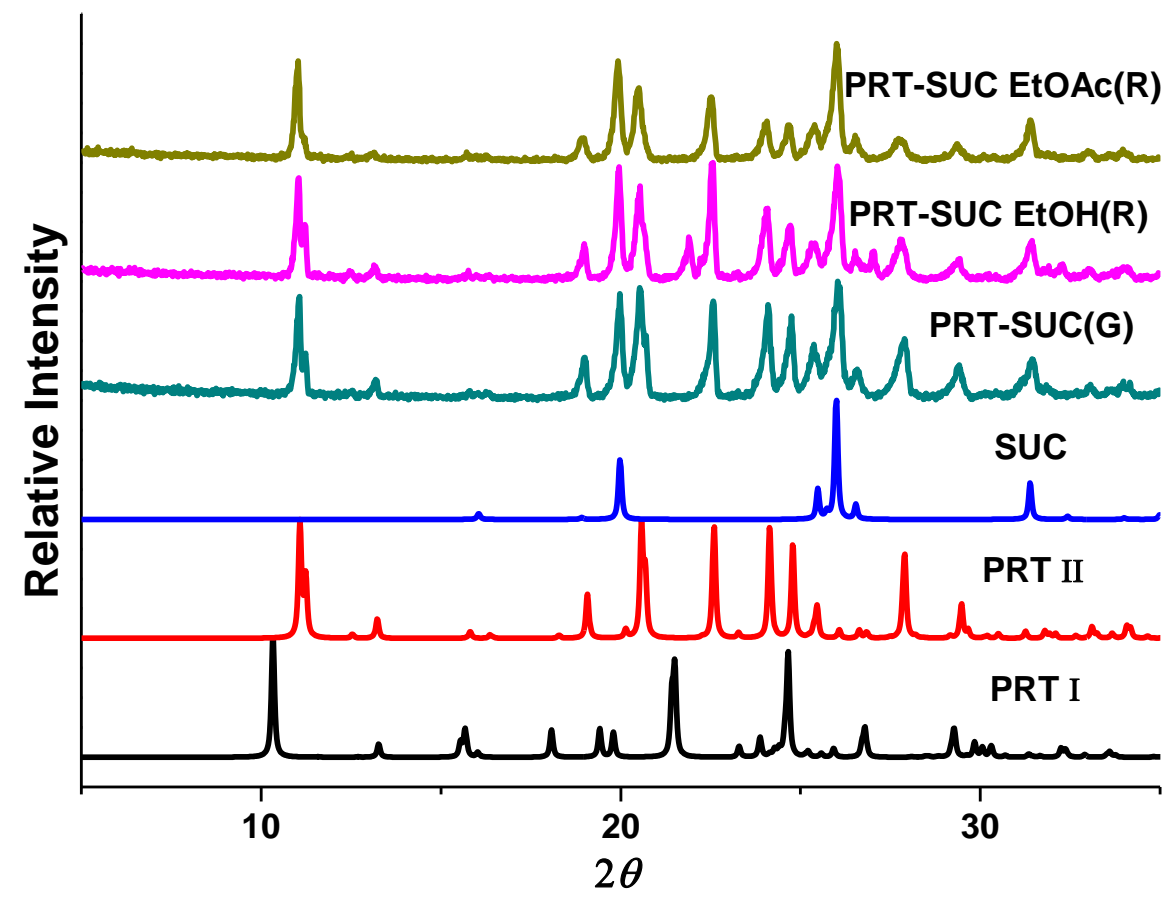

Figure S30. PXRD pattern of PRT-SUC eutectic along with PRT and SUC.

- PRT-INZ

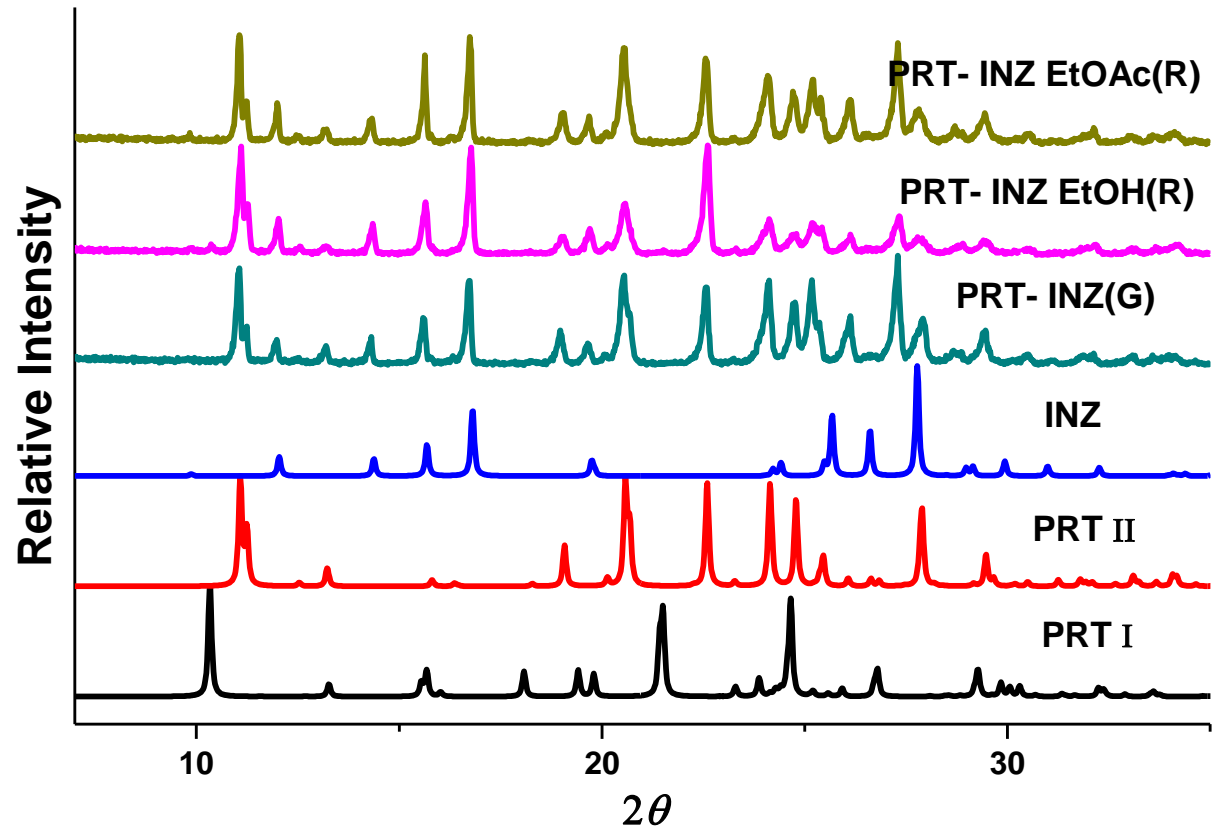

Figure S31. PXRD pattern of PRT-INZ eutectic along with PRT and INZ. 
- PRT-DTX

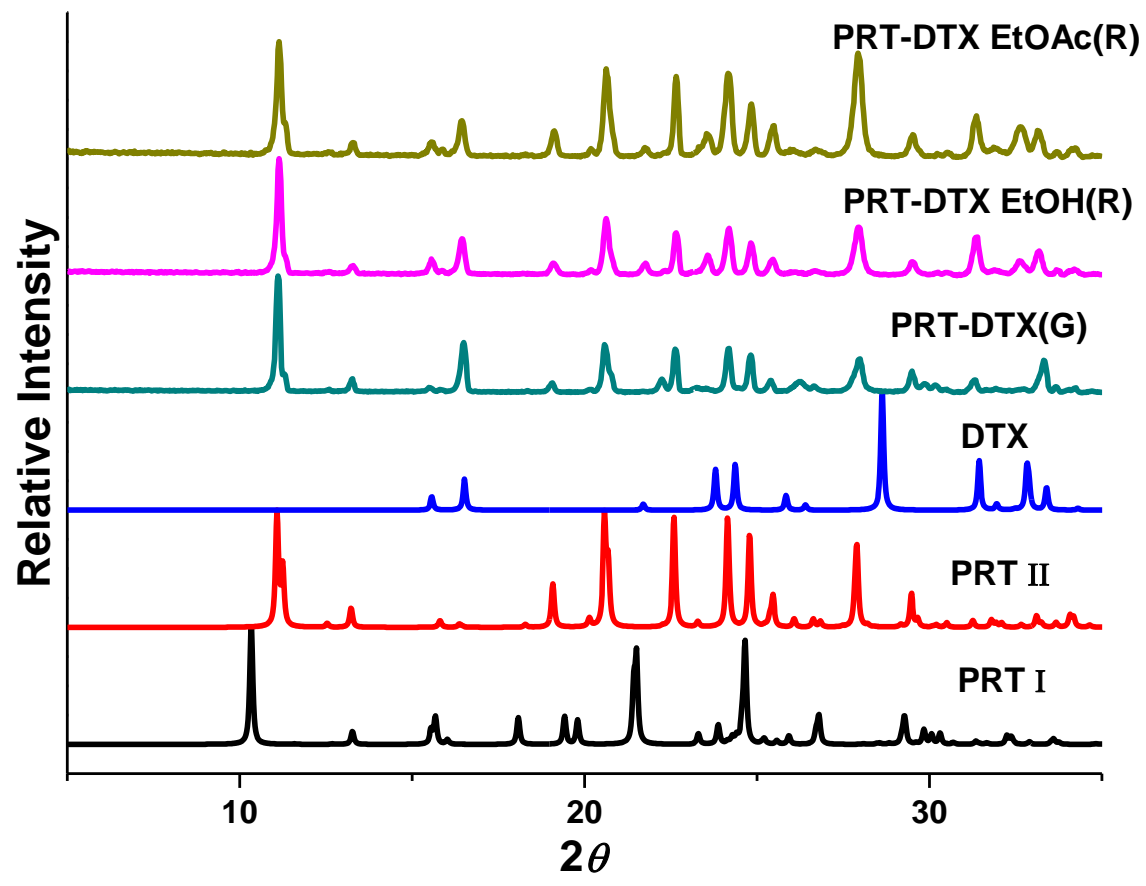

Figure S32. PXRD pattern of PRT-DTX eutectic along with PRT and DTX.

- PRT-ASA

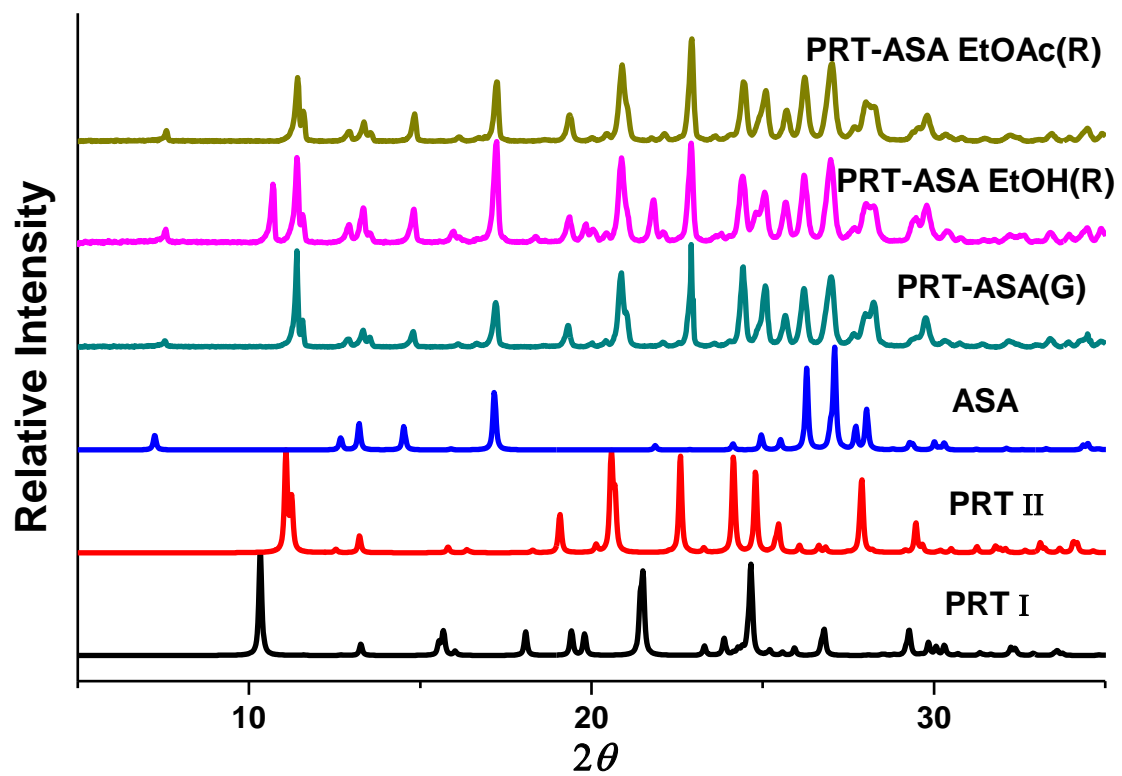

Figure S33. PXRD pattern of PRT-ASA eutectic along with PRT and ASA. 
- PRT-ABA

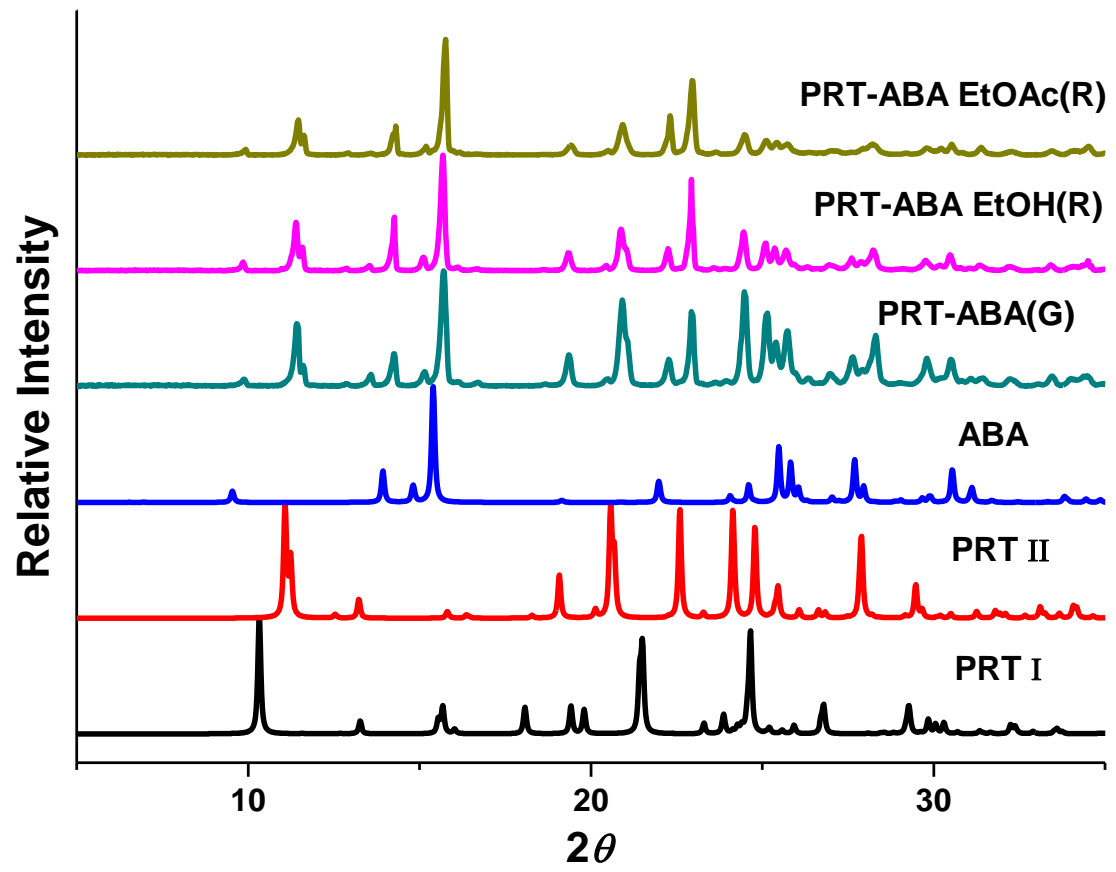

Figure S34. PXRD pattern of PRT-ABA eutectic along with PRT and ABA.

- PRT-34DHB

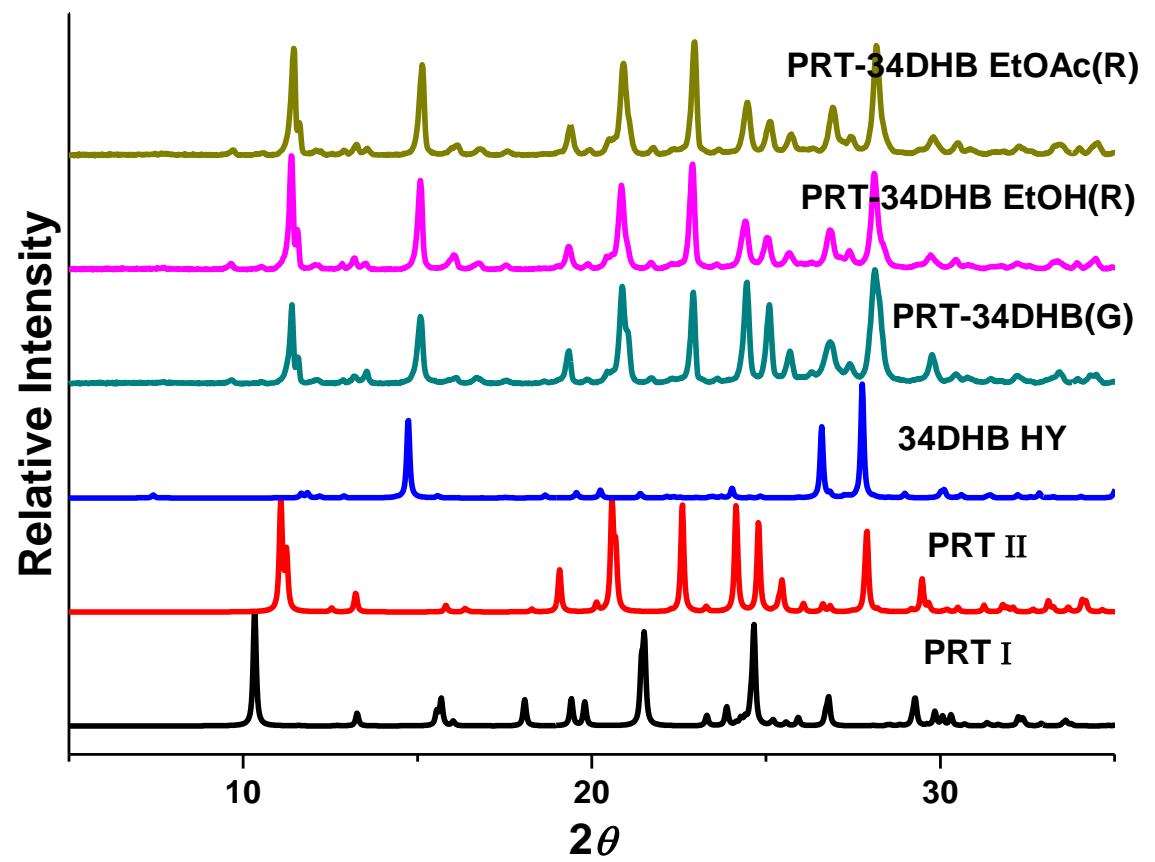

Figure S35. PXRD pattern of PRT-34DHB eutectic along with PRT and 34DHB. 
- PRT-URE

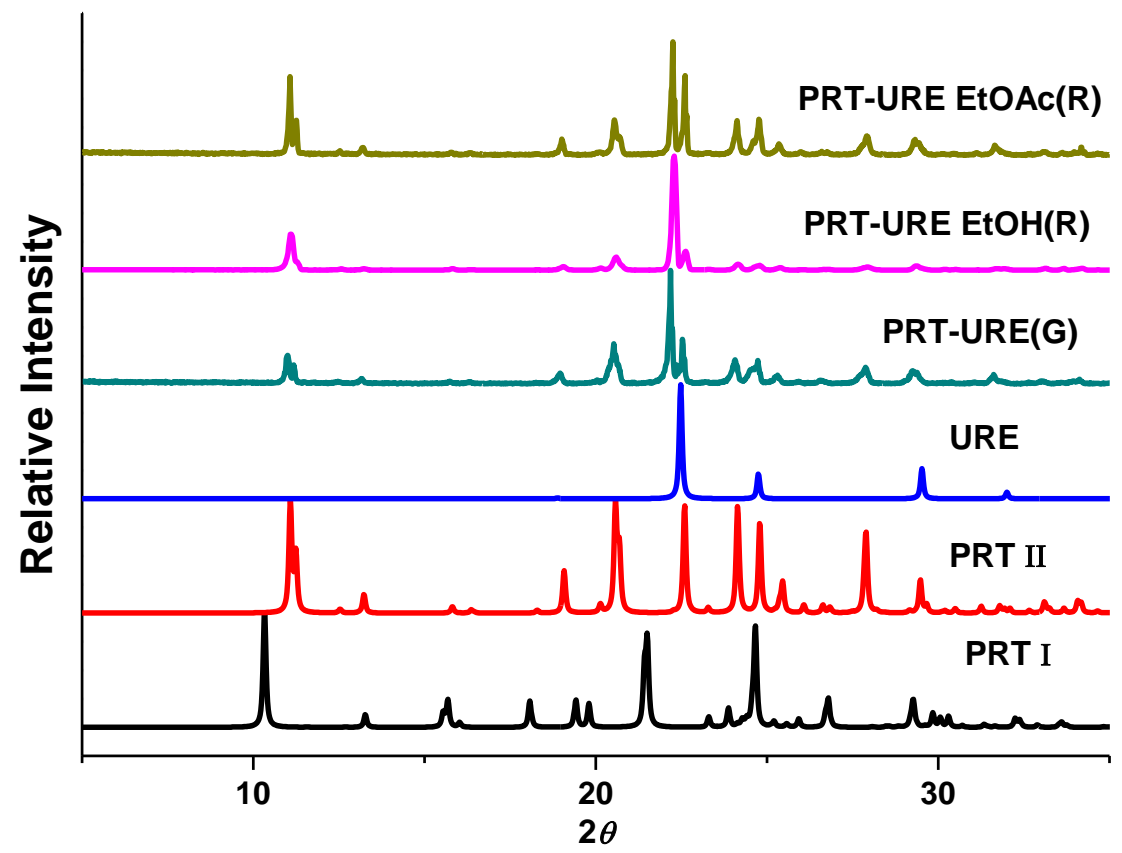

Figure S36. PXRD pattern of PRT-URE eutectic along with PRT and URE. BINARY PHASE DIAGRAM SHOWING EUTECTIC COMPOSITION

- PRT-NTA

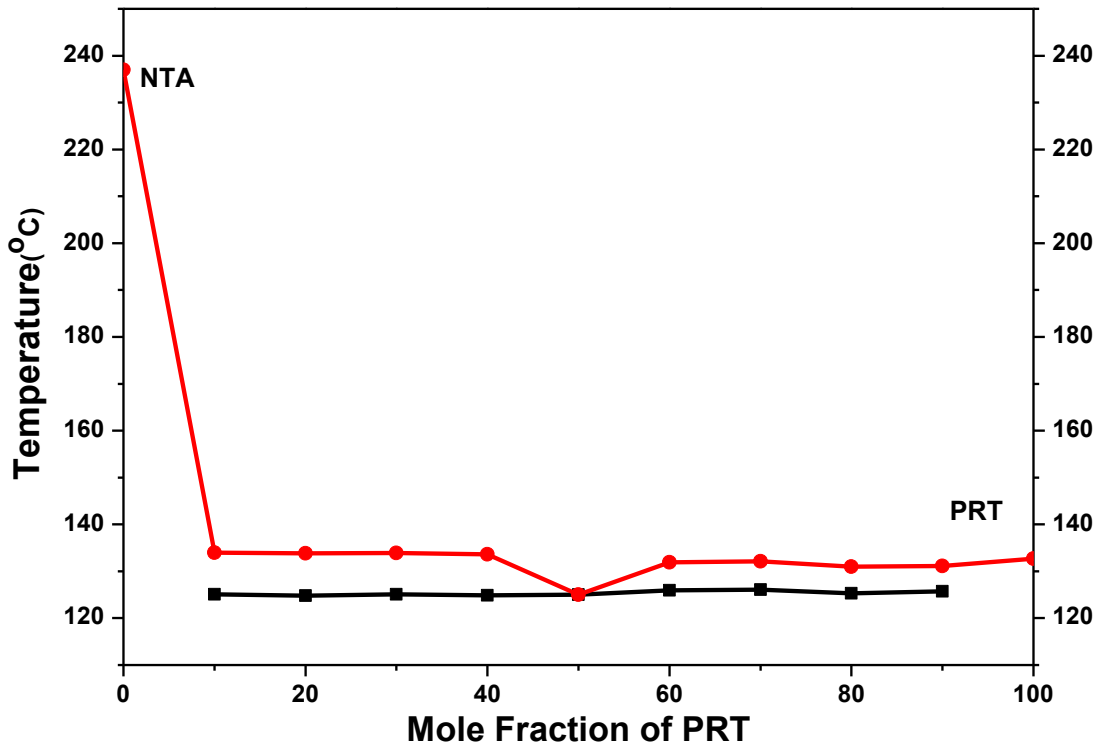

Figure S37. PRT with NTA forms a eutectic system with composition 1:1. 
- PRT-PCA

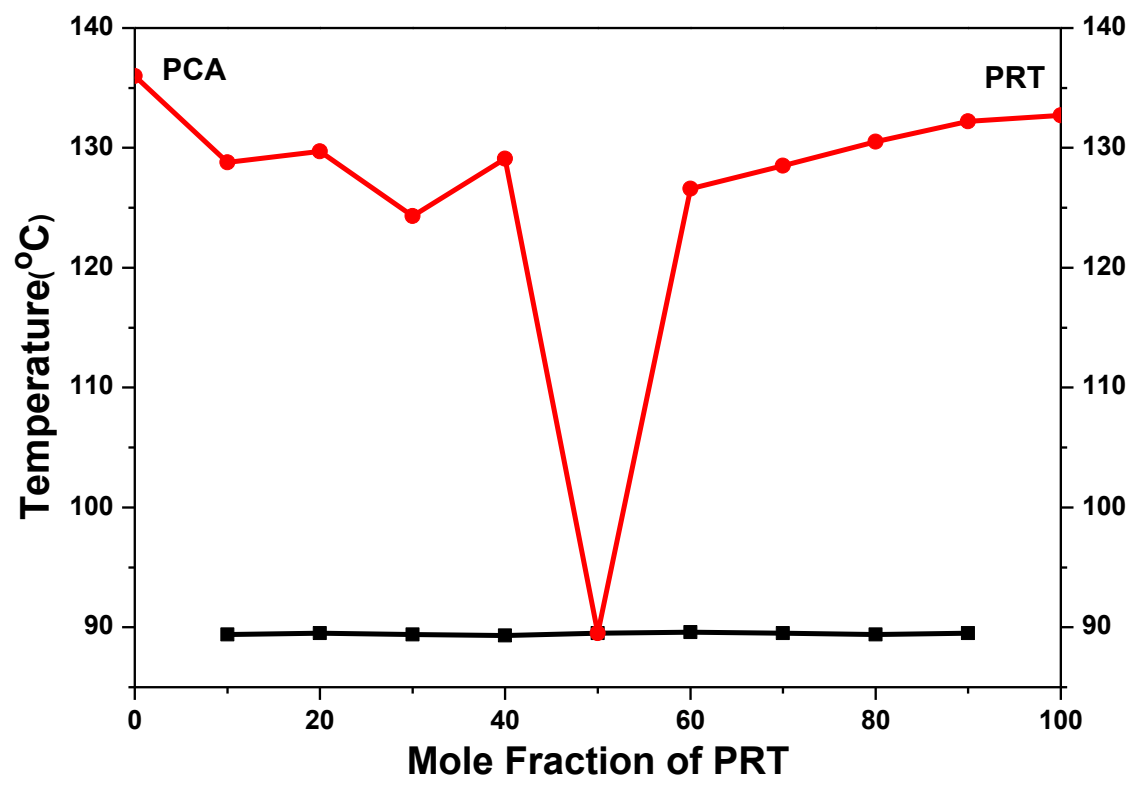

Figure S38. PRT with PCA forms a eutectic system with composition 1:1.

- PRT- HQN

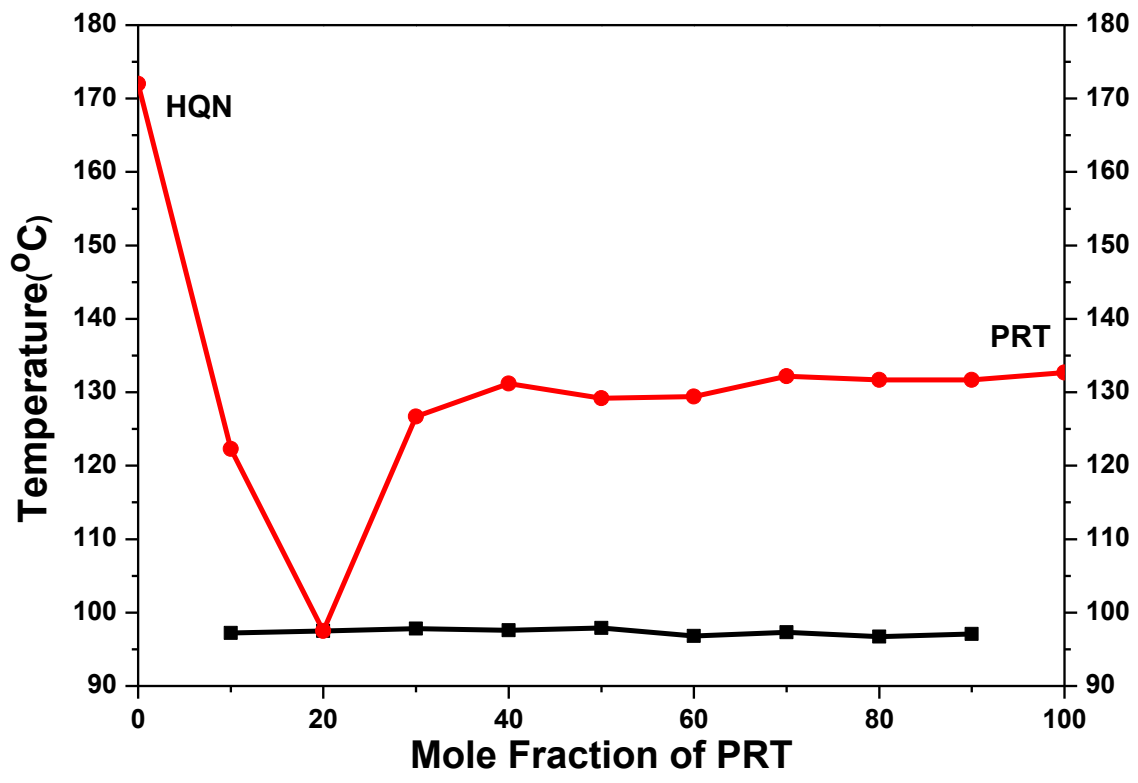

Figure S39. PRT with HQN forms a eutectic system with composition 1:4. 
- PRT-ADA

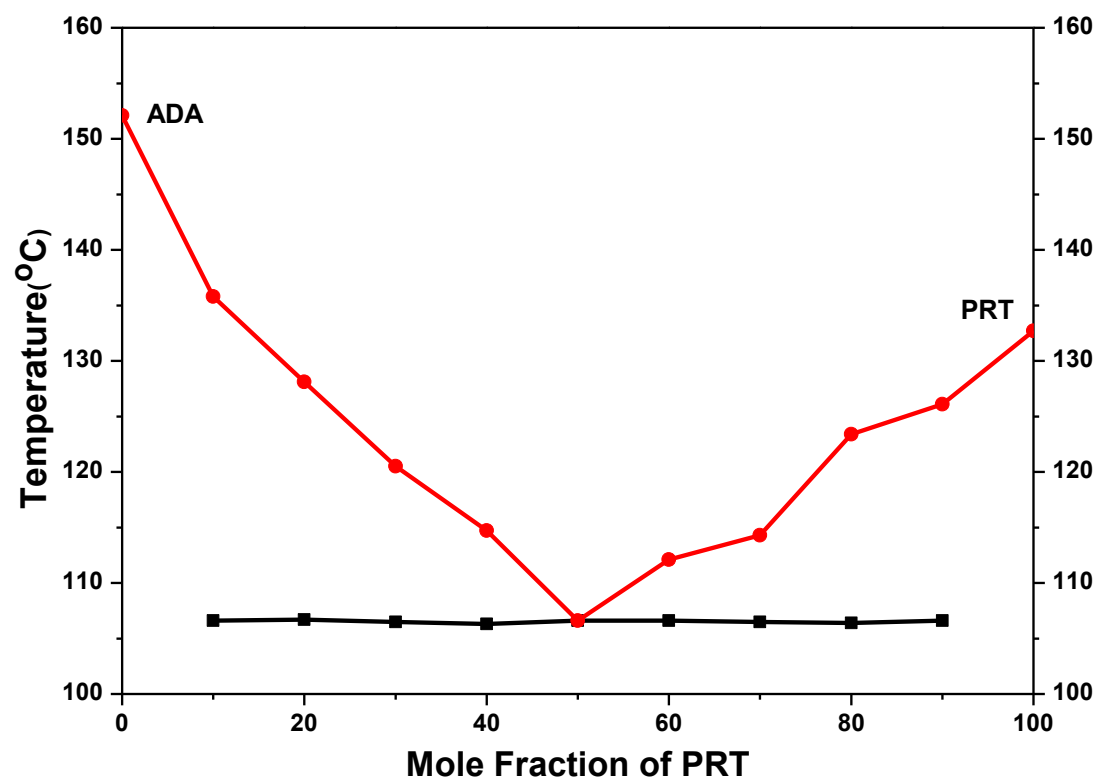

Figure S40. PRT with ADA forms a eutectic system with composition 1:1.

\section{- PRT-SUC}

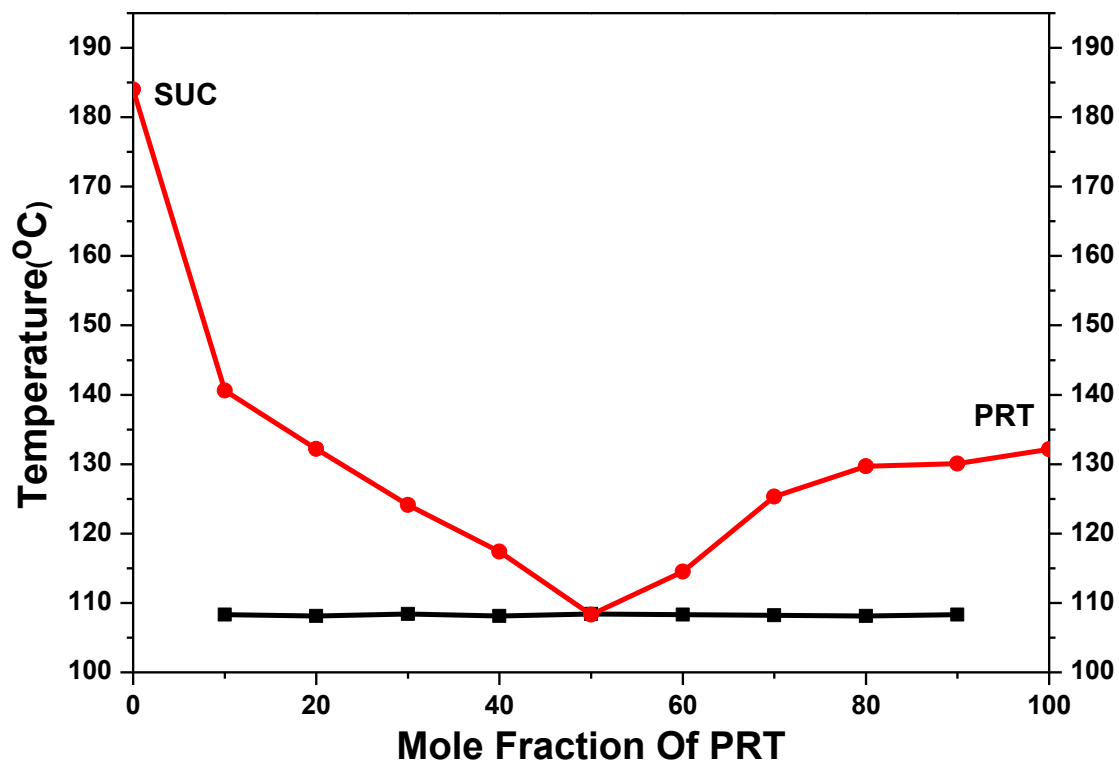

Figure S41. PRT with NTA forms a eutectic system with composition 1:1. 


\section{- PRT-THU}

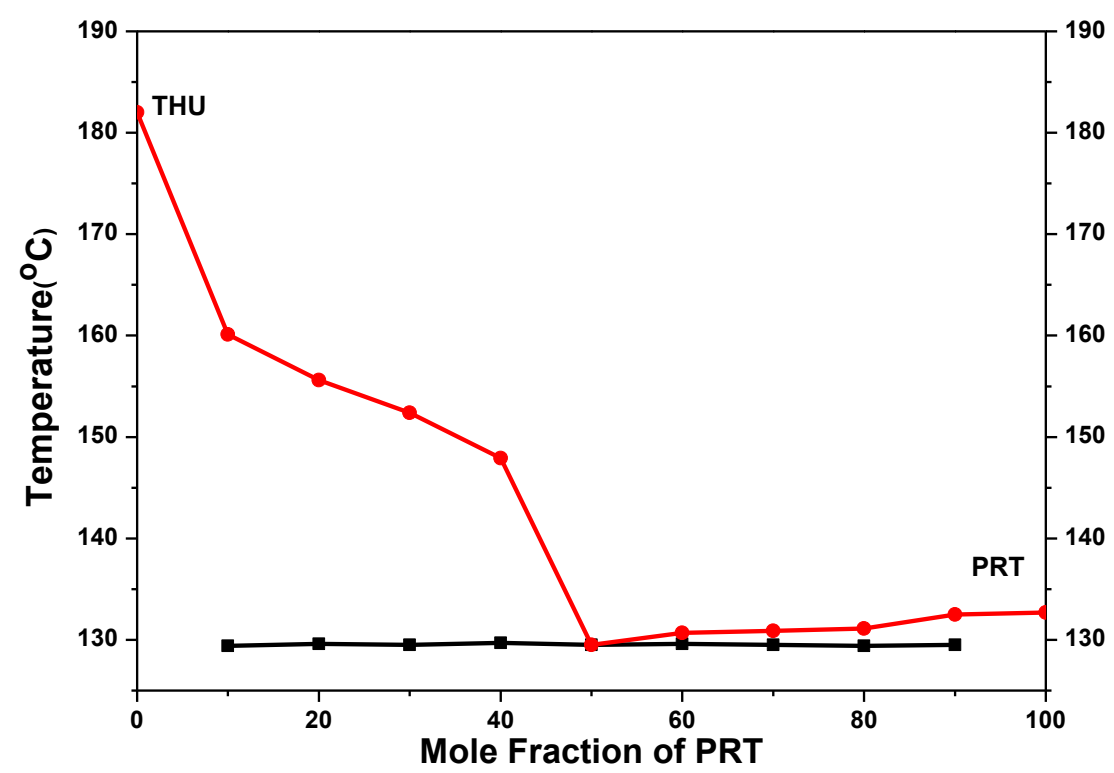

Figure S42. PRT with THU forms a eutectic system with composition 1:1.

We established the composition as 1:1 for PRT-THU, but could not estimate the composition of the PRT-DTX and PRT-URE. The melting temperature of the PRT-URE mixture showed a significant drop in the melting temperature (123.28) than its THU counterpart (129.25).

- $\quad$ PRT-INZ

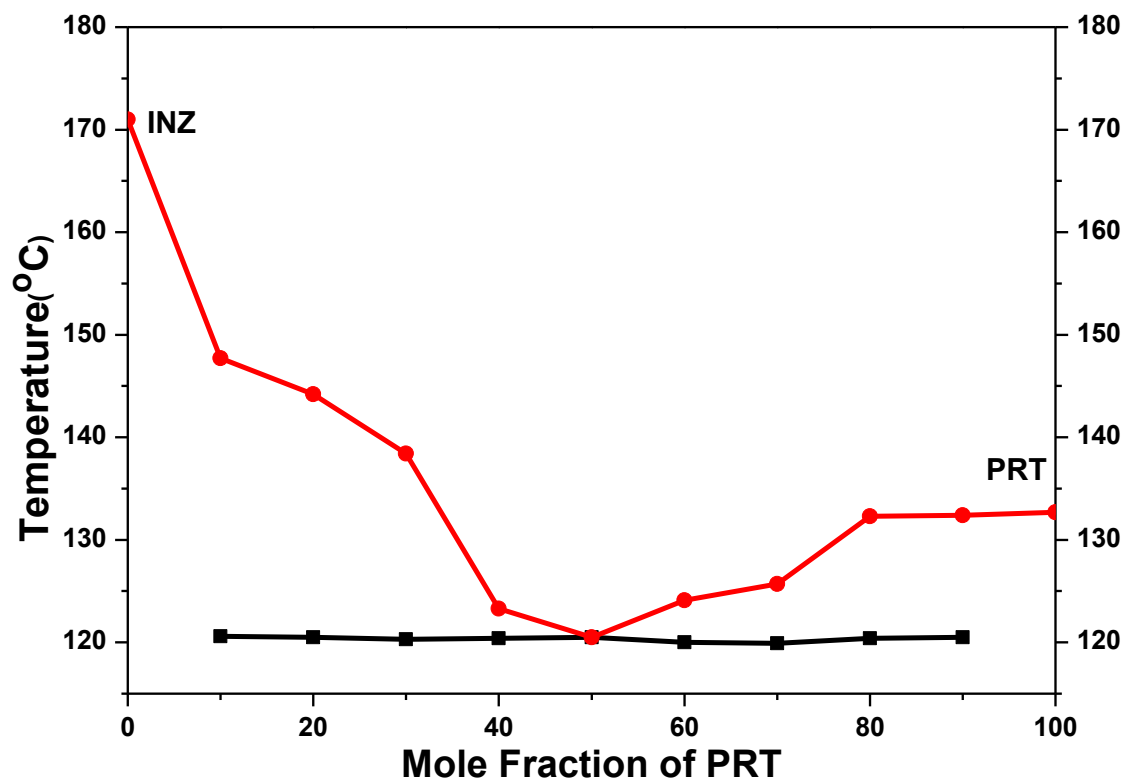

Figure S43. PRT with INZ forms a eutectic system with composition 1:1. 


\section{MELTING POINT RESULTS FOR EUTECTIC SYSTEMS}

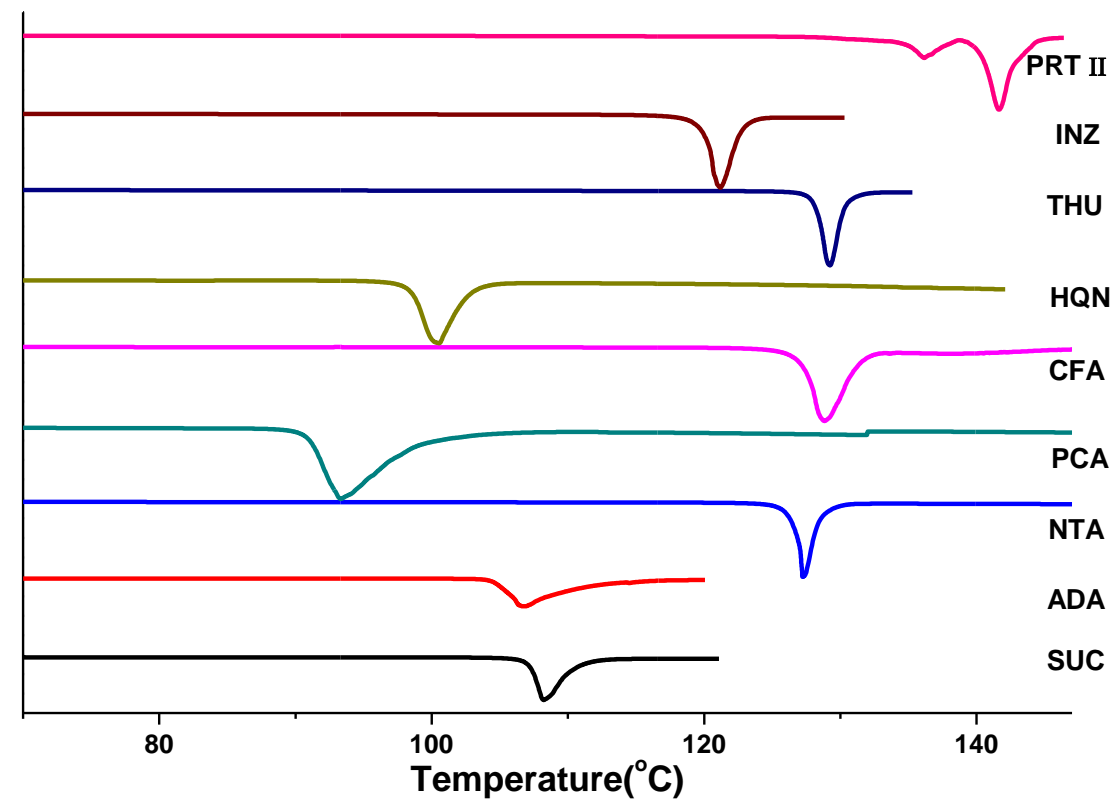

Figure S44. The DSC thermogram for the eutectics formed by PRT with different coformers. All the systems show a melting point lower than their parent compounds, confirming them to be eutectic systems.

Table S5. Melting temperatures of the eutectic mixtures

\begin{tabular}{ccccc}
\hline SL NO & DRUG/COFORMERS & TEMP $\left({ }^{\circ} \mathbf{C}\right)$ & EUTECTICS & TEMP $\left({ }^{\circ} \mathbf{C}\right)$ \\
\hline & PRT & $137.7,142.5$ & & \\
\hline 1 & & & & \\
2 & SUC & 184 & PRT-SUC & 108.2 \\
\hline & ADA & 152 & PRT-ADA & 106.6 \\
\hline 3 & & & & 127.2 \\
4 & NTA & 237 & PRT-NTA & 128.8 \\
5 & CFA & 223 & PRT-CFA & 120.0 \\
6 & INZ & 171 & PRT-INZ & 93.2 \\
\hline \multicolumn{7}{r}{} & PCA & 136 & PRT-PCA & \\
\hline 7 & HQN & 172 & PRT-HQN & 97.5 \\
\hline 8 & THU & 182 & PRT-THU & 129.2 \\
\hline
\end{tabular}




\section{IR RESULTS OF EUTECTIC SYSTEMS}

\section{- PRI-NTA}

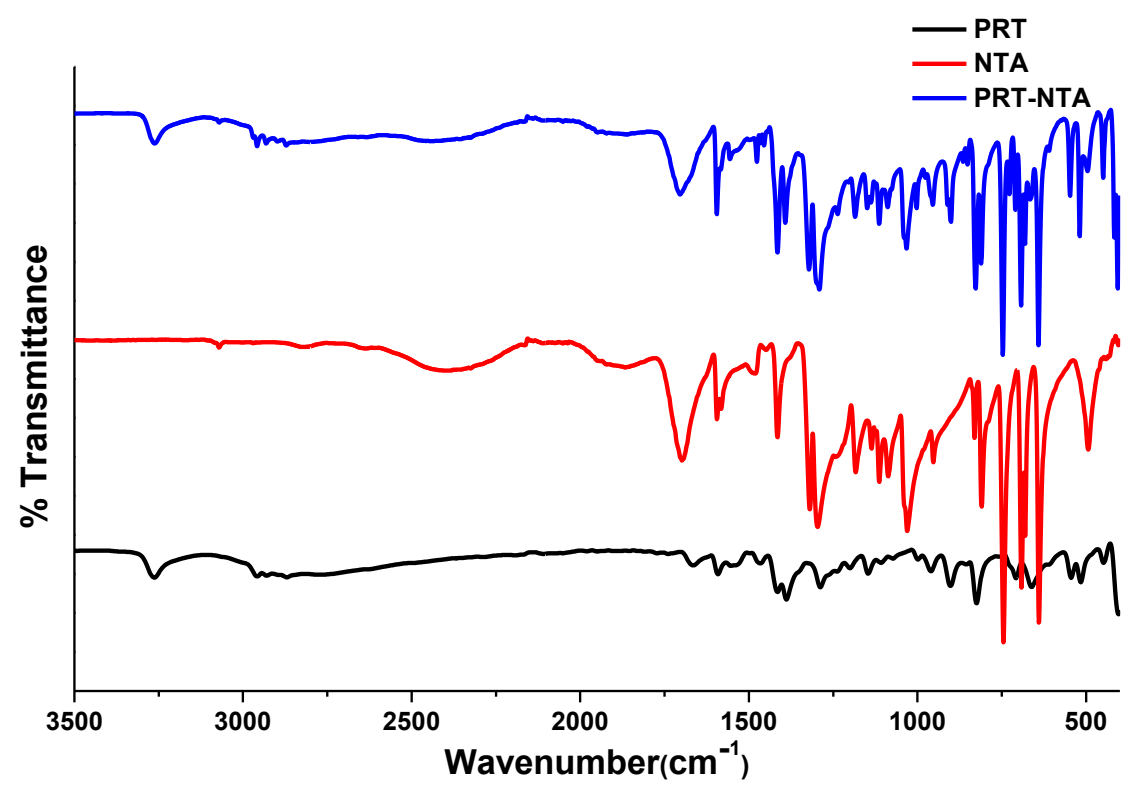

Figure S45. IR spectrum of PRT-NTA eutectic and the parent compounds. No shift in the frequency of the vibrations, indicating no complex formation.

- PRT-PCA

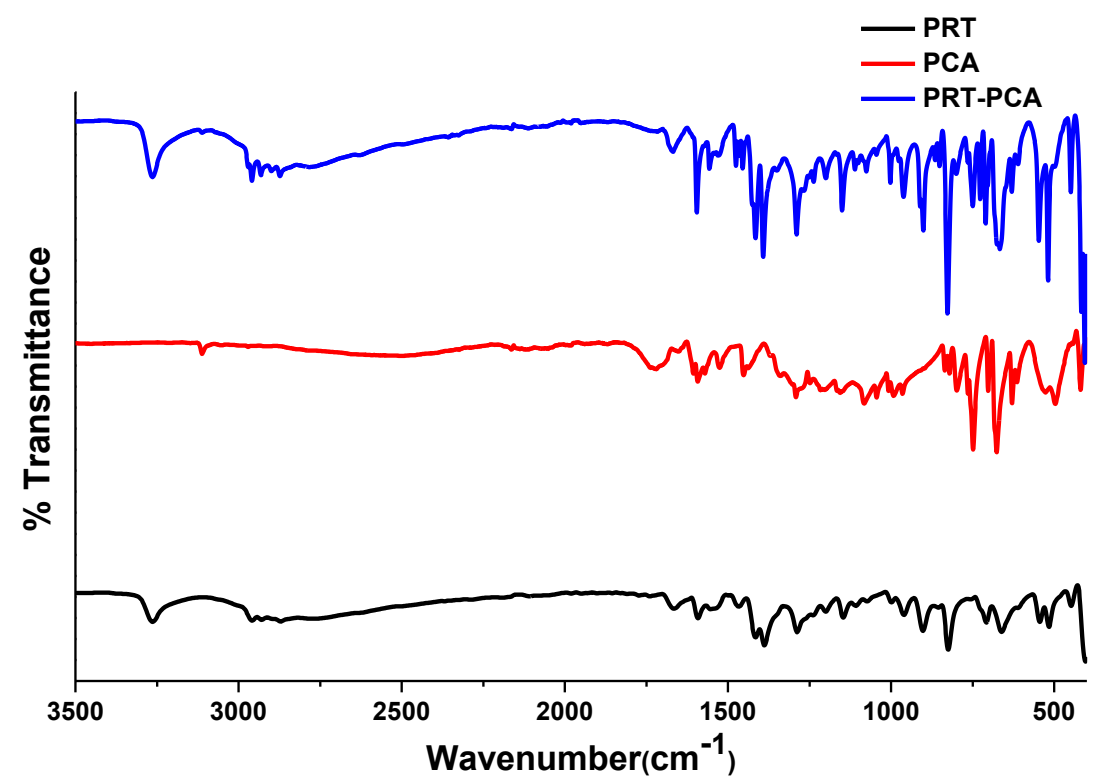

Figure S46. IR spectrum of PRT-PCA eutectic and the parent compounds. 
- PRT-CFA

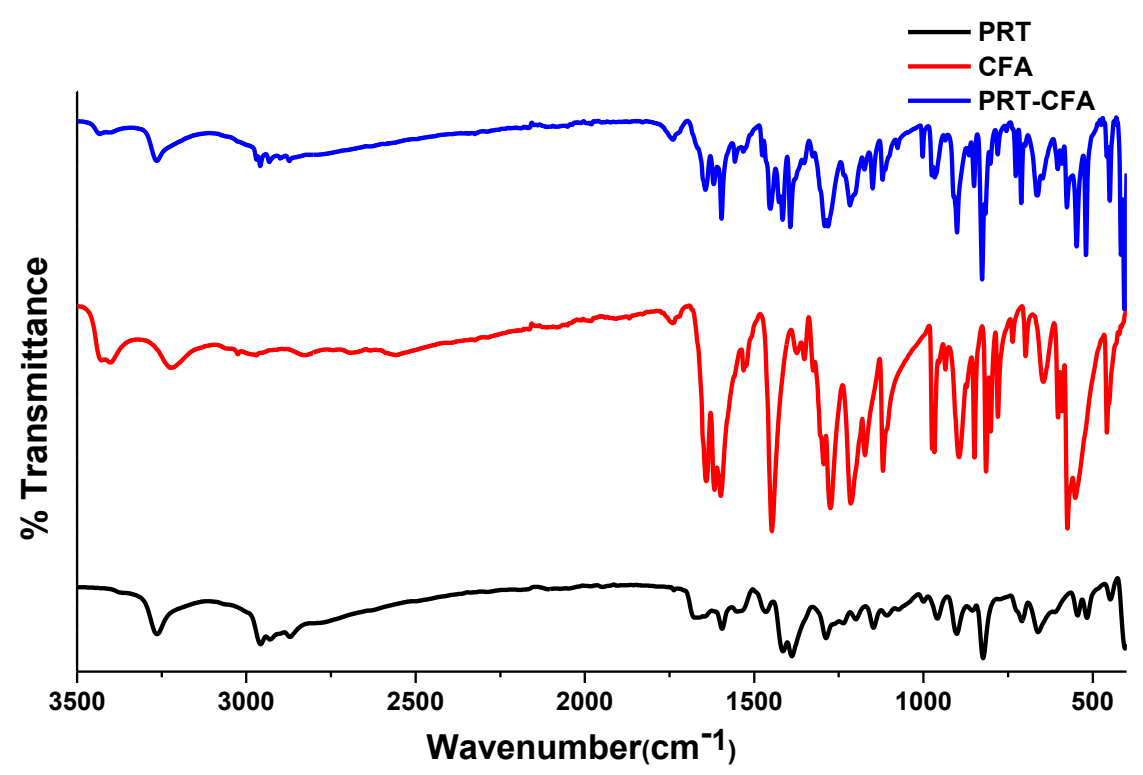

Figure S47. IR spectrum of PRT-CFA eutectic and the parent compounds.

- PRT-HQN

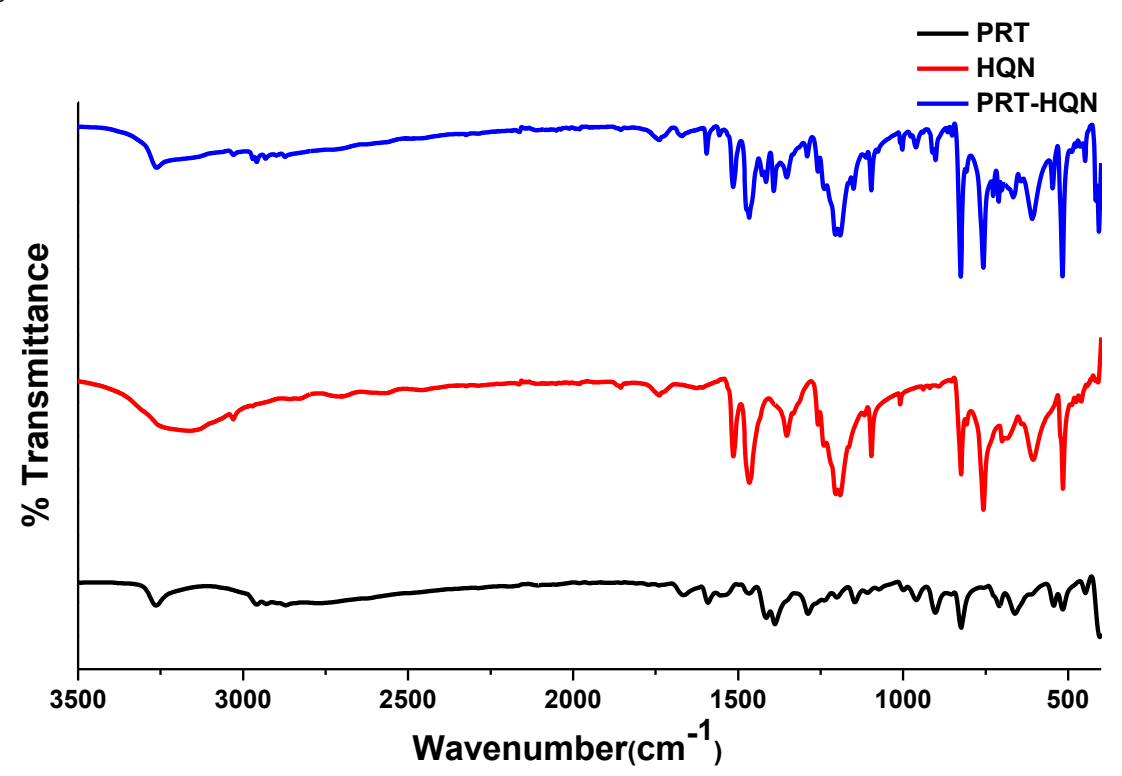

Figure S48. IR spectrum of PRT-HQN eutectic and the parent compounds. 
- PRT-THU

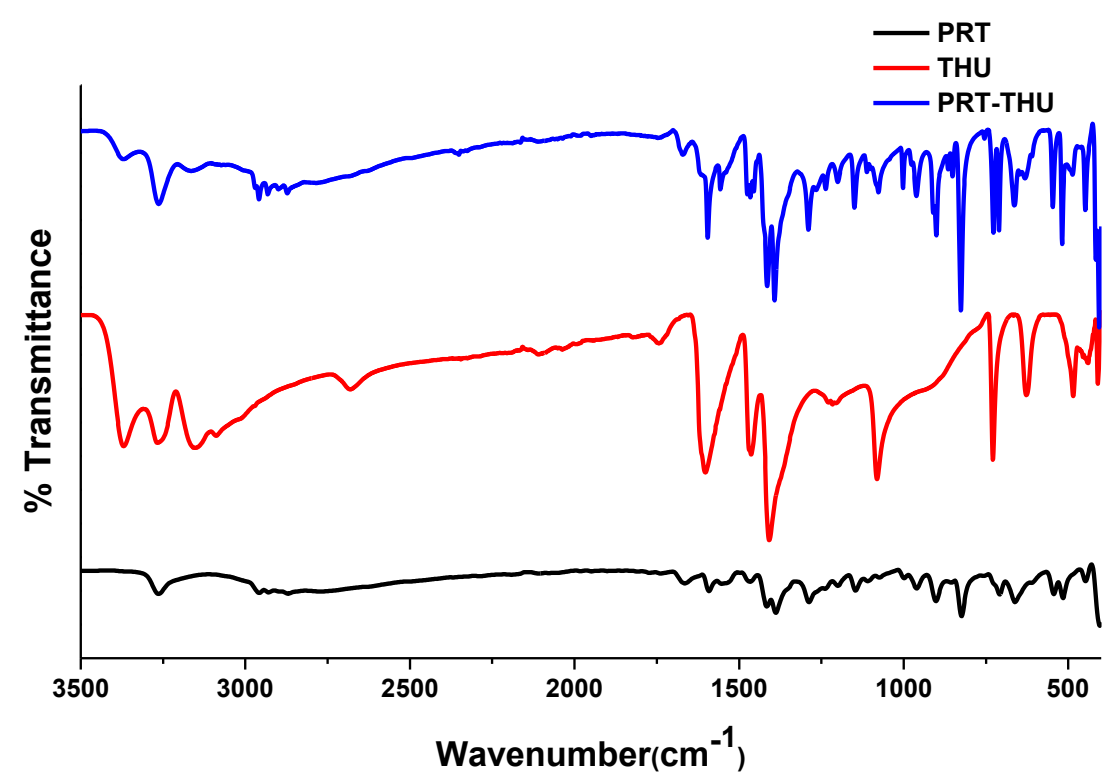

Figure S49. IR spectrum of PRT-THU eutectic and the parent compounds.

- PRT-INZ

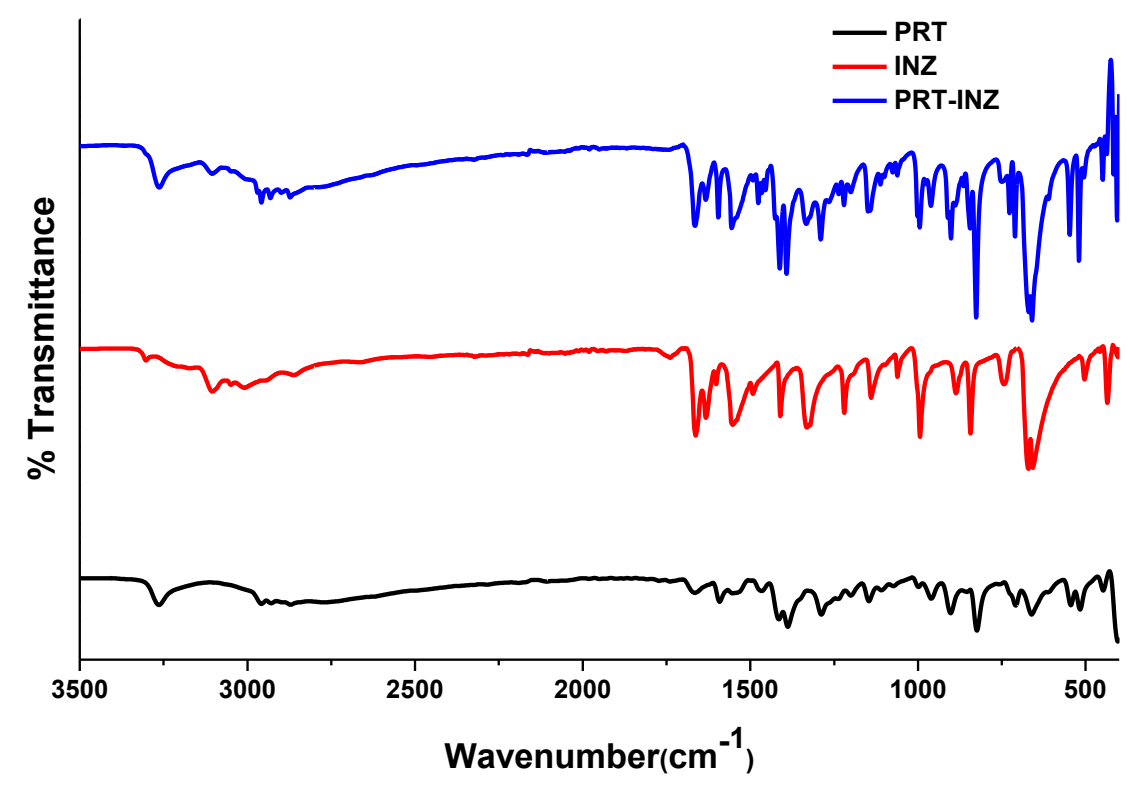

Figure S50. IR spectrum of PRT-INZ eutectic and the parent compounds. 


\section{SOLUBILITY AND DISSOLUTION STUDIES}

Calculation of epsilon value

BEER-LAMBERT LAW

$$
\mathrm{A}=\varepsilon \mathrm{CL}
$$

A=Absorbance $\varepsilon=$ Molar attenuation coefficient $\mathrm{C}=$ Concentration $\mathrm{L}=$ Optical Path length $\varepsilon$ for Prothionamide $=1800.00$

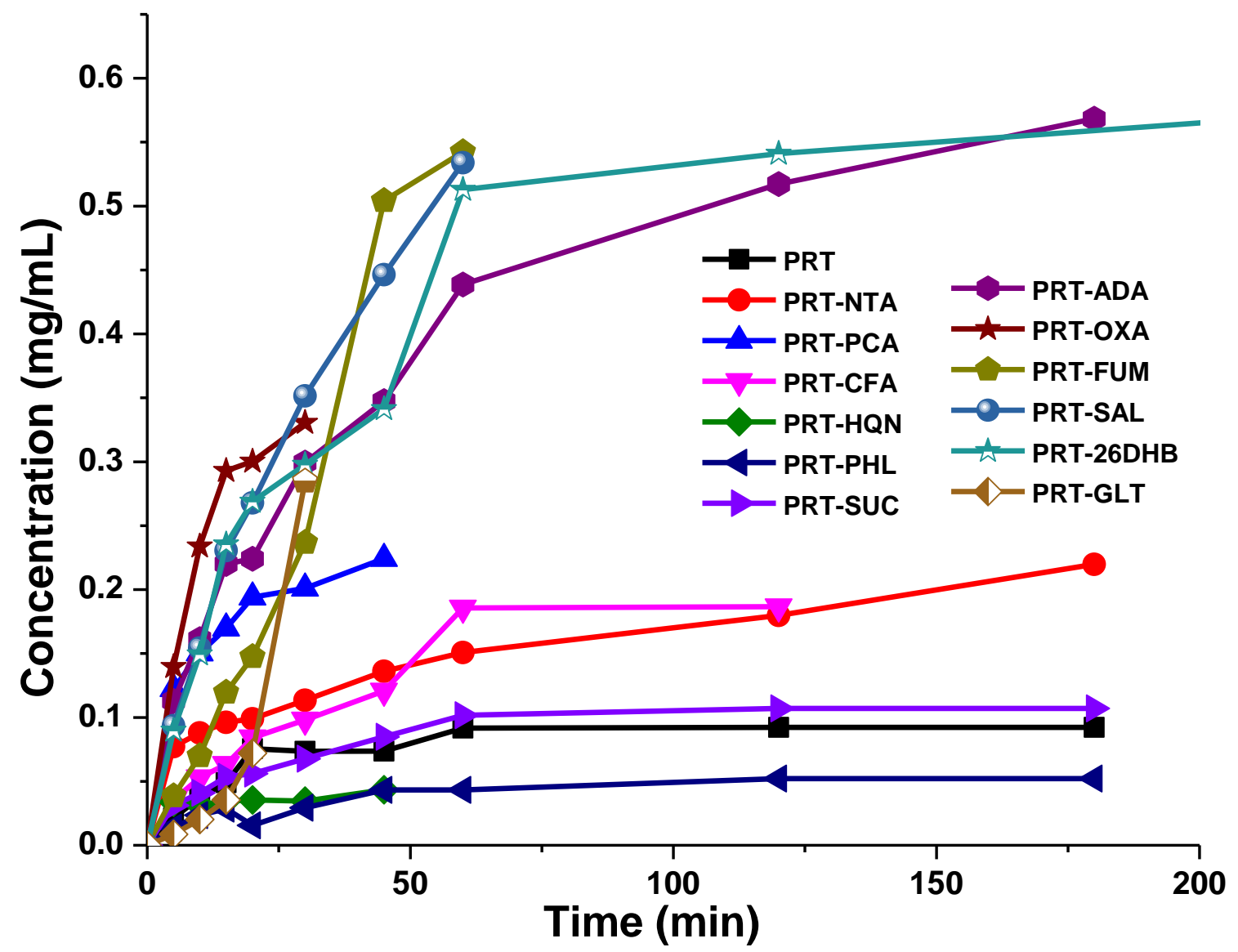

Figure S51. Both cocrystals and eutectic systems show enhancement in their solubility than PRT except PRT-PHL and PRT-HQN. Among the systems, PRT-ADA attained the highest concentration in 24hr. PRT-OXA and PRT-FUM attained the highest concentration at a faster rate compared to all the systems. 


\begin{tabular}{|c|c|c|c|}
\hline SL NO & TIME & ABSORBANCE & $\begin{array}{c}\text { CONCENTRATION } \\
(\mathbf{m g} / \mathbf{m l})\end{array}$ \\
\hline 1 & $5 \mathrm{~min}$ & 0.214 & 0.0214 \\
\hline 2 & 10 & 0.375 & 0.0375 \\
\hline 3 & 15 & 0.490 & 0.0490 \\
\hline 4 & 20 & 0.755 & 0.0755 \\
\hline 5 & 30 & 0.735 & 0.0735 \\
\hline 6 & 45 & 0.736 & 0.0736 \\
\hline 7 & $1 \mathrm{hr}$ & 0.917 & 0.0917 \\
\hline 8 & 2 & 0.922 & 0.0922 \\
\hline 9 & 3 & 0.922 & 0.0922 \\
\hline 10 & 4 & 0.922 & 0.0922 \\
\hline 11 & 6 & 0.922 & 0.0922 \\
\hline 12 & 18 & 0.975 & 0.0975 \\
\hline 13 & $24 \mathrm{hr}$ & 0.977 & 0.0977 \\
\hline
\end{tabular}

\section{- PRT-NTA}

\begin{tabular}{|c|c|c|c|}
\hline SL NO & TIME & ABSORBANCE & $\begin{array}{c}\text { CONCENTRATION } \\
(\mathbf{m g} / \mathbf{m l})\end{array}$ \\
\hline 1 & $5 \mathrm{~min}$ & 0.458 & 0.0771 \\
\hline 2 & 10 & 0.522 & 0.0879 \\
\hline 3 & 15 & 0.571 & 0.0962 \\
\hline 4 & 20 & 0587 & 0.0989 \\
\hline 5 & 30 & 0.673 & 0.1134 \\
\hline 6 & 45 & 0.808 & 0.1361 \\
\hline 7 & $1 \mathrm{hr}$ & 0.895 & 0.1508 \\
\hline 8 & 2 & 1.067 & 0.1798 \\
\hline 9 & 3 & 1.304 & 0.2197 \\
\hline 10 & 4 & 1.304 & 0.2197 \\
\hline
\end{tabular}

\section{- PRT-PCA}

\begin{tabular}{|c|c|c|c|}
\hline SL NO & TIME & ABSORBANCE & $\begin{array}{c}\text { CONCENTRATION } \\
(\mathbf{m g} / \mathbf{m l})\end{array}$ \\
\hline 1 & $5 \mathrm{~min}$ & 0.727 & 0.1225 \\
\hline 2 & 10 & 0.892 & 0.1503 \\
\hline 3 & 15 & 1.008 & 0.1698 \\
\hline 4 & 20 & 1.152 & 0.1941 \\
\hline 5 & 30 & 1.193 & 0.2010 \\
\hline 6 & 45 & 1.334 & 0.2242 \\
\hline
\end{tabular}




\section{- PRT-CFA}

\begin{tabular}{|c|c|c|c|}
\hline SL NO & TIME & ABSORBANCE & $\begin{array}{c}\text { CONCENTRATION } \\
(\mathbf{m g} / \mathbf{m l})\end{array}$ \\
\hline 1 & $5 \mathrm{~min}$ & 0.177 & 0.0354 \\
\hline 2 & 10 & 0.264 & 0.0528 \\
\hline 3 & 15 & 0.317 & 0.0634 \\
\hline 4 & 20 & 0.420 & 0.0841 \\
\hline 5 & 30 & 0.490 & 0.0981 \\
\hline 6 & 45 & 0.603 & 0.1207 \\
\hline 7 & $1 \mathrm{hr}$ & 0.927 & 0.1856 \\
\hline 8 & 2 & 0.932 & 0.1866 \\
\hline
\end{tabular}

- PRT-HQN

\begin{tabular}{|c|c|c|c|}
\hline SL NO & TIME & ABSORBANCE & $\begin{array}{c}\text { CONCENTRATION } \\
(\mathbf{m g} / \mathbf{m l})\end{array}$ \\
\hline 1 & $5 \min$ & 0.209 & 0.03371 \\
\hline 2 & 10 & 0.1925 & 0.03154 \\
\hline 3 & 15 & 0.2145 & 0.03460 \\
\hline 4 & 20 & 0.2195 & 0.03541 \\
\hline 5 & 30 & 0.2140 & 0.03450 \\
\hline 6 & 45 & 0.2690 & 0.04339 \\
\hline
\end{tabular}

- PRT-PHL

\begin{tabular}{|c|c|c|c|}
\hline SL NO & TIME & ABSORBANCE & $\begin{array}{c}\text { CONCENTRATION } \\
(\mathbf{m g} / \mathbf{m l})\end{array}$ \\
\hline 1 & $5 \mathrm{~min}$ & 0.081 & 0.01378 \\
\hline 2 & 10 & 0.138 & 0.02348 \\
\hline 3 & 15 & 0.168 & 0.02859 \\
\hline 4 & 20 & 0.092 & 0.01560 \\
\hline 5 & 30 & 0.172 & 0.02927 \\
\hline 6 & 45 & 0.254 & 0.0433 \\
\hline 7 & $1 \mathrm{hr}$ & 0.254 & 0.0433 \\
\hline 8 & 2 & 0.306 & 0.0521 \\
\hline 9 & 3 & 0.307 & 0.0522 \\
\hline 10 & 4 & 0.314 & 0.0535 \\
\hline 11 & 6 & 0.361 & 0.0615 \\
\hline 12 & 18 & 0.452 & 0.0769 \\
\hline 13 & $24 \mathrm{hr}$ & 0.663 & 0.1129 \\
\hline
\end{tabular}




\section{- PRT-SUC}

\begin{tabular}{|c|c|c|c|}
\hline SL NO & TIME & ABSORBANCE & $\begin{array}{c}\text { CONCENTRATION } \\
(\mathbf{m g} / \mathbf{m l})\end{array}$ \\
\hline 1 & $5 \mathrm{~min}$ & 0.188 & 0.0311 \\
\hline 2 & 10 & 0.247 & 0.0409 \\
\hline 3 & 15 & 0.323 & 0.0535 \\
\hline 4 & 20 & 0.339 & 0.0561 \\
\hline 5 & 30 & 0.409 & 0.0677 \\
\hline 6 & 45 & 0.512 & 0.0848 \\
\hline 7 & $1 \mathrm{hr}$ & 0.614 & 0.1017 \\
\hline 8 & 2 & 0.646 & 0.1070 \\
\hline 9 & 3 & 0.646 & 0.1070 \\
\hline 10 & 4 & 0.646 & 0.1070 \\
\hline
\end{tabular}

- PRT-ADA

\begin{tabular}{|c|c|c|c|}
\hline SL NO & TIME & ABSORBANCE & $\begin{array}{c}\text { CONCENTRATION } \\
(\mathbf{m g} / \mathbf{m l})\end{array}$ \\
\hline 1 & $5 \mathrm{~min}$ & 0.612 & 0.1129 \\
\hline 2 & 10 & 0.874 & 0.1612 \\
\hline 3 & 15 & 1.193 & 0.2200 \\
\hline 4 & 20 & 1.215 & 0.2241 \\
\hline 5 & 30 & 1.623 & 0.2994 \\
\hline 6 & 45 & 1.884 & 0.3474 \\
\hline 7 & $1 \mathrm{hr}$ & 2.378 & 0.4386 \\
\hline 8 & 2 & 2.804 & 0.5172 \\
\hline 9 & 3 & 3.082 & 0.5684 \\
\hline 10 & 6 & 2.568 & 0.4736 \\
\hline 11 & 24 & 3.156 & 0.5821 \\
\hline
\end{tabular}

- PRT-OXA

\begin{tabular}{|c|c|c|c|}
\hline SL NO & TIME & ABSORBANCE & $\begin{array}{c}\text { CONCENTRATION } \\
(\mathbf{m g} / \mathbf{m l})\end{array}$ \\
\hline 1 & $5 \mathrm{~min}$ & 0.912 & 0.1396 \\
\hline 2 & 10 & 1.557 & 0.2338 \\
\hline 3 & 15 & 1.951 & 0.2929 \\
\hline 4 & 20 & 2.000 & 0.3003 \\
\hline 5 & 30 & 2.202 & 0.3306 \\
\hline
\end{tabular}


- PRT-FUM

\begin{tabular}{|c|c|c|c|}
\hline SL NO & TIME & ABSORBANCE & $\begin{array}{c}\text { CONCENTRATION } \\
(\mathbf{m g} / \mathbf{m l})\end{array}$ \\
\hline 1 & $5 \mathrm{~min}$ & 0.234 & 0.0385 \\
\hline 2 & 10 & 0.425 & 0.0699 \\
\hline 3 & 15 & 0.726 & 0.1195 \\
\hline 4 & 20 & 0.896 & 0.1475 \\
\hline 5 & 30 & 1.438 & 0.2367 \\
\hline 6 & 45 & 3.068 & 0.5041 \\
\hline 7 & $1 \mathrm{hr}$ & 3.294 & 0.5423 \\
\hline
\end{tabular}

- PRT-SAL

\begin{tabular}{|c|c|c|c|}
\hline SL NO & TIME & ABSORBANCE & $\begin{array}{c}\text { CONCENTRATION } \\
(\mathbf{m g} / \mathbf{m l})\end{array}$ \\
\hline 1 & $5 \mathrm{~min}$ & 0.530 & 0.0936 \\
\hline 2 & 10 & 0.873 & 0.1542 \\
\hline 3 & 15 & 1.305 & 0.2305 \\
\hline 4 & 20 & 1.516 & 0.2678 \\
\hline 5 & 30 & 1.990 & 0.3515 \\
\hline 6 & 45 & 2.527 & 0.4464 \\
\hline 7 & $1 \mathrm{hr}$ & 3.023 & 0.5340 \\
\hline
\end{tabular}

- PRT-26DHB

\begin{tabular}{|c|c|c|c|}
\hline SL NO & TIME & ABSORBANCE & $\begin{array}{c}\text { CONCENTRATION } \\
(\mathbf{m g} / \mathbf{m l})\end{array}$ \\
\hline 1 & $5 \mathrm{~min}$ & 0.4726 & 0.0877 \\
\hline 2 & 10 & 0.664 & 0.1232 \\
\hline 3 & 15 & 0.804 & 0.1491 \\
\hline 4 & 20 & 0.805 & 0.1493 \\
\hline 5 & 30 & 1.117 & 0.2072 \\
\hline 6 & 45 & 1.265 & 0.2347 \\
\hline 7 & $1 \mathrm{hr}$ & 1.374 & 0.2549 \\
\hline 8 & 2 & 1.773 & 0.3489 \\
\hline 9 & 4 & 1.906 & 0.3536 \\
\hline
\end{tabular}


- PRT-GLT

\begin{tabular}{|c|c|c|c|}
\hline SL NO & TIME & ABSORBANCE & $\begin{array}{c}\text { CONCENTRATION } \\
(\mathbf{m g} / \mathbf{m l})\end{array}$ \\
\hline 1 & $5 \mathrm{~min}$ & 0.050 & 0.0086 \\
\hline 2 & 10 & 0.117 & 0.0202 \\
\hline 3 & 15 & 0.205 & 0.0355 \\
\hline 4 & 20 & 0.416 & 0.0721 \\
\hline 5 & 30 & 1.643 & 0.2847 \\
\hline 6 & 45 & 1.643 & 0.2847 \\
\hline
\end{tabular}

Table S6. Computed strength of homo- and hetero-synthons, and the calculated the $\Delta E$ values for the combinations

\begin{tabular}{ccccccc}
\hline Combination & Coformer & PRT & Cocrystal & $\Delta \mathrm{E}$ & Complex & True/False \\
\hline PRT-OXA & -45.92 & -25.29 & -37.14 & 16.51 & $\mathrm{~N}$ & $\mathrm{~F}$ \\
PRT-ADA & -48.96 & -25.29 & -33.24 & 9.57 & $\mathrm{~N}$ & $\mathrm{~T}$ \\
PRT-SUC & -48.25 & -25.29 & -30.58 & 7.62 & $\mathrm{~N}$ & $\mathrm{~T}$ \\
PRT-GLT & -63.2 & -25.29 & -37.42 & -0.49 & $\mathrm{Y}$ & $\mathrm{T}$ \\
PRT-FUM & -58.79 & -25.29 & -32.94 & -0.56 & $\mathrm{Y}$ & $\mathrm{T}$ \\
PRT-URE & -81.73 & -25.29 & -57.12 & 0.68 & $\mathrm{~N}$ & $\mathrm{~T}$ \\
PRT-THU & -43.33 & -25.29 & -24.51 & 6.47 & $\mathrm{~N}$ & $\mathrm{~T}$ \\
\hline PRT-NTA & -37.64 & -25.29 & -20.16 & 7.81 & $\mathrm{~N}$ & $\mathrm{~T}$ \\
PRT-INZ & -21.19 & -25.29 & -21.387 & 25.49 & $\mathrm{~N}$ & $\mathrm{~T}$ \\
PRT-DHT & -55.7 & -25.29 & -24.13 & -6.28 & $\mathrm{Y}$ & $\mathrm{T}$ \\
\hline
\end{tabular}


Table S7. Torsion angles

\begin{tabular}{ccc}
\hline Complex & Torsion angle $\left(^{\circ}\right)$ & Class \\
\hline PRT-I & 34.13 & I \\
PRT-OXA & 38.63 & I \\
PRT-OXA & -30.21 & I \\
PRT-SAL & 33.17 & I \\
PRT-26DHB & 33.55 & I \\
PRT-II & 141.32 & II \\
PRT-FUM & 7.41 & III \\
\hline
\end{tabular}

PRT-GLU: SEM images before and after stability study

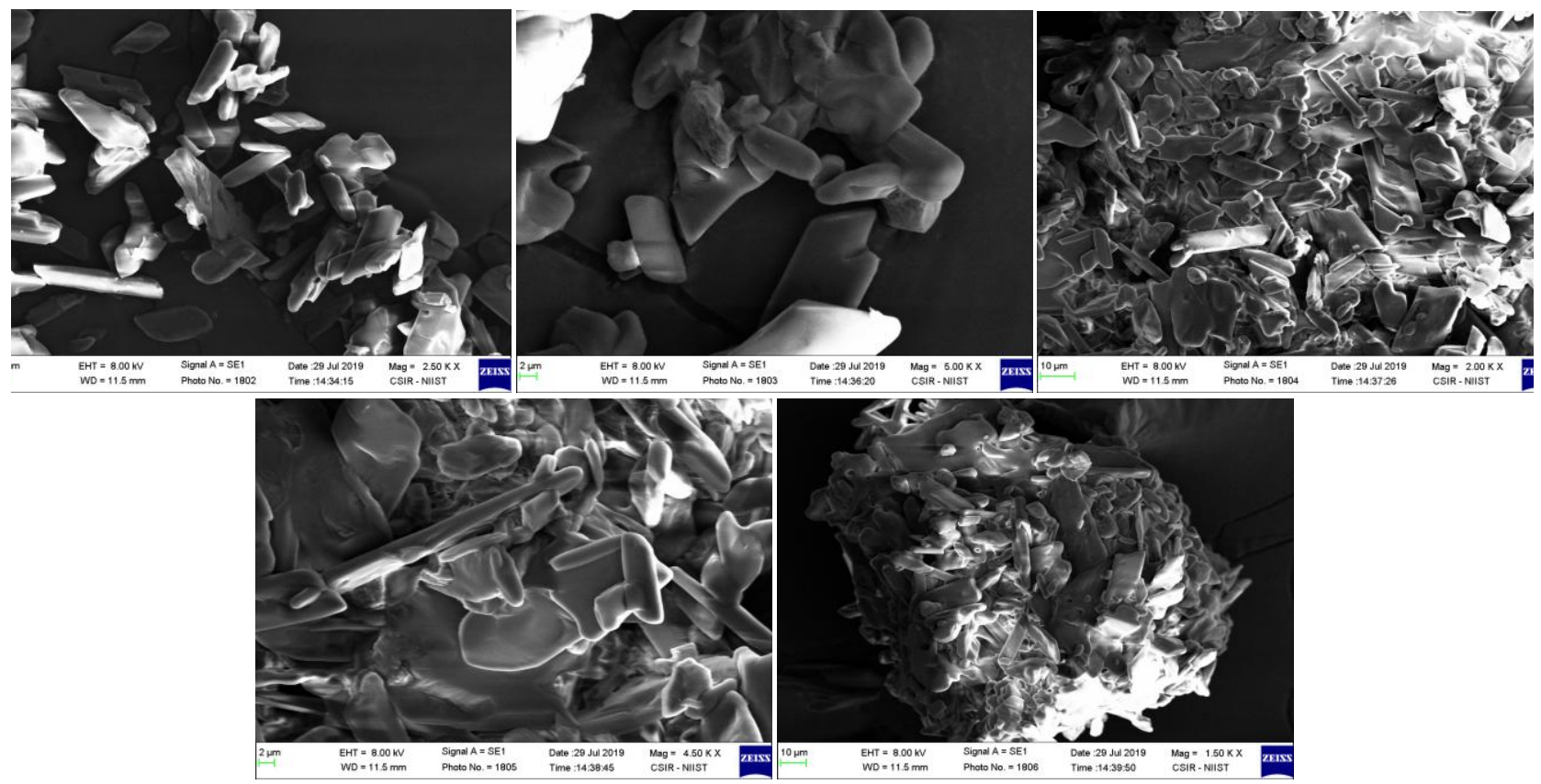

Figure S51. PRT-GLT initial ground sample 


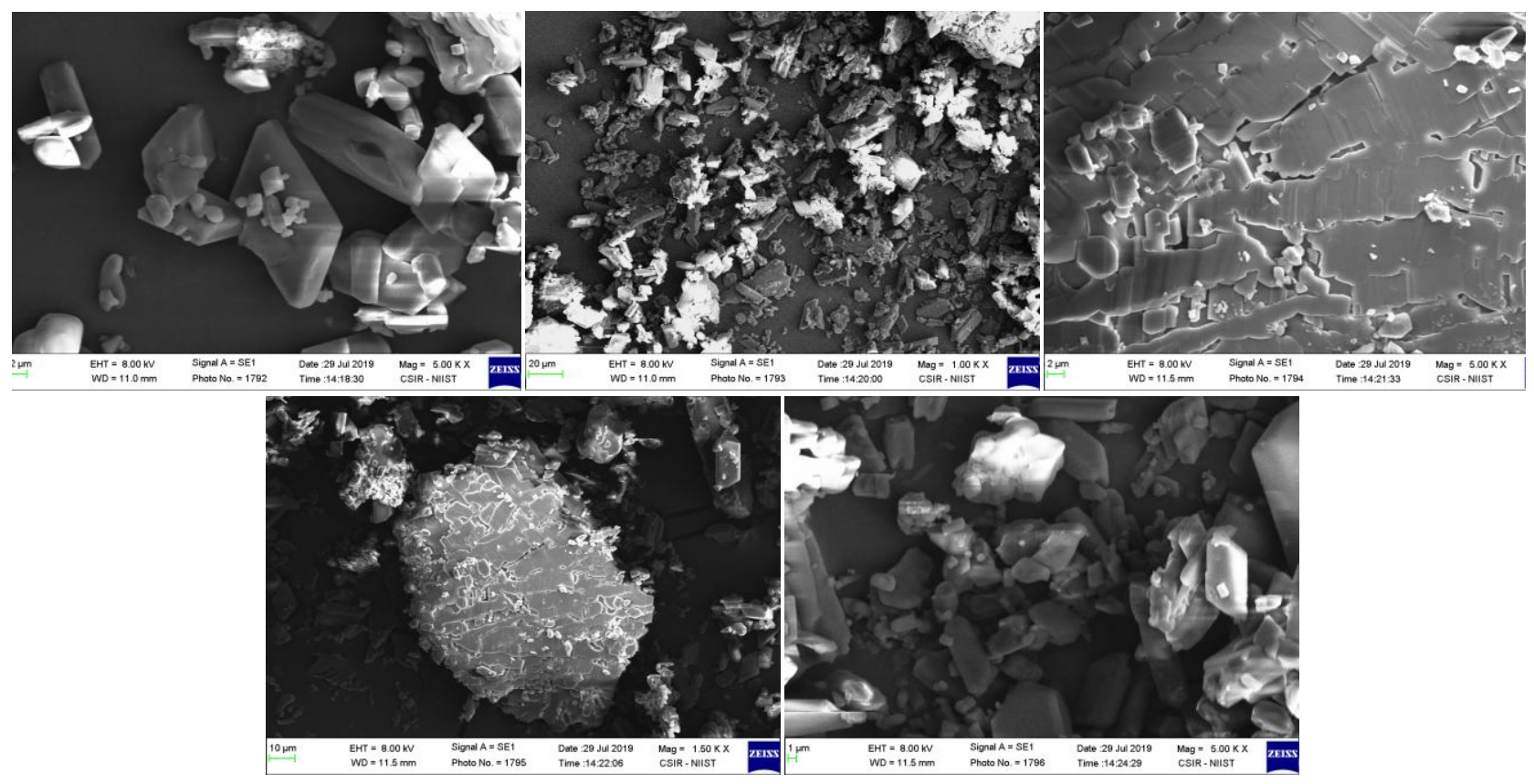

Figure S52. PRT-GLT ground sample after exposure to high humidity for three weeks

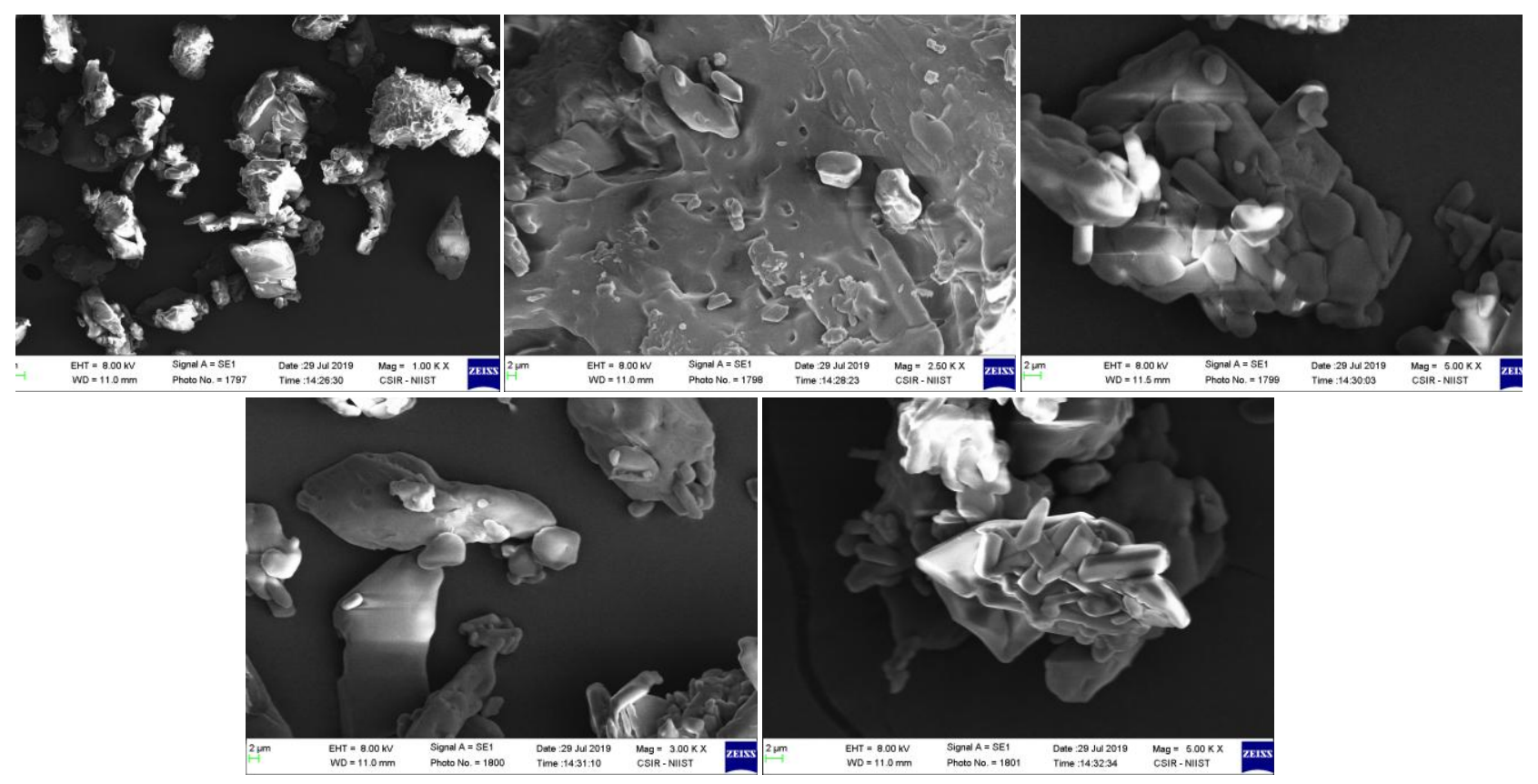

Figure S53. PRT-GLT initial sample obtained by fast evaporation of an ethanol solution. 


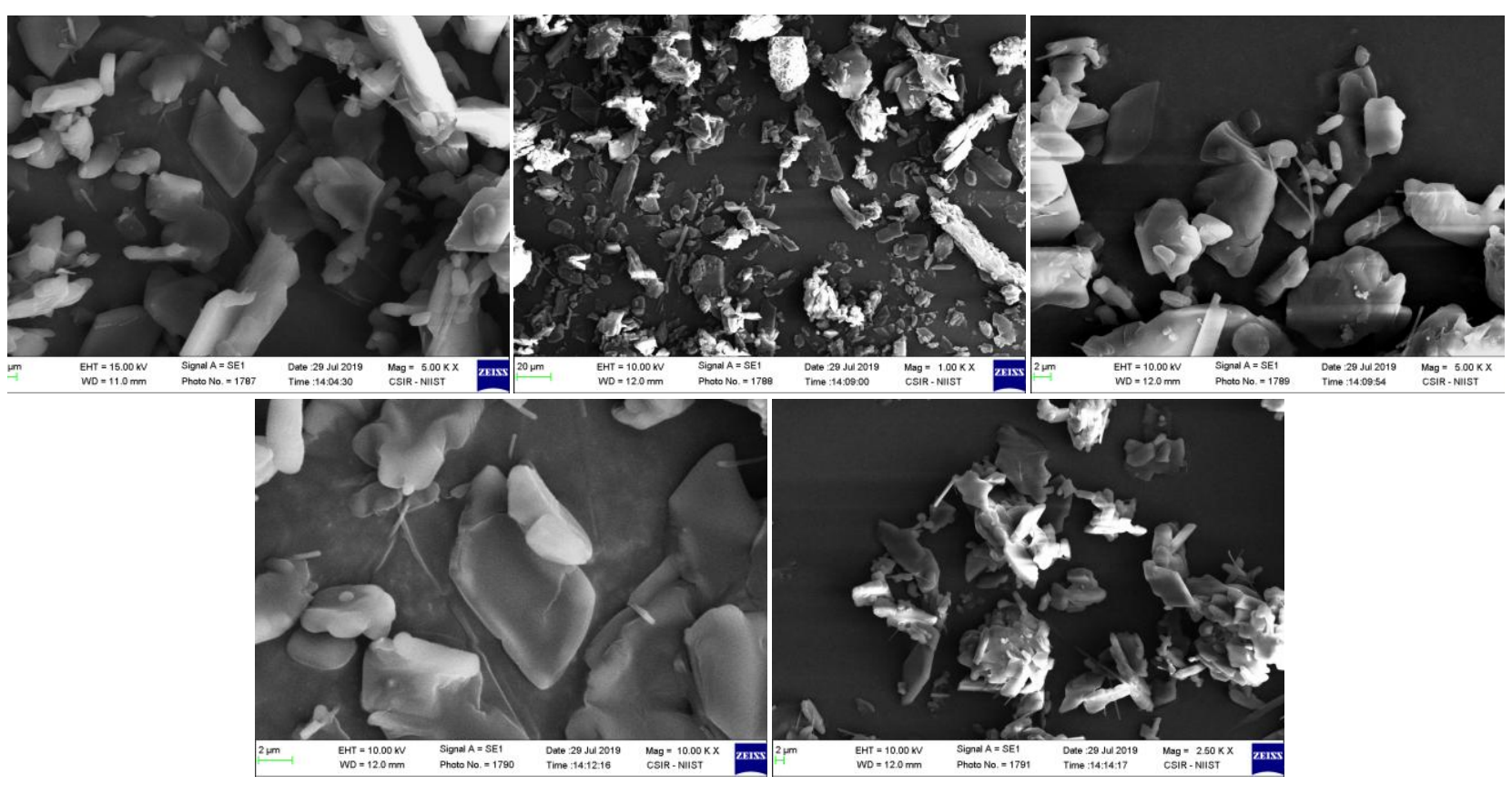

Figure S54. PRT-GLT fast evaporated sample after exposure to high humidity for three weeks 
Table S8. A comparative table of different co-crystallization methods for the coformers adopted

\begin{tabular}{|c|c|c|c|c|c|}
\hline COMPLEXES & $\begin{array}{c}\text { NEAT } \\
\text { GRINDING }\end{array}$ & $\begin{array}{c}\text { LIQUID } \\
\text { ASSISTED } \\
\text { GRINDING }\end{array}$ & $\begin{array}{c}\text { RAPID } \\
\text { SOLVENT } \\
\text { REMOVAL }\end{array}$ & $\begin{array}{c}\text { CRYSTALLIZATION } \\
\text { FROM } \\
\text { SOLVENT/S }\end{array}$ & $\begin{array}{l}\text { SEEDING } \\
\text { METHOD }\end{array}$ \\
\hline \multicolumn{6}{|c|}{ Aliphatic dicarboxylic acids } \\
\hline PRT-OXA & $\checkmark$ & $\checkmark$ & $\checkmark$ & $\checkmark$ & NA \\
\hline PRT-FUM & $x$ & $\checkmark$ & $\checkmark$ & $\checkmark$ & NA \\
\hline PRT-GLT & $\checkmark$ & $\checkmark$ & $\checkmark$ & $\checkmark$ & $x$ \\
\hline PRT-MAL & $x$ & $\mathrm{X}$ & $\mathrm{x}$ & $\mathrm{x}$ & NA \\
\hline PRT-SUC & $x$ & $x$ & $x$ & $X$ & NA \\
\hline PRT-ADP & $x$ & $\mathrm{X}$ & $\mathrm{x}$ & $x$ & NA \\
\hline \multicolumn{6}{|c|}{ Hydroxybenzoic acids } \\
\hline PRT-SAL & $\checkmark$ & $\checkmark$ & $\checkmark$ & $\mathrm{x}$ & $\checkmark$ \\
\hline PRT-26DHB & $\checkmark$ & $\checkmark$ & $\checkmark$ & $\mathrm{X}$ & $\checkmark$ \\
\hline PRT-DHT & $\checkmark$ & $\checkmark$ & $\checkmark$ & $\checkmark$ & NA \\
\hline PRT-34DHB & $x$ & $x$ & $x$ & $x$ & NA \\
\hline & & & & & \\
\hline PRT-ABA & $\mathrm{X}$ & $\mathrm{X}$ & $\mathrm{X}$ & $\mathrm{X}$ & NA \\
\hline PRT-ASA & $x$ & $\mathrm{x}$ & $x$ & $x$ & NA \\
\hline PRT-CFA & $x$ & $x$ & $x$ & $x$ & NA \\
\hline \multicolumn{6}{|c|}{ N-heterocyclic compounds } \\
\hline PRT-INZ & $\mathrm{x}$ & $x$ & $x$ & $\mathrm{X}$ & NA \\
\hline PRT-NTA & $x$ & $x$ & $\mathrm{x}$ & $x$ & NA \\
\hline PRT-PCA & $x$ & $x$ & $x$ & $x$ & NA \\
\hline \multicolumn{6}{|c|}{ Phenols } \\
\hline PRT-HQN & $\mathrm{X}$ & $\mathrm{X}$ & $\mathrm{x}$ & $\mathrm{x}$ & NA \\
\hline PRT-PHL & $x$ & $x$ & $x$ & $x$ & NA \\
\hline \multicolumn{6}{|c|}{ Urea } \\
\hline PRT-URE & $x$ & $x$ & $\mathrm{x}$ & $\mathrm{X}$ & NA \\
\hline PRT-THU & $x$ & $x$ & $x$ & $x$ & NA \\
\hline \multicolumn{6}{|c|}{ Others } \\
\hline PRT-DTX & $\mathrm{X}$ & $\mathrm{X}$ & $\mathrm{X}$ & $x$ & NA \\
\hline
\end{tabular}

